\title{
Adding life to years
}

Citation for published version (APA):

Beerens, H. C. (2016). Adding life to years: quality of life of people with dementia receiving long-term care. [Doctoral Thesis, Maastricht University]. https://doi.org/10.26481/dis.20160429hb

Document status and date:

Published: 01/01/2016

DOI:

10.26481/dis.20160429hb

Document Version:

Publisher's PDF, also known as Version of record

\section{Please check the document version of this publication:}

- A submitted manuscript is the version of the article upon submission and before peer-review. There can be important differences between the submitted version and the official published version of record.

People interested in the research are advised to contact the author for the final version of the publication, or visit the DOI to the publisher's website.

- The final author version and the galley proof are versions of the publication after peer review.

- The final published version features the final layout of the paper including the volume, issue and page numbers.

Link to publication

\footnotetext{
General rights rights.

- You may freely distribute the URL identifying the publication in the public portal. please follow below link for the End User Agreement:

www.umlib.nl/taverne-license

Take down policy

If you believe that this document breaches copyright please contact us at:

repository@maastrichtuniversity.nl

providing details and we will investigate your claim.
}

Copyright and moral rights for the publications made accessible in the public portal are retained by the authors and/or other copyright owners and it is a condition of accessing publications that users recognise and abide by the legal requirements associated with these

- Users may download and print one copy of any publication from the public portal for the purpose of private study or research.

- You may not further distribute the material or use it for any profit-making activity or commercial gain

If the publication is distributed under the terms of Article $25 \mathrm{fa}$ of the Dutch Copyright Act, indicated by the "Taverne" license above, 


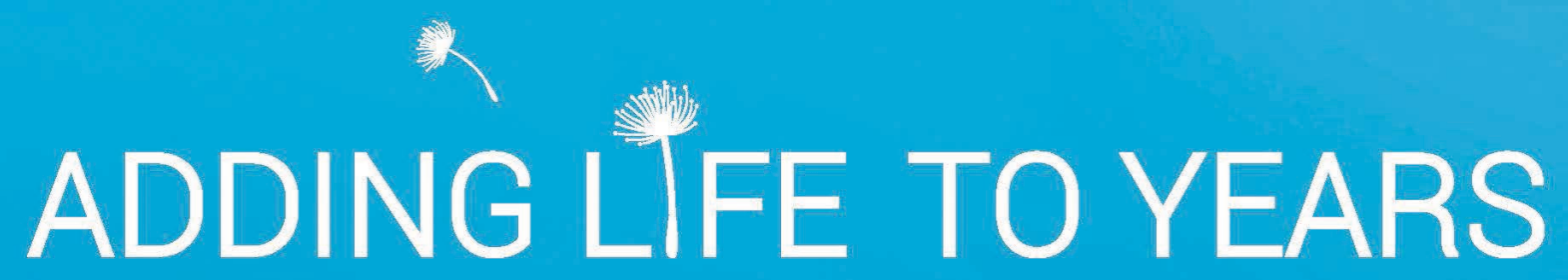
QUALITY OF LIFE OF PEOPLE WITH DEMENTIA RECEIVING LONG-TERM CARE
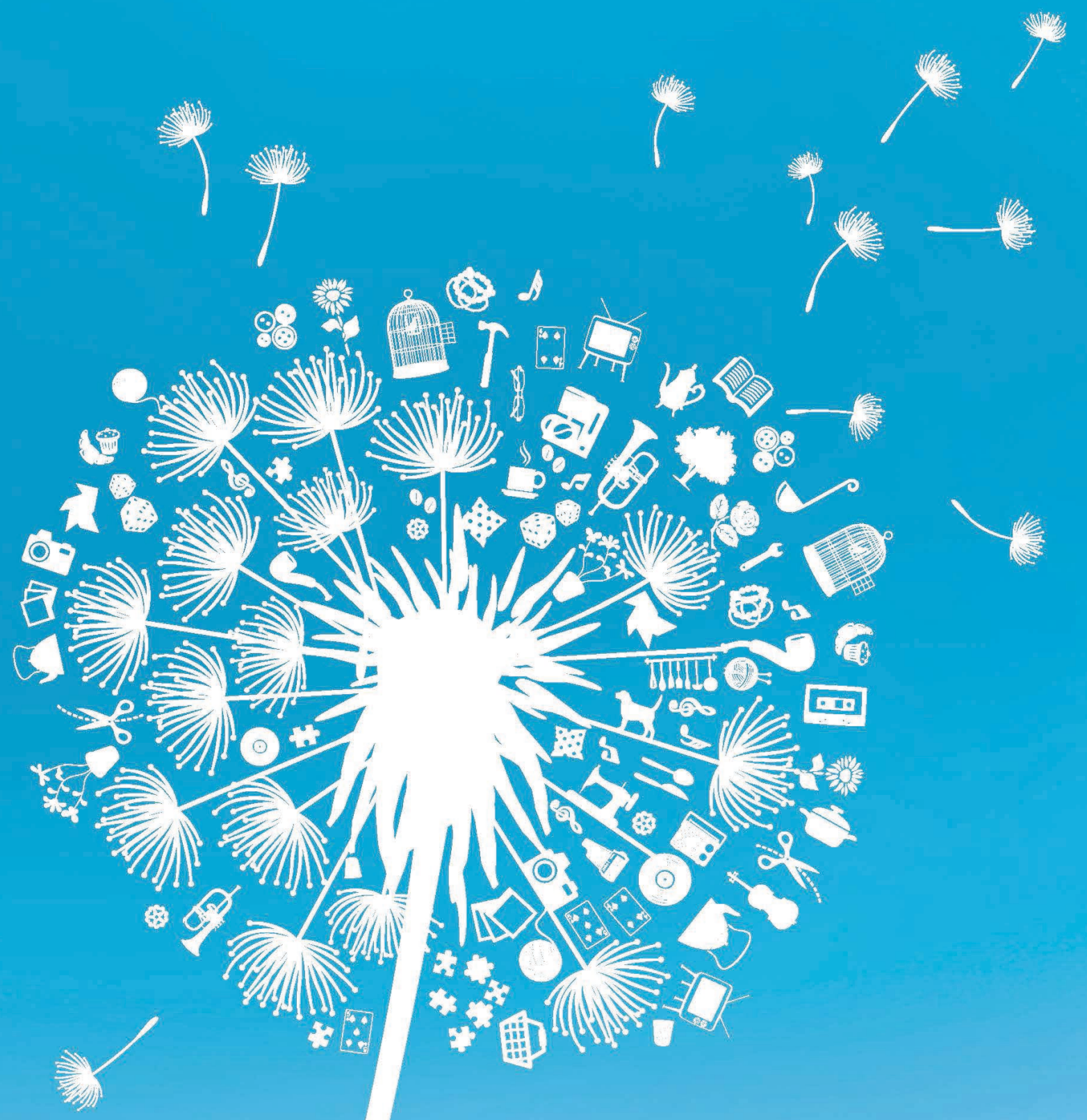
The research presented in this dissertation was conducted at the School for Public Health and Primary Care (CAPHRI), department of Health Services Research, Maastricht University. CAPHRI is part of the Netherlands School of Primary Care Research (CaRe), which has been acknowledged by the Royal Netherlands Academy of Science (KNAW). This research was funded under a grant from the European Commission within the seventh framework program (project 242153) and Maastricht University.

Cover: Marcella Brevé

Layout \& Print: Datawyse | Universitaire Pers Maastricht

(C) Hanneke Beerens, Maastricht 2016

ISBN 9789461595393

Financial support for printing this thesis has been kindly provided by the Internationale Stichting Alzheimer Onderzoek (ISAO) and Alzheimer Nederland.
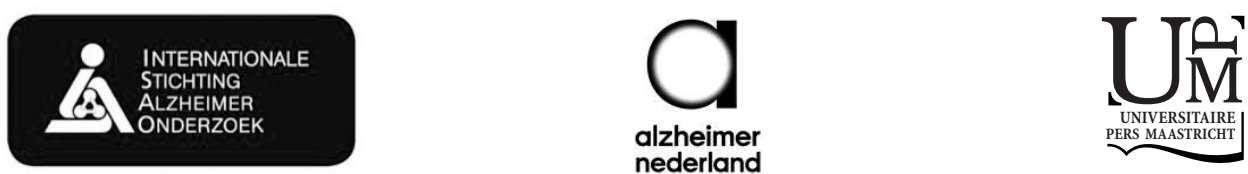


\title{
Adding life to years
}

\section{Quality of life of people with dementia receiving long-term care}

\author{
PROEFSCHRIFT \\ ter verkrijging van de graad van doctor aan de Universiteit Maastricht, \\ op gezag van de Rector Magnificus, Prof. dr. LLG Soete, \\ volgens het besluit van het College van Decanen, \\ in het openbaar te verdedigen \\ op vrijdag 29 april 2016 om 16:00 \\ door \\ Hanneke Christien Beerens
}




\section{Promotores}

Prof. dr. JPH Hamers

Prof. dr. D Ruwaard

\section{Copromotor}

Dr. SMG Zwakhalen

\section{Beoordelingscommissie}

Prof. dr. FRJ Verhey (voorzitter)

Prof. dr. S Beurskens

Prof. dr. RM Dröes (VU University Medical Center)

Prof. dr. JMGA Schols

Prof. dr. MJ Schuurmans (University Medical Center Utrecht) 


\section{Contents}

Chapter 1 General introduction

Chapter 2 Factors associated with quality of life of people with dementia in long-term care facilities: A systematic review International Journal of Nursing Studies, 2013

Chapter 3 Quality of life and quality of care for people with dementia receiving longterm institutional care or professional home care: The European RightTimePlaceCare study Journal of the American Medical Directors Association, 2014

Chapter 4 Change in quality of life of people with dementia recently admitted to longterm care facilities Journal of Advanced Nursing, 2014

Chapter 5 Daily lives of residents with dementia in nursing homes: Development of the Maastricht Electronic Daily Life Observation Tool International Psychogeriatrics, 2016

Chapter 6 The association between aspects of daily life and quality of life of people with dementia living in long-term care facilities: a momentary assessment study International Psychogeriatrics, 2016

Chapter 7 The relation between mood, activity and interaction in long-term dementia care

Submitted for publication

Chapter 8 General discussion

Summary

Samenvatting

Valorization addendum

Dankwoord

About the author

Publications 



\section{CHAPTER 1}

General introduction
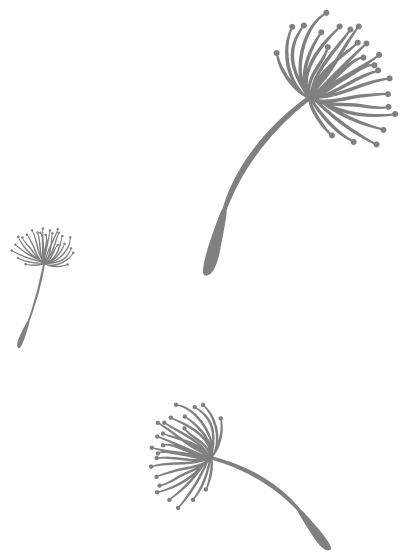

This dissertation examines the quality of life (QoL) of people with dementia (PwD) who receive long-term care. In this first chapter, background information regarding longterm care, dementia, and QoL is provided. Furthermore, the aim and outline of this dissertation are described. Finally, the projects included in this dissertation are outlined in this chapter.

\section{LONG-TERM CARE}

Long-term care is defined as a range of services (either at home or in an institution) required by people who are dependent on help with basic activities of daily living, ${ }^{1}$ for example bathing, dressing and/or eating. Currently, 12\% of the population aged 65 and over in OECD countries receives long-term care. This number varies across countries, with percentages in the Netherlands and Sweden being $19 \%$ and $16 \%$, respectively. In contrast, in Germany (12\%), Spain (7\%) and Estonia (6\%), fewer people aged over 65 receive long-term care. $^{2}$ Because the population aged 65 and older is increasing, a growing number of people will become recipients of long-term care. ${ }^{2}$

As suggested by the varying percentages of people receiving long-term care, models of long-term care vary greatly across countries. ${ }^{3,4}$ As opposed to countries in the south, east and center of Europe, long-term care in Scandinavian countries and the Netherlands is characterized by high public expenditure and low family responsibility. The governments in these countries assume a high degree of responsibility for long-term care provision. ${ }^{5}$ As a result, relatively many older people in these countries become recipients of institutional care. ${ }^{2}$ Two examples illustrate differences in long-term care provision between European countries. With regard to home care, the Dutch national government provides a framework in which municipalities and independent agencies develop their own rules. As opposed to this Dutch 'framework type', some other national governments play a more dominant (for example France and Portugal) or a weaker role (for example Bulgaria and Romania) in home care governance. ${ }^{3}$ With regard to institutional care, Dutch nursing homes employ - in contrast to other countries - a whole multidisciplinary team consisting of nursing staff, specially trained physicians (i.e. elderly care physician), and (para)medical staff. ${ }^{6}$

Governments in OECD countries have taken an increasingly active role in regulating and inspecting the quality of long-term care services. ${ }^{1}$ Indicators for good quality of care (QoC) include among others the absence of pressure ulcers, malnutrition, physical restraint use, and psychotropic drug prescriptions. ${ }^{1}$ It is suggested that the QoC for longterm care recipients differs among countries. ${ }^{7,8}$ Although there are tools available which can facilitate the comparison of QoC between countries (for example the Minimum Data Set ${ }^{9}$ ), very little is known about country-specific strengths and weaknesses in long-term care delivery. 10 


\section{DEMENTIA}

Dementia is one of the main reasons why people increasingly need to rely on long-term care, either at home or in a long-term care facility such as a nursing home. ${ }^{11,12}$ With the aging population, the number of PwD in Europe is projected to rise from 9.95 million in 2010 to 18.65 million in $2050 .{ }^{13}$ In the Netherlands, the number of people living with dementia is expected to rise from 260,000 to 500,000 in $2050 .{ }^{14}$ With a growing number of people having dementia and the increasing burden on health systems providing long-term care, dementia has become a public health priority in many countries. ${ }^{2,15,16}$

Dementia is characterized by problems in (short-term) memory, concentration, planning, organizing, language, visual perception, and orientation in time and place. In addition, PwD often experience changes in their mood and behavior, resulting in for example depressive symptoms, agitation, wandering behavior, or anxiety. ${ }^{17}$ In 50-75\% of the cases, dementia is caused by Alzheimer's disease. Other common causes of dementia are vascular dementia (20-30\%), frontotemporal dementia (5-10\%), and dementia with Lewy Bodies $(<5 \%){ }^{18}$ Dementia is progressive, meaning that the symptoms gradually become worse over time. How quickly and in what way the dementia and its symptoms progress differ individually and are also dependent on the etiology of the dementia. ${ }^{17}$

Several risk factors of dementia have been identified. First, non-modifiable factors such as increasing age, female gender, and genetic factors increase the likelihood of developing dementia. People aged 65 and older have a 10\% risk of developing dementia, whereas people aged 90 or older have a $40 \%$ risk. Second, modifiable factors such as higher educational achievement, mentally stimulating activities, physical activity, and social engagement may all be considered protective factors. ${ }^{18}$ However, despite efforts to prevent or treat dementia, it is still incurable. ${ }^{18}$ Consequently, psychosocial outcomes such as QoL have become well established hallmarks in judging QoC for PwD. ${ }^{19,20}$ Therefore, QoL has gained a dominant position in international research agendas. ${ }^{21,22}$

\section{QUALITY OF LIFE}

In 1995, the World Health Organization (WHO) defined QoL as "the 'individuals' perceptions of their position in life in the context of the culture and value systems in which they live, and in relation to their goals, expectations, standards and concerns". ${ }^{23}$ This broad definition is generally applicable, but lacks specificity for PWD. In addition, from the perspective of PwD, their cognitive ability to make complex judgements about their own lives is often limited. Lawton $(1983,1994)$ provided a widely used theoretical framework for dementia-specific QoL. ${ }^{24,25}$ According to this framework, QoL consists of both objective (behavioral competence and the objective environment) and subjective domains (psychological well-being and perceived QoL): 
- Behavioral competence includes physical health, dependence in activities of daily living, cognitive functioning, and social behavior;

- The objective environment includes material possessions, social support and one's network;

- Perceived QoL is defined as the set of evaluations that is made about each aspect that is important in one's life, for example social contacts and income;

- Psychological well-being is one's overall subjective evaluation of QoL and may be regarded as the ultimate outcome of a QoL model. ${ }^{24,25}$

The QoL domains as suggested by Lawton are interrelated. For example, a poor mental health may affect people's social relationships and their overall evaluation of QoL and vice versa. Furthermore, the operationalizations of the four domains should be adapted to the stage of the dementia of the population under study, as what matters in life can change and priorities may become different as the dementia progresses. ${ }^{26}$ In contrast to medical models of QoL that assume that QoL declines as a disease progresses, people with chronic conditions may report an excellent or good QoL because they are able to adjust well to their personal circumstances. Therefore, people with advanced dementia do not automatically have a lower QoL than people in an earlier stage of dementia. This is highlighted by evidence showing conflicting results about how QoL of PwD evolves over time. ${ }^{27-32}$ This phenomenon is also referred to as the disability paradox. ${ }^{33}$

QoL does not play a key role in all dementia research yet. ${ }^{34} \mathrm{~A}$ possible reason for this is that gaining insight into PwD's QoL is challenging. Although affected by cognitive deficits, self-reports of QoL are generally preferred over proxy-measures. People with mild, moderate and sometimes even severe cognitive impairment are able to express their own views, needs, and concerns. ${ }^{35,36}$ When PwD are not able to make judgments about their own QoL anymore, proxies such as relatives or formal caregivers can provide meaningful and important information about PwD's QoL. However, PwD and caregivers do not consider exactly the same domains important for PWD's QoL. ${ }^{37}$ Consequently, a Dutch study showed that caregivers pay relatively little attention to two QoL domains that were considered important by PwD: 'financial situation' and 'being useful/giving meaning to life'. ${ }^{38}$ In addition to this, as with other chronic conditions, ${ }^{39}$ selfreports and proxy-reports are not perfectly correlated and caregivers tend to value PwD's QoL lower than PwD themselves. ${ }^{40,41}$ It is suggested that proxy-related characteristics such as burden or depressive symptoms influence their QoL ratings of PWD negatively. ${ }^{40,42,43}$ As an alternative to conversations with PwD or proxies, PwD's QoL could also be directly observed by independent observers. ${ }^{44,45}$ Observing PwD is a unique way of presenting their experiences. Insight into variations in important QoL domains enables researchers to "capture the film of PwD's daily life rather than a snapshot of daily life reality". ${ }^{46}$ Such observations may be labor intensive, but provide rich data about the quality of the daily lives of PWD. Yet only few studies have used this type of observation to gain more insight into PwD's QoL. 
To meet the ultimate goal of dementia care - an optimal QoL for all PwD - the identification of factors that are associated with a high or a low QoL is essential. Former research has indicated that clinical factors such as depressive symptoms, behavioral disturbances, dependence in activities of daily living (ADL) and cognition may be associated with QoL or changes in QoL. ${ }^{47-53}$ Nevertheless, studies have provided inconsistent results. In addition, the association between QoL and two other types of factors remain largely unaddressed. First, there is little knowledge about the association between QoL and QoC. One study indicated that the QoC indicator 'pain' is negatively associated with QoL, ${ }^{54}$ but many other indicators for QoC have, to date, received little attention. Second, little is known about how a variety of aspects of daily life contribute to a good QoL. Aspects of daily life include for example PwD's activities and social engagement during the day. One study found that PWD who engage in a variety of activities have a higher QoL compared to those who are inactive. ${ }^{55}$ However, a detailed insight into the relationship between QoL and daily life in a broad context does not yet exist.

Besides the earlier hypothesized correlates of QoL, PwD's living environment may also influence QoL ratings. Yet it is unknown to what extent place of residence influences QoL ratings. ${ }^{56}$ A substantial number of studies has not made a distinction between PwD living at home and residents of long-term care facilities. However, people living in long-term care facilities may differ from community-dwelling people with regard to factors such as functional status and cognition, which both may influence QoL assessment. In addition, conflicting conclusions have been inferred about whether QoL improves or decreases after admission to a long-term care facility. ${ }^{28,53}$

Finally, QoL and associations with QoL may also differ among countries. Currently there are no European studies that have assessed QoL of PwD in a European context. A QoL survey among European citizens in general ${ }^{57}$ shows great country-differences in well-being levels (an important indicator for QoL ${ }^{24,25}$ ). These differences could only be explained in part by economic indicators such as gross domestic product. Cultural factors may also play a role in QoL assessment as culture influences peoples' definitions of well-being and their tendency to give socially desirable answers. ${ }^{58}$ To support PwD and achieve an optimal QoL, it is important to have a better understanding of factors that may be important for their QoL. Such an understanding can be used to provide guidance to long-term care staff, policy makers, and researchers on how to improve PWD's QoL.

\section{AIM AND OUTLINE}

\section{Aim}

The aim of this dissertation is twofold. First, it aims at gaining insight into QoL of PwD receiving long-term care at home and in long-term care facilities. Second, it aims to 
investigate which factors are associated with QoL of PwD receiving long-term care at home and in long-term care facilities. Several factors such as clinical factors (e.g. depressive symptoms and behavioral symptoms), QoC indicators (e.g. pressure ulcers and malnutrition) and aspects of daily life (e.g. social interaction and activity engagement) are hypothesized to be influential on QoL. Both PwD living in the Netherlands and PwD living in other European countries are investigated. PwD at the 'break-point' from home care to institutional care (people recently admitted to a long-term care facility and people who live at home at risk for admission within six months) and those who live in a long-term care facility for longer periods of time are studied.

\section{Outline}

Chapter 2 provides the findings of a systematic literature review on factors associated with QoL of PwD living in long-term care facilities. Chapter 3 delineates an international cross-sectional survey obtaining information on QoL and QoC indicators. QoL and QoC in eight European countries and two types of living arrangements (i.e. at home at risk for admission and newly admitted to long-term care facility) were investigated. Furthermore, the association between QoL and QoC indicators was assessed. Chapter 4 presents the results of a longitudinal survey about QoL in the three months after admission to a long-term care facility. PwD living in one of the eight participating European countries were included. Both the course of QoL and the association between changes in QoL and clinical factors were investigated. Chapter 5 reports on the development, reliability, and feasibility of the Maastricht Electronic Daily Life Observational-tool (MEDLO-tool). This is an observation instrument that supports obtaining in-depth information about the daily lives of PwD using ecological momentary assessments. Chapter 6 provides the results of a study on the association between QoL and aspects of daily life which were observed and recorded using the MEDLO-tool. Dutch PwD living in long-term care facilities for longer periods of time were included. Chapter 7 describes the results of a final study that investigated associations with variations in mood during daily life, which is an important indicator for QoL. Again the momentary assessments that were performed using the MEDLO-tool were used to obtain in-depth insight into the daily lives of Dutch PwD living in long-term care facilities for longer periods of time. The main findings and implications of all studies are discussed in Chapter 8 . Theoretical and methodological considerations are discussed, and recommendations for care professionals and further research are addressed.

\section{PROJECTS}

To collect data on QoL and QoC in a European context, the RightTimePlaceCare (RTPC) study $^{59}$ was conducted. In this study, PwD were included in a clinical survey when they 
were at risk for admission to a long-term care facility or when they lived in a facility for no longer than three months. There was a baseline measurement and a follow-up measurement three months later. The following countries participated: England, Estonia, Finland, France, Germany, the Netherlands, Spain, and Sweden. Using the RTPC data, the association between (self-reported and proxy-reported) QoL and QoC indicators in the period before and after admission to a long-term care facility could be investigated from a European perspective. Furthermore, predictors of change in QoL were investigated. The RTPC data was used for the studies described in Chapters 3 and 4 . This study was supported by a grant from the European Commission within the seventh framework program (project 242153).

To gain more in-depth insight into the quality of the daily lives of PwD living in longterm care facilities, an observational study was conducted in the Netherlands. ${ }^{60}$ In this study, 84 momentary assessments of 115 individual PwD were recorded. To do so, the MEDLO-tool was developed first. Using the data collected with the MEDLO-tool, the association between QoL and aspects of daily life (e.g. social interaction, activities) were examined. In addition, the association between mood, activities, and social interaction was assessed. The data that was collected in this project was used for the studies described in Chapters 5, 6, and 7. This project was funded by ZonMw (project 72801.0002). 


\section{REFERENCES}

1. OECD. The OECD Health Project. Long-term Care for Older People. Paris: OECD Publishing, 2005.

2. OECD. Health at a Glance 2013: OECD indicators: OECD Publishing, 2013.

3. Genet N, Boerma W, Kroneman M, et al. Home care across Europe. Current structure and future challenges. World Health Organization, 2012.

4. Conroy S, Van Der Cammen T, Schols J, et al. Medical services for older people in nursing homescomparing services in England and the Netherlands. The Journal of Nutrition, Health and Aging 2009;13:559-563.

5. Verbeek-Oudijk D, I. W, Eggink E and Putman L. Who cares in Europe? A comparison of long-term care for the over-50s in sixteen European countries. The Hague: The Netherlands Institute for Social Research, 2014.

6. Koopmans RT, Lavrijsen J, Hoek JF, et al. Dutch elderly care physician: A new generation of nursing home physician specialists. Journal of the American Geriatrics Society 2010;58:1807-1809.

7. Bos JT, Frijters DH, Wagner C, et al. Variations in quality of Home Care between sites across Europe, as measured by Home Care Quality Indicators. Aging Clinical and Experimental Research 2007;19:323-329.

8. Onder G, Carpenter I, Finne-Soveri $\mathrm{H}$, et al. Assessment of nursing home residents in Europe: the Services and Health for Elderly in Long TERm care (SHELTER) study. BMC Health Services Research 2012;12:5.

9. Mor V. A comprehensive clinical assessment tool to inform policy and practice: applications of the minimum data set. Medical Care 2004;42:III-50-III-59.

10. Katz PR. An international perspective on long term care: Focus on nursing homes. Journal of the American Medical Directors Association 2011;12:487-492.

11. Luppa M, Luck T, Weyerer S, et al. Prediction of institutionalization in the elderly. A systematic review. Age and Ageing 2010;39:31-38.

12. Prince M, Prina M, Guerchet $M$ and Alzheimer's Disease International. World Alzheimer Report 2013: Journey of Caring. An analysis of long-term care for dementia. London: Alzheimer's Disease International, 2013.

13. Prince $M$, Bryce $R$, Albanese $E$, et al. The global prevalence of dementia: a systematic review and metaanalysis. Alzheimer's \& Dementia 2013;9:63-75.

14. Alzheimer Nederland. Cijfers en feiten over dementie 2015. Available from: http://www.alzheimernederland.nl/media/840711/factsheet_dementie_algemeen_-_publieksversie_16-07-2015.pdf.

15. World Health Organization and Alzheimer's Disease International. Dementia. A public health priority. United Kingdom: World Health Organization and Alzheimer's Disease International, 2012.

16. Lipszyc B, Sail E and Xavier A. European Economy. Long-term care: need, use and expenditure in the EU27. Brussels: European Commission, 2012.

17. Alzheimer's Society. What is Dementia? London: Alzheimer's Society; 2014. Available from: http://www.alzheimers.org.uk/site/scripts/documents_info.php?documentID=106.

18. Prince M, Albanese E, Guerchet M and Prina M. World Alzheimer Report 2014. Dementia and Risk Reduction. An analysis of protective and modifiable factors. London: Alzheimer's Disease International, 2014.

19. Rabins PV and Black BS. Measuring quality of life in dementia: purposes, goals, challenges and progress. International Psychogeriatrics 2007;19:401-407.

20. Kitwood T. Dementia reconsidered: The person comes first. Buckingham: Open University Press, 1997.

21. Tolson D, Rolland Y, Andrieu S, et al. International Association of Gerontology and Geriatrics: a global agenda for clinical research and quality of care in nursing homes. Journal of the American Medical Directors Association 2011;12:184-189.

22. Moniz-Cook E, Vernooij-Dassen M, Woods R, et al. A European consensus on outcome measures for psychosocial intervention research in dementia care. Aging \& Mental Health 2008;12:14-29.

23. World Health Organization. The World Health Organization Quality of Life assessment (WHOQOL): position paper from the World Health Organization. Social Science and Medicine 1995;41:1403-1409. 


\section{CHAPTER 1}

24. Lawton MP. Environment and other determinants of weil-being in older people. The Gerontologist 1983;23:349-357.

25. Lawton MP. Quality of Life in Alzheimer Disease. Alzheimer Disease and Associated Disorders 1994;8:138150.

26. Ettema TP, Dröes RM, de Lange J, et al. The concept of quality of life in dementia in the different stages of the disease. International Psychogeriatrics 2005;17:353-370.

27. Conde-Sala JL, Turro-Garriga O, Garre-Olmo J, et al. Discrepancies Regarding the Quality of Life of Patients with Alzheimer's Disease: A Three-Year Longitudinal Study. Journal of Alzheimer's Disease 2013;39:511525.

28. Funaki Y, Kaneko F and Okamura H. Study on factors associated with changes in quality of life of demented elderly persons in group homes. Scandinavian Journal of Occupational Therapy 2005;12:4-9.

29. Clare L, Woods RT, Nelis SM, et al. Trajectories of quality of life in early-stage dementia: individual variations and predictors of change. International Journal of Geriatric Psychiatry 2013;29:616-623.

30. Lyketsos CG, Gonzales-Salvador T, Chin JJ, et al. A follow-up study of change in quality of life among persons with dementia residing in a long-term care facility. International Journal of Geriatric Psychiatry 2003;18:275-281.

31. Selwood A, Thorgrimsen $L$ and Orrell M. Quality of life in dementia. A one-year follow-up study. International Journal of Geriatric Psychiatry 2005;20:232-237.

32. Hoe J, Hancock G, Livingston G, et al. Changes in the quality of life of people with dementia living in care homes. Alzheimer Disease and Associated Disorders 2009;23:285-290.

33. Albrecht GL and Devlieger PJ. The disability paradox: high quality of life against all odds. Social Science and Medicine 1999;48:977-988.

34. Scholzel-Dorenbos CJ. Quality of life in dementia. From concept to practice [Doctoral thesis]. Nijmegen: Radboud University, 2011.

35. Thorgrimsen L, Selwood A, Spector A, et al. Whose quality of life is it anyway? The validity and reliability of the Quality of Life-Alzheimer's Disease (QoL-AD) scale. Alzheimer Disease and Associated Disorders 2003;17:201-208.

36. de Boer ME, Hertogh CM, Dröes RM, et al. Advance directives in dementia: issues of validity and effectiveness. International Psychogeriatrics 2010;22:201-208

37. Dröes R-M, Boelens-Van Der Knoop EC, Bos J, et al. Quality of life in dementia in perspective An explorative study of variations in opinions among people with dementia and their professional caregivers, and in literature. Dementia 2006;5:533-558.

38. Gerritsen DL, Ettema TP, Boelens E, et al. Quality of life in dementia: do professional caregivers focus on the significant domains? American Journal of Alzheimer's Disease and Other Dementias 2007;22:176-183.

39. Sneeuw KC, Sprangers MA and Aaronson NK. The role of health care providers and significant others in evaluating the quality of life of patients with chronic disease. Journal of Clinical Epidemiology 2002;55:1130-1143.

40. Arons AM, Krabbe PF, Scholzel-Dorenbos CJ, et al. Quality of life in dementia: a study on proxy bias. BMC Medical Research Methodology 2013;13:110.

41. Gräske J, Meyer S and Wolf-Ostermann K. Quality of life ratings in dementia care. A cross-sectional study to identify factors associated with proxy-ratings. Health and Quality of Life Outcomes 2014;12:177.

42. Gräske J, Fischer T, Kuhlmey A and Wolf-Ostermann K. Quality of life in dementia care-differences in quality of life measurements performed by residents with dementia and by nursing staff. Aging \& Mental Health 2012;16:819-827.

43. Sands LP, Ferreira P, Stewart AL, et al. What explains differences between dementia patients' and their caregivers' ratings of patients' quality of life? American Journal of Geriatric Psychiatry 2004;12:272-280.

44. Algar K, Woods RT and Windle G. Measuring the quality of life and well-being of people with dementia: A review of observational measures. Dementia (London) 2014:(Epub ahead of print).

45. Kitwood T and Bredin K. Towards a theory of dementia care: personhood and well-being. Ageing and Society 1992;12:269-287. 
46. Myin-Germeys I, Oorschot M, Collip D, et al. Experience sampling research in psychopathology: opening the black box of daily life. Psychological Medicine 2009;39:1533-1547.

47. Barca ML, Engedal K, Laks J and Selbaek G. Quality of life among elderly patients with dementia in institutions. Dementia and Geriatric Cognitive Disorders 2011;31:435-442.

48. Hoe J, Hancock G, Livingston G and Orrell M. Quality of life of people with dementia in residential care homes. The British Journal of Psychiatry 2006;188:460-464.

49. Banerjee S, Smith S, Lamping D, et al. Quality of life in dementia: more than just cognition. An analysis of associations with quality of life in dementia. Journal of Neurology, Neurosurgery and Psychiatry 2006;77:146-148.

50. Banerjee S, Samsi K, Petrie CD, et al. What do we know about quality of life in dementia? A review of the emerging evidence on the predictive and explanatory value of disease specific measures of health related quality of life in people with dementia. International Journal of Geriatric Psychiatry 2009;24:15-24.

51. Logsdon RG, Gibbons LE, McCurry SM and Teri L. Assessing quality of life in older adults with cognitive impairment. Psychosomatic Medicine 2002;64:510-519.

52. Wetzels RB, Zuidema SU, de Jonghe JF, et al. Determinants of quality of life in nursing home residents with dementia. Dementia and Geriatric Cognitive Disorders 2010;29:189-197.

53. Hoe J, Katona C, Orrell M and Livingston G. Quality of life in dementia: care recipient and caregiver perceptions of quality of life in dementia: the LASER-AD study. International Journal of Geriatric Psychiatry 2007;22:1031-1036.

54. Sixsmith A, Hammond M and Gibson G. Quality of Life and Dementia. In: M Vaarama, R Pieper and A Sixsmith, eds. Care-Related Quality of Life in Old Age. Concepts, Models and Empirical Findings. New York: Springer, 2008.

55. Edvardsson D, Petersson L, Sjogren K, et al. Everyday activities for people with dementia in residential aged care: associations with person-centredness and quality of life. International Journal of Older People Nursing 2014;9:269-276.

56. Nikmat AW, Hawthorne G and Al-Mashoor SH. Quality of life in dementia patients: nursing home versus home care. International Psychogeriatrics 2011;23:1692-1700.

57. Eurofound. Third European Quality of Life Survey - Quality of life in Europe: Impacts of the crisis. Luxembourg: Publications Office of the European Union, 2012.

58. Diener E, Oishi S and Lucas RE. Personality, culture, and subjective well-being: Emotional and cognitive evaluations of life. Annual Review of Psychology 2003;54:403-425.

59. Verbeek H, Meyer $\mathrm{G}$, Leino-Kilpi $\mathrm{H}$, et al. A European study investigating patterns of transition from home care towards institutional dementia care: the protocol of a RightTimePlaceCare study. BMC Public Health 2012;12:68.

60. de Boer B, Hamers JPH, Beerens HC, et al. Living at the farm, innovative nursing home care for people with dementia - design of an observational longitudinal study. BMC Geriatrics 2015;2:144. 



\section{CHAPTER 2}

Factors associated with quality of life of people with dementia in long-term care facilities: A systematic review

This chapter was published as:

Beerens HC, Zwakhalen SMG, Verbeek H, Ruwaard D, Hamers JPH. Factors associated with quality of life of people with dementia in long-term care facilities: A systematic review. International Journal of Nursing Studies 2013;50:1259-1270.

doi:10.1016/j.ijnurstu.2013.02.005 


\section{ABSTRACT}

Background: Quality of life has become an important outcome measure in dementia research. Currently there is no convincing evidence about which factors are associated with quality of life of people with dementia living in long-term care facilities.

Objective: This study aims to investigate which factors are associated with quality of life, including factors associated with change over time, of people with dementia living in long-term care facilities.

Design: A systematic literature review was performed.

Data sources: Cochrane, Pubmed, CINAHL, Web of Science, and PsycINFO were searched.

Review methods: Three researchers independently assessed studies for eligibility. The inclusion criteria were: 1 ) the primary focus was on factors related to quality of life; 2 ) the study was performed in long-term care facilities; 3 ) the study regarded quality of life as multidimensional construct. Methodological quality of studies included in the review was assessed with a quality criteria checklist.

Results: Ten cross-sectional and three longitudinal articles were included in the review. In cross-sectional studies, depressive symptoms were negatively related to self-rated quality of life of people with dementia. The association between depressive symptoms and proxy-rated quality of life was less clear. Behavioural disturbances, especially agitation, appeared to be negatively related to proxy-rated quality of life. There appeared to be a negative relation between quality of life, activities of daily living and cognition, although this could not be confirmed in all studies. In longitudinal studies, depressive symptoms were negatively related and cognition was positively related to self-rated quality of life, whereas dependency and depressive symptoms were negatively related to proxy-rated quality of life.

Conclusions: There are only few high quality studies that investigate associations of (change in) quality of life of people with dementia living in long-term care facilities. Our results suggest that depressive symptoms and agitation are related to lower quality of life. Perspective of quality of life measurement, i.e. self- or proxy rating, may influence its associations. Longitudinal studies are needed to determine which factors are related to change in quality of life over time. This information is essential for the development of interventions that aim to improve quality of life. 


\section{BACKGROUND}

Dementia affects an increasing number of people each year. It is estimated that in Europe the number of people with dementia will increase to reach 13 million in 2040. This is important because these people are heavy consumers of health care. ${ }^{1}$ As there is no sign yet of a cure for the syndrome, dementia care should focus on contributing to maximizing quality of life (QoL). Therefore, over the last decade QoL has become a highly important outcome measure in dementia research. ${ }^{2,3}$

QoL is a complex, multidimensional construct and is defined by the World Health Organization as 'individuals' perceptions of their position in life in the context of the culture and value systems in which they live, and in relation to their goals, expectations, standards and concerns'. ${ }^{4}$ Both objective (e.g. behavioural competence and environment) and subjective (e.g. perceived QoL and psychological well-being) components are generally considered to be important domains in QoL of people with dementia. ${ }^{5}$

A large number of studies have investigated factors influencing QoL and factors influencing changes in QoL of people with dementia living at home. Current literature shows that there is no consensus on which variables are related to QoL and which to change in QoL. There are, however, indications that high levels of depression, the presence of behavioural disturbances, substantial cognitive impairment, and high dependence in activities of daily living ( $A D L$ ) might be related to low QoL of people with dementia living at home. ${ }^{6-12}$

Many psychosocial and pharmacological interventions have been developed and implemented to improve QoL. Many of these interventions focus directly on people with dementia (e.g. cognitive stimulation therapy and antidepressant medication use), but interventions focusing on the environment are also common (e.g. family carer interventions or staff training interventions). ${ }^{13-16}$

The issue of how to improve QoL in institutional care by means of interventions is gaining increasing attention, confirmed by the number of research studies that have focused on investigating QoL of institutionalized people with dementia as the main outcome parameter. ${ }^{17-19}$ However, information about the factors influencing QoL and changes in QoL in people with dementia living in long-term care settings is currently lacking. Consequently, it is not known what interventions in institutional care should focus on when aiming to improve QoL. Current scientific knowledge regarding the factors related to QoL of people with dementia living at home cannot be straightforwardly translated to people with dementia living in long-term care settings. People living in long-term care facilities differ from community-dwelling people with regard to factors like behaviour, functional status, and cognition, which might influence QoL assessment. Furthermore, it is not known to what extent place of residence influences QoL ratings. ${ }^{20}$ Conflicting conclusions have been inferred about whether QoL improves or decreases after institutionalization. ${ }^{9}{ }^{21}$ In order to bridge this gap in the existing knowledge, this systematic review aims to examine current evidence regarding the factors associated 
with QoL and the changes in QoL of people with dementia living in long-term care facilities.

\section{METHODS}

\section{Search strategy}

A literature search was performed. Relevant articles published between January 2000 and May 2012 were obtained by searching in five electronic databases: Cochrane, Pubmed, CINAHL, Web of Science, and PsycINFO. Additional articles were searched by exploring references from retrieved publications.

The main outcome measure 'quality of life' was used as a search term and combined with the Boolean operator 'AND' with other search terms with respect to the disease (dementia OR Alzheimer), the place of residence (care home* OR nursing home* OR institutional care OR institutional long term care OR care institution* OR residential care OR residential home* OR assisted living OR small scale setting* OR small scale living OR small scale facilit* OR shared housing arrangement* OR special care facilit* OR institutionalised, OR institutionalized OR sheltered housing), and the focus of the research question (determinant* OR factor* OR correlate*, OR predict* OR relate* OR associate*).

\section{Study selection}

\section{Eligibility criteria}

Studies were eligible if they 1) mainly focused on factors influencing QoL of people with dementia living in long-term care settings, which are defined as places of collective living wherein care and accommodation are provided as a package by a public agency or a non-profit or private company, ${ }^{22}$ 2) used QoL as a primary outcome measure, and 3) used a multidimensional construct to assess QoL, which means that QoL consists of several domains. Studies were excluded when they evaluated interventions or focused primarily on people with cognitive impairment without a diagnosis of dementia, people with psychiatric diseases or people receiving end-of-life care. There were no restrictions with regard to language.

\section{Study screening and data extraction strategy}

Titles and abstracts of articles were screened for relevance by two researchers independently ( $\mathrm{HB}$ and $\mathrm{HV}$ ). Subsequently, remaining abstracts were independently assessed for eligibility by two researchers (HB and SZ). Finally, full-text articles were independently obtained and screened for final inclusion by three researchers (HB, HV, and SZ). At each step references were categorized by each researcher as 'include', 'possibly 
include' (provided with reason), or 'exclude'. Disagreements between the researchers were discussed in order to reach consensus about which references should be in/excluded in this review.

Data were extracted using a standardized data sheet that contains information about publication type, study aims, study methods, sample characteristics, independent variables in relation to the outcome measure QoL, study results, and recommendations and limitations from included references.

\section{Methodological quality}

Each article was assessed for methodological quality by means of a checklist. This quality judgement was used for the interpretation of the results: results of studies of low quality were treated more cautiously. This checklist was tailored for use in this systematic review and was based on existing critical appraisal tools. ${ }^{23,24}$ We looked for bias in recruitment, assessment, analysis, and interpretation of the results. In accordance with the recommendations of Sanderson et al. (2007), no overall numerical score was computed but articles were divided into two categories: 'moderate to high quality' or 'low quality'. ${ }^{25}$ In order to be judged as an article of 'moderate to high quality', the following four criteria had to be met as a minimum: 1 ) adequate sample size in relation to predictors, 2) use of valid and reliable measures, 3) use of appropriate statistical testing, and $4)$ discussion and conclusion in line with the results. Additional criteria were: 5) appropriate description of sampling method, 6) clear description of in- and exclusion criteria, 7) appropriate description of participants, 8) appropriate description of cases lost to follow-up (applicable for longitudinal studies), and 9) description of cut-off point for clinical relevance (applicable for longitudinal studies).

\section{Analyses}

The data presented include information on sample size, characteristics of the study population, and measurement instruments used to rate QoL. Both bivariate and multivariate results were obtained from all studies, if possible. In the tables results were differentiated by perspective (self-assessment, proxy-assessment, or observational assessment) and, if applicable, by subgroup (e.g. based on severity of dementia). For quality reasons only results based on validated measurement instruments were included. We have arranged the results by socio-demographic characteristics, depressive symptoms and anxiety, behaviour, dependency in activities of daily living, cognition, severity of dementia, and medication use. Longitudinal studies are displayed separately. 


\section{RESULTS}

\section{Search results}

The electronic database search yielded 2178 publications. After removal of duplicates, 1505 articles remained. Stepwise screening resulted in the inclusion of ten crosssectional articles and three longitudinal articles, which were all written in English. No additional articles could be obtained via reference tracking. Figure 1 gives an overview of the selection process from initial search to final retrieved articles.

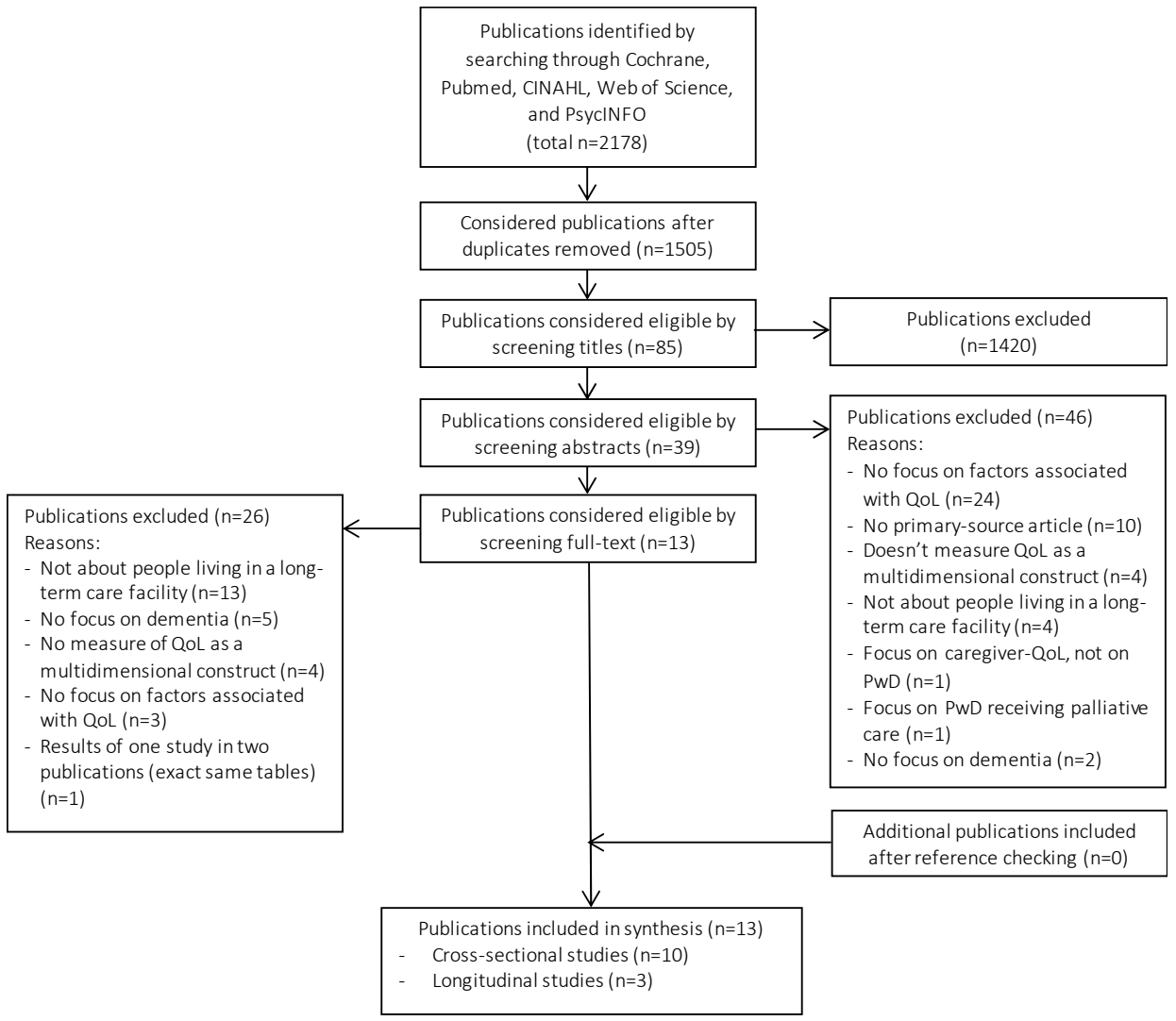

Figure 1. Flow diagram illustrating data collection strategy

\section{Methodological quality}

Assessments of the publications are shown in Table 1. Eight cross-sectional articles were considered to be of moderate to high quality, ${ }^{26-33}$ of which five studies met all quality criteria. Two cross-sectional articles were considered to be low-quality articles. ${ }^{34,35}$ With 
respect to the longitudinal studies, only the article by Hoe et al. (2009) ${ }^{36}$ was considered to be a high quality article, whereas the studies by Funaki et al. $(2005)^{21}$ and Lyketsos et al. $(2003)^{37}$ were not.

Table 1. Methodological quality of included studies

\begin{tabular}{|c|c|c|c|c|c|c|c|c|c|c|c|c|c|}
\hline & \multicolumn{10}{|c|}{ Cross-sectional studies } & \multicolumn{3}{|c|}{$\begin{array}{l}\text { Longitudinal } \\
\text { studies }\end{array}$} \\
\hline & 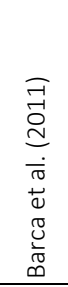 & 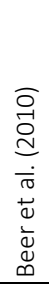 & 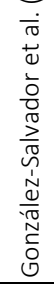 & 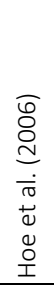 & 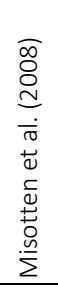 & 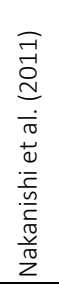 & 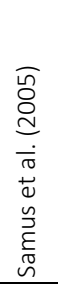 & 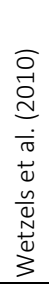 & 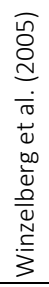 & 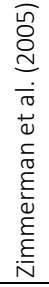 & 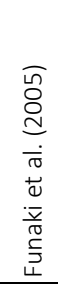 & 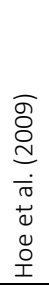 & 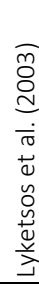 \\
\hline $\begin{array}{l}\text { Adequate sample size in relation to } \\
\text { predictors* }\end{array}$ & + & + & + & + & + & + & + & + & + & - & - & + & - \\
\hline Measures used are valid and reliable* & + & + & + & + & + & + & + & + & - & - & + & + & + \\
\hline $\begin{array}{l}\text { Appropriate statistical testing was } \\
\text { conducted* }\end{array}$ & + & + & + & + & + & + & + & + & + & - & - & + & + \\
\hline $\begin{array}{l}\text { Discussion and/or conclusion is in line with } \\
\text { results* }\end{array}$ & + & + & + & + & + & + & + & + & - & - & + & + & + \\
\hline Appropriate description of sampling method & $d-$ & + & - & + & + & + & + & + & - & + & - & + & - \\
\hline $\begin{array}{l}\text { Inclusion- and exclusion criteria are clearly } \\
\text { described }\end{array}$ & - & + & - & + & + & + & - & + & - & + & + & + & - \\
\hline $\begin{array}{l}\text { Appropriate description of characteristics of } \\
\text { participating people with dementia }\end{array}$ & + & + & + & + & + & + & + & + & + & - & + & + & + \\
\hline $\begin{array}{l}\text { LS: appropriate description cases lost to } \\
\text { follow-up }\end{array}$ & NA & NA & NA & NA & NA & NA & NA & NA & NA & NA & - & + & + \\
\hline $\begin{array}{l}\text { LS: description of cut-off point clinical } \\
\text { relevance }\end{array}$ & NA & NA & NA & NA & NA & NA & NA & NA & NA & NA & - & + & - \\
\hline $\begin{array}{l}\text { Final assessment overall quality } \\
(+, \text { moderate to high quality; -, low quality) }\end{array}$ & + & + & + & + & + & + & + & + & - & - & - & + & - \\
\hline
\end{tabular}

LS = longitudinal studies; NA = not applicable

* Criterion that had to be met in order to be judged as an article of moderate to high quality

\section{Factors influencing QoL}

Table 2 gives an overview of the cross-sectional results regarding factors relating to QoL. Winzelberg et al. (2005) $)^{34}$ and Zimmerman et al. $(2005)^{35}$ drew conclusions based on the same study population, and therefore their results are presented together, when applicable. 


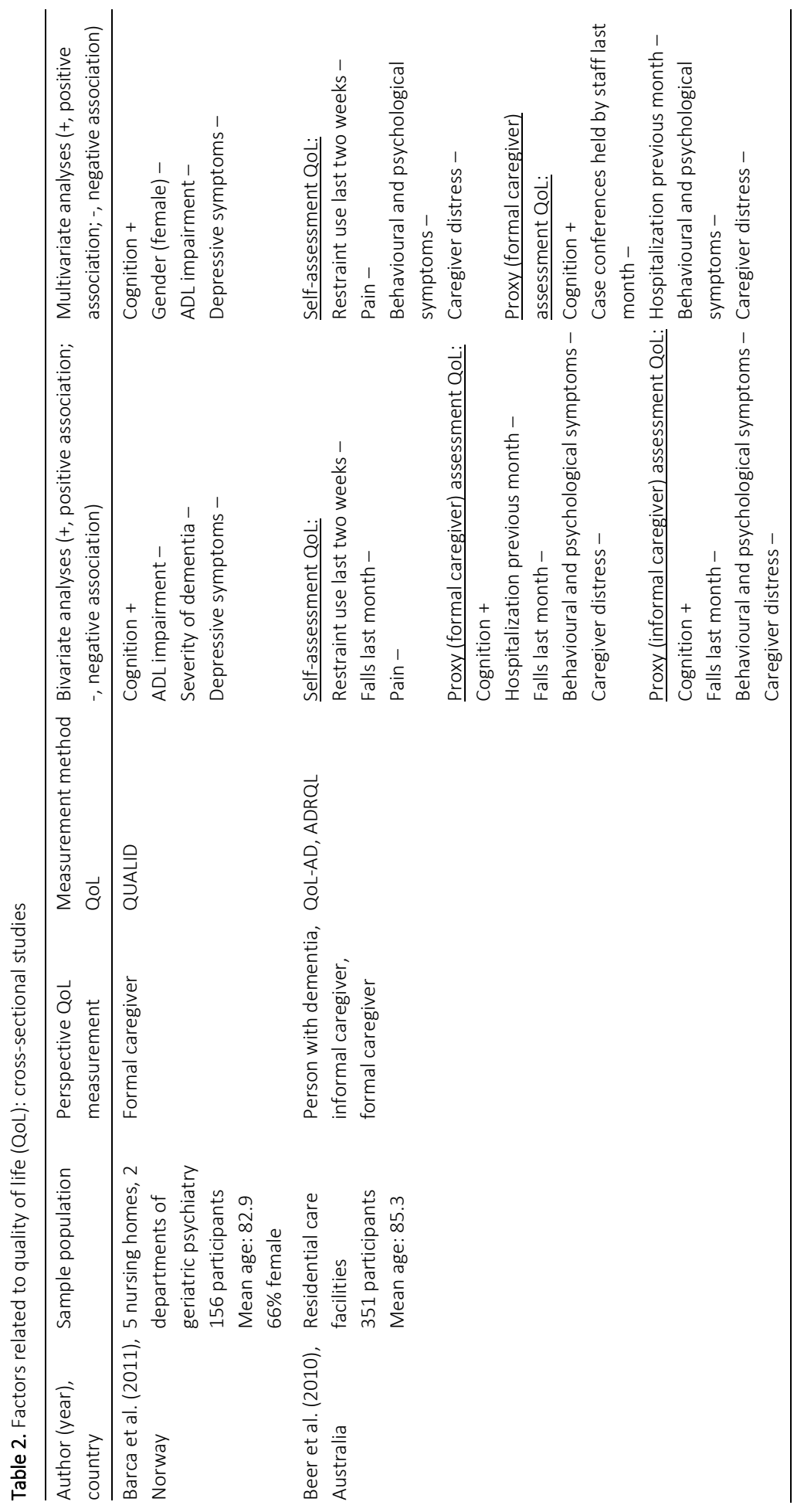




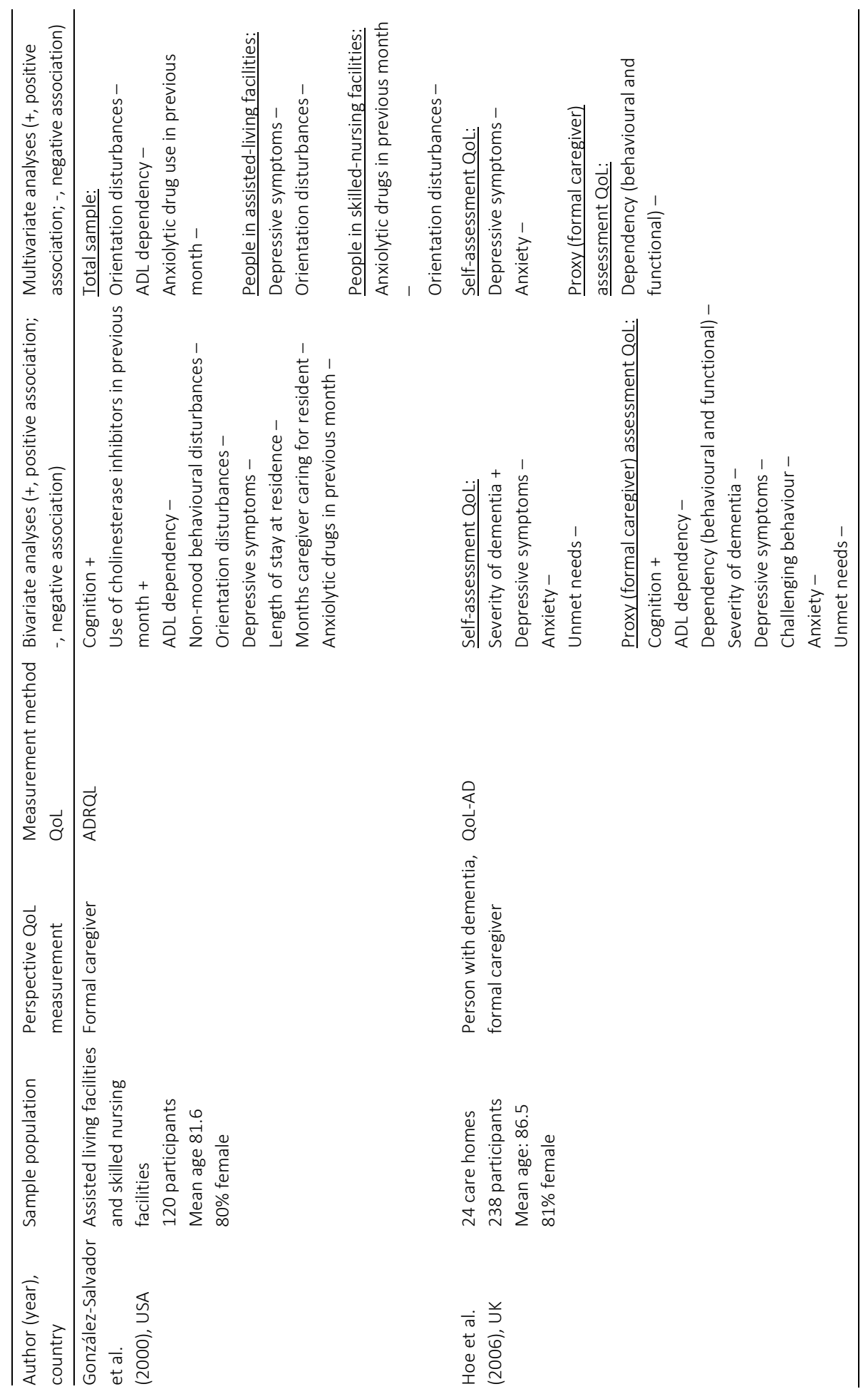




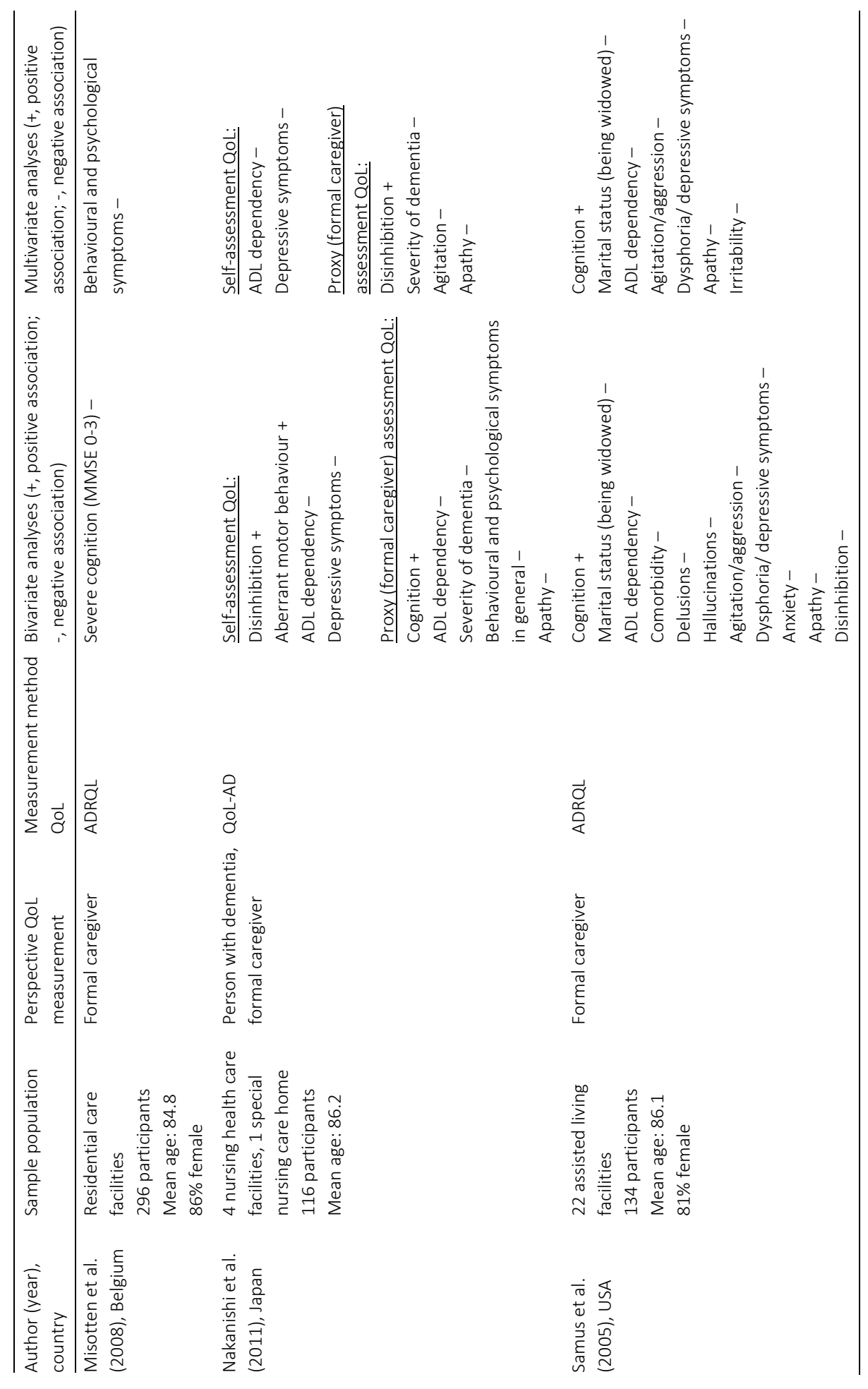




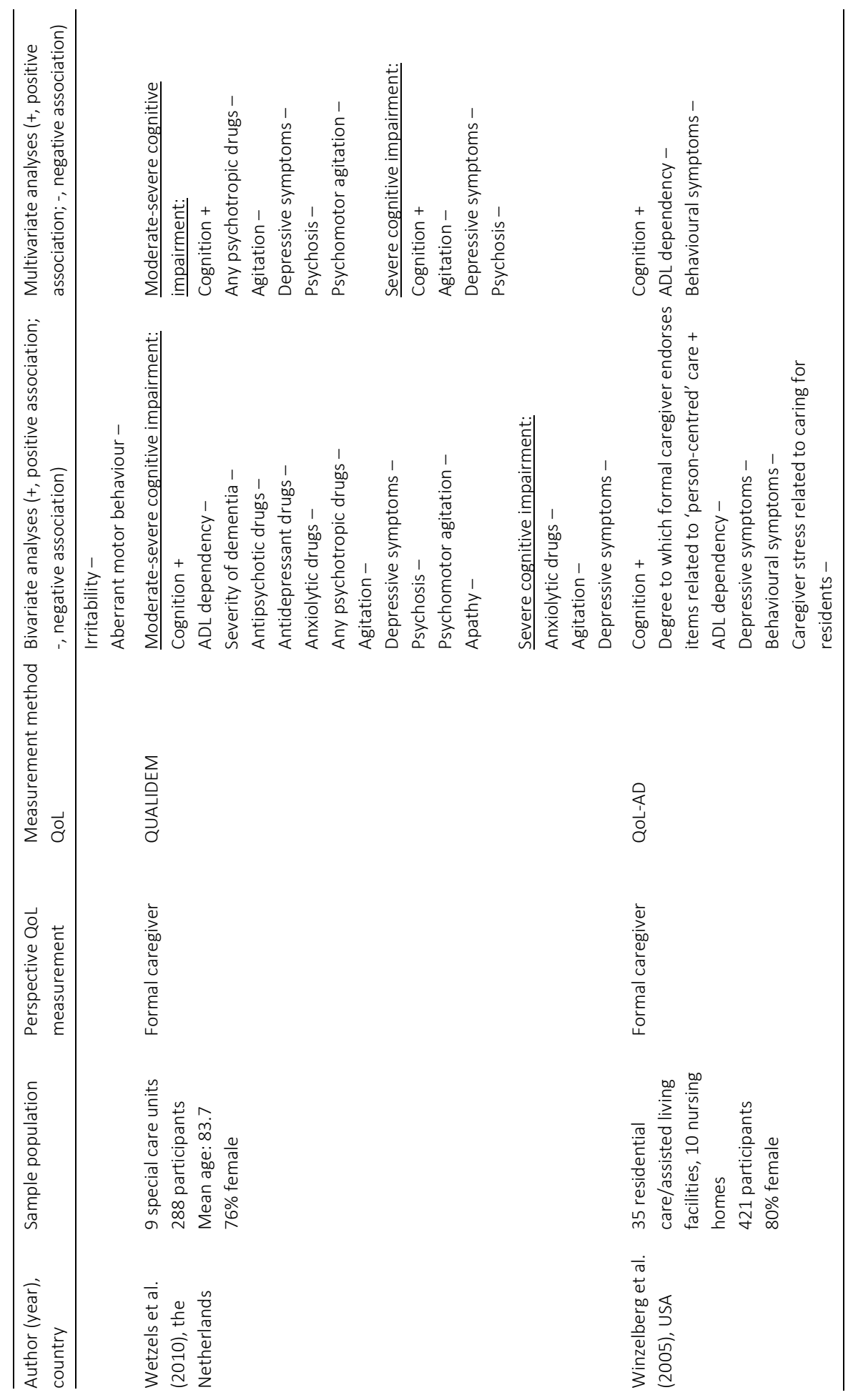




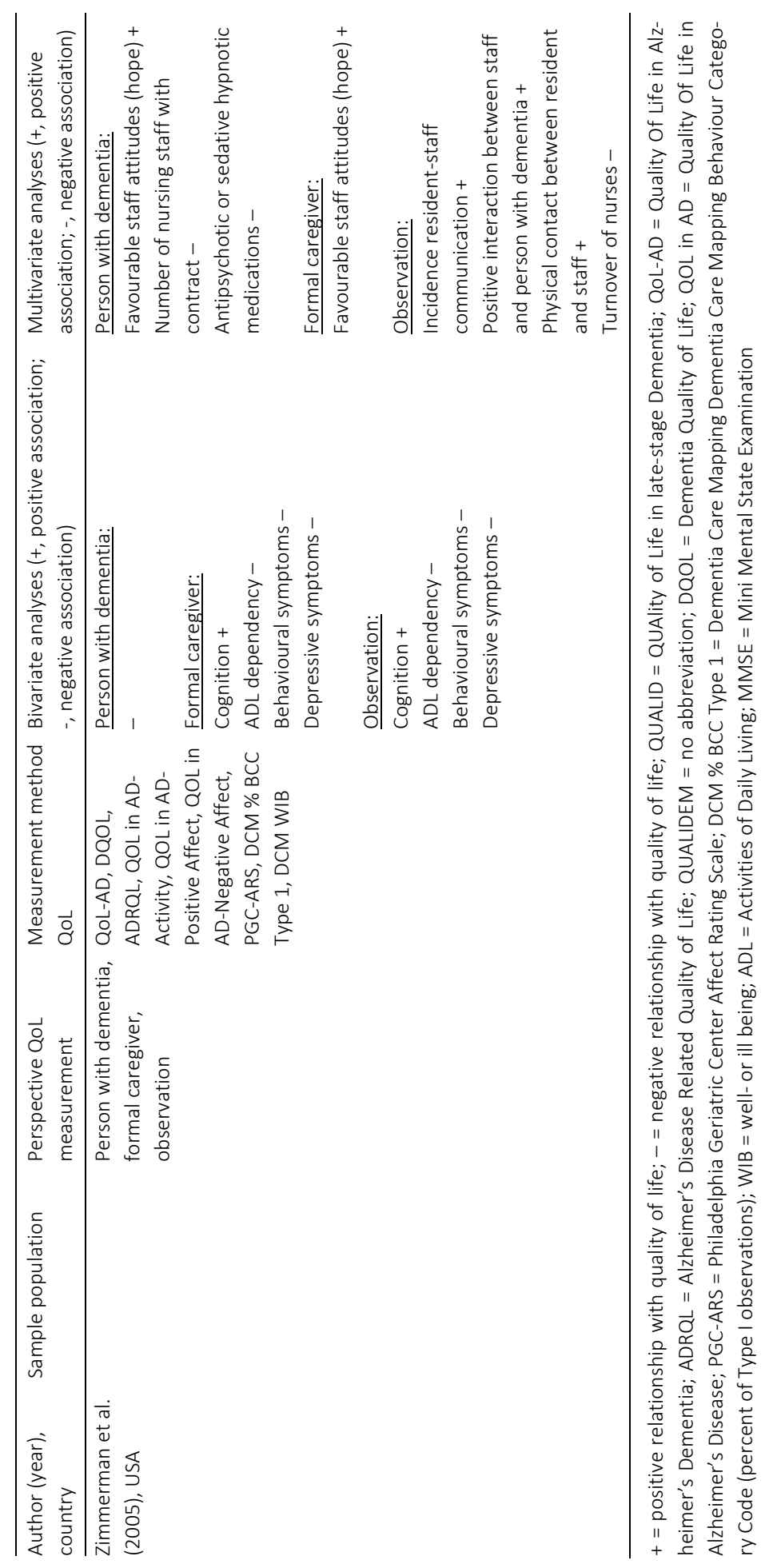




\section{Socio-demographic characteristics}

Eight cross-sectional studies took several socio-demographic characteristics (e.g. age, gender, race, marital status) into account. Most studies ( $n=6)$ did not find any relationship with socio-demographic characteristics. ${ }^{27,28,31,33-35}$ One study found female gender to be negatively associated with QoL, ${ }^{26}$ whereas five other studies did not find a relationship with gender. ${ }^{27,31,33-35}$ A negative association with being widowed was found by Samus et al. (2005), ${ }^{32}$ but two other studies did not find an association with marital status. ${ }^{33,35}$

\section{Depressive symptoms and anxiety}

Depressive symptoms and anxiety, which are both indicators for mood, were taken into account by several cross-sectional studies.

Most studies ( $n=8)$, except for Beer et al. $(2010)^{27}$ and Missotten et al. (2008), ${ }^{30}$ investigated whether there was a relationship between QoL and depressive symptoms. Bivariate as well as multivariate analyses showed a negative relationship between selfreported QoL and depressive symptoms, indicating that more depressive symptoms are related to lower QoL. Regarding the association between proxy-reported QoL and depressive symptoms, studies show ambiguous results. Wetzels et al. (2010) noted that the association between depressive symptoms and proxy-rated QoL was stronger in people with mild to moderately severe dementia than in those with severe dementia. ${ }^{33}$ This seems to be in line with the study of González-Salvador et al. (2000), who found a negative association with proxy-reported QoL in assisted living facilities, but not in skilled nursing facilities. ${ }^{28}$ Their study population had significantly lower cognition in skilled nursing facilities compared with people living in assisted living facilities. Winzelberg et al. (2005) were not able to take depressive symptoms into account in multivariate analyses because of multicollinearity with behavioural symptoms. ${ }^{34}$

Three cross-sectional studies of moderate to high quality examined the relationship between QoL and anxiety. ${ }^{29,31,32}$ Two studies found a negative association between QoL and anxiety in bivariate analyses, ${ }^{29}, 32$ indicating that the presence of more anxious symptoms is related to lower QoL. In multivariate analyses, only Hoe et al. (2006) detected a negative association between self-reported QoL and anxiety, ${ }^{29}$ whereas the other studies found no association. ${ }^{31,32}$ In the study by Hoe et al. (2006) depressive symptoms and anxiety were the only factors significantly related to self-assessed QoL. Their final multivariate model accounted for $34 \%$ of the variance. ${ }^{29}$

\section{Behaviour}

Behavioural symptoms were taken into account by nine of the ten cross-sectional studies. Most studies reported an association between proxy-rated QoL and behaviour, especially agitation, in bivariate as well as multivariate analyses. Behaviour was measured in two different ways. 
In the first place, six studies ${ }^{27-30,34,35}$ measured several behavioural domains using a comprehensive questionnaire (e.g. the NPI-Q). ${ }^{38}$ Their bivariate analyses found a negative association between QoL and behavioural symptoms, indicating that more behavioural disturbances are related to lower QoL. Three studies of moderate to high quality reported behavioural symptoms to be negatively related to QoL in multivariate analyses as well, ${ }^{27,} 30,34$ whereas one study reported no association. ${ }^{28}$ It should be noted that Beer et al. (2010), Hoe et al. (2006), and Zimmerman et al. (2005) compared selfassessments with proxy-assessments and only found these bivariate associations with proxy-reported QoL, and not with self-reported QoL. ${ }^{27,29,35}$ Furthermore, Missotten et al. (2008) reported that behavioural disturbances explain between $17.99 \%$ and $34.45 \%$ of the total QoL score. ${ }^{30}$ In the second place, three studies of moderate to high quality described the relationship between $\mathrm{QoL}$ and several separate behavioural symptoms. ${ }^{31-}$ 33 In multivariate analyses they all concluded that more agitation is related to lower proxy-rated QoL. Also several other behavioural symptoms were found to be negatively related to proxy-rated QoL (e.g. apathy, irritability, psychomotor agitation). The studies showed no agreement, however, about which behavioural factors were negatively related to QoL.

\section{Dependency in activities of daily living}

Most cross-sectional studies ( $n=9$ ) included impairment or dependency in activities of daily living (ADL) as an independent variable, except for Beer et al. (2010). ${ }^{27}$ Bivariate analyses show that $A D L$ dependency is negatively related to QoL, indicating that greater dependency is related to lower QoL ratings. In multivariate analyses, studies show ambiguous results. Five studies of moderate to high quality and one low-quality study reported a negative relationship between ADL dependency and QoL, ${ }^{26,28,31,32,34}$ whereas two studies of moderate to high quality did not. ${ }^{29,} 30$ In addition, González-Salvador et al. (2000) only reported this association in an analysis of their total sample, but not when assisted-living and skilled nursing facilities were analysed separately, ${ }^{28}$ and Nakanishi et al. (2011) reported this relationship only with self-reported QoL but not with proxyassessments of QoL. ${ }^{31}$ Wetzels et al. (2010) excluded ADL from multivariate analyses because of its multicollinearity with cognition. ${ }^{33}$

\section{Cognition}

All cross-sectional studies $(n=10)$ included cognition as an independent variable. Bivariate analyses indicated that cognition was positively related to proxy-rated QoL, indicating that better cognitive abilities were related to higher QoL. This association was never found in the self-assessments of QoL. ${ }^{27,29,31}$ In multivariate analyses, however, the relationship between better cognitive function and higher proxy-rated QoL was maintained in only five studies, one of which was of lower quality. ${ }^{26,27,32-34}$ Again, there was no association with self-assessed QoL. 
In multivariate analyses, Wetzels et al. (2010) included cognition in their final model but had to remove ADL because of multicollinearity between these two factors. ${ }^{33}$ Barca et al. (2011) included ADL as a covariate and found no intercorrelation between cognition and $A D L .{ }^{26}$ With regard to the other three studies in which cognition was significantly related to QoL, it is not known whether the authors were aware of the possible multicollinearity between ADL and cognition. Four studies of moderate to high quality that did include ADL as a covariate found that the relationship with cognition disappeared. ${ }^{28-31}$ Missotten et al. (2008) divided people with dementia into five subgroups based on their cognitive abilities and found only significant lower QoL ratings in the lowest cognition group compared with the other groups. The other four subgroups did not differ significantly from each other, indicating the lack of a linear relationship between QoL and cognitive function. ${ }^{30}$

\section{Severity of dementia}

Five cross-sectional studies of moderate to high quality investigated the association between QoL and the severity or stage of dementia. ${ }^{26,29-31,33}$ Four studies performed bivariate analyses and concluded that severity of dementia is negatively associated with proxy-rated QoL, indicating that more severe dementia is related to lower QoL. The relationship with self-assessed $\mathrm{QoL}$ is unclear. According to multivariate analyses, there is little evidence for the association between QoL and severity of dementia.

\section{Medication use}

Three cross-sectional studies of moderate to high quality investigated the relationship between medication use and QoL of people with dementia. Beer et al. (2010) found no evidence for the relationship between QoL and quantity of medication use. ${ }^{27}$ GonzálezSalvador et al. (2000) and Wetzels et al. (2010) found no convincing evidence for the association between psychotropic medication use and QoL. ${ }^{28,33}$

González-Salvador et al. (2000) investigated the relationship between psychopharmacological treatment in the previous month and QoL. They found that cholinesterase inhibitors (drugs that inhibit cognitive deterioration) were positively related to QoL in bivariate analyses, but not in multivariate analyses. They reported in their bivariate as well as in multivariate results that anxiolytic drugs (antianxiety agents) were negatively associated with QoL of people living in skilled nursing facilities, indicating that the use of anxiolytic drugs is related to lower QoL. ${ }^{28}$ Wetzels et al. (2010) investigated the association between psychotropic use on one day of assessment and QoL. In bivariate analyses, psychotropic drug use in general, antipsychotics, antidepressants and anxiolytic drugs were negatively related to QoL in people with mild to moderately severe dementia, indicating that these types of medications are associated with lower QoL. In people with severe dementia, only the use of anxiolytic drugs was significantly negatively associated with QoL. In multivariate analyses only psychotropic drug use in general was negatively associated with QoL in people with mild to moderately severe dementia. ${ }^{33}$ 


\section{Factors influencing change in QoL}

Conclusions of the three longitudinal studies with regard to factors related to change in QoL are shown in Table 3.

Hoe et al. (2009) ${ }^{36}$ conducted the only high-quality longitudinal study and reports associations between QoL and QoL at baseline, depressive symptoms, anxiety, cognition, and dependency in behaviour and function. With regard to self-assessment of QoL, in multivariate analyses a decrease in QoL in two years was related to a high QoL score at baseline and few depressive and anxiety symptoms at baseline. A decrease in QoL in two years was also related to an increase of depressive symptoms and deteriorating cognition over two years. With regard to the QoL assessment of formal caregivers, in multivariate analyses a decrease in QoL in two years was related to a high QoL score at baseline and low dependency in behavioural and functional aspects at baseline. An increase in functional and behavioural dependency and depressive symptoms over two years were also related to a decrease in QoL. According to multivariate analyses, there were no associations with (change in) ADL or severity of dementia.

The other two longitudinal studies scored lower on the quality criteria. QoL of the study population of Lyketsos et al. (2003) ${ }^{37}$ decreased between baseline and follow-up 20 weeks later. According to their multivariate analyses, QoL at baseline assessed by a formal caregiver was associated with less of a decline in QoL at follow-up. Lyketsos et al. (2003) found no association between change in QoL and cognition, behavioural disturbance, ADL, or depressive symptoms. QoL of the study population of Funaki et al. $(2005)^{21}$ increased over three months. It should be noted that this study population consisted of people who were recently institutionalized. Funaki et al. (2005) report bivariate results regarding the relationship between QoL and several rehabilitation factors, but the directions of these associations were not clearly reported and are therefore not reported here. In multivariate analyses, Funaki et al. (2005) suggest that an increase in the number of housekeeping activity items such as cooking or shopping that can be acquired is related to improvements in QoL. No relationship was found between change in QoL and ADL, behaviour, or severity of dementia. 


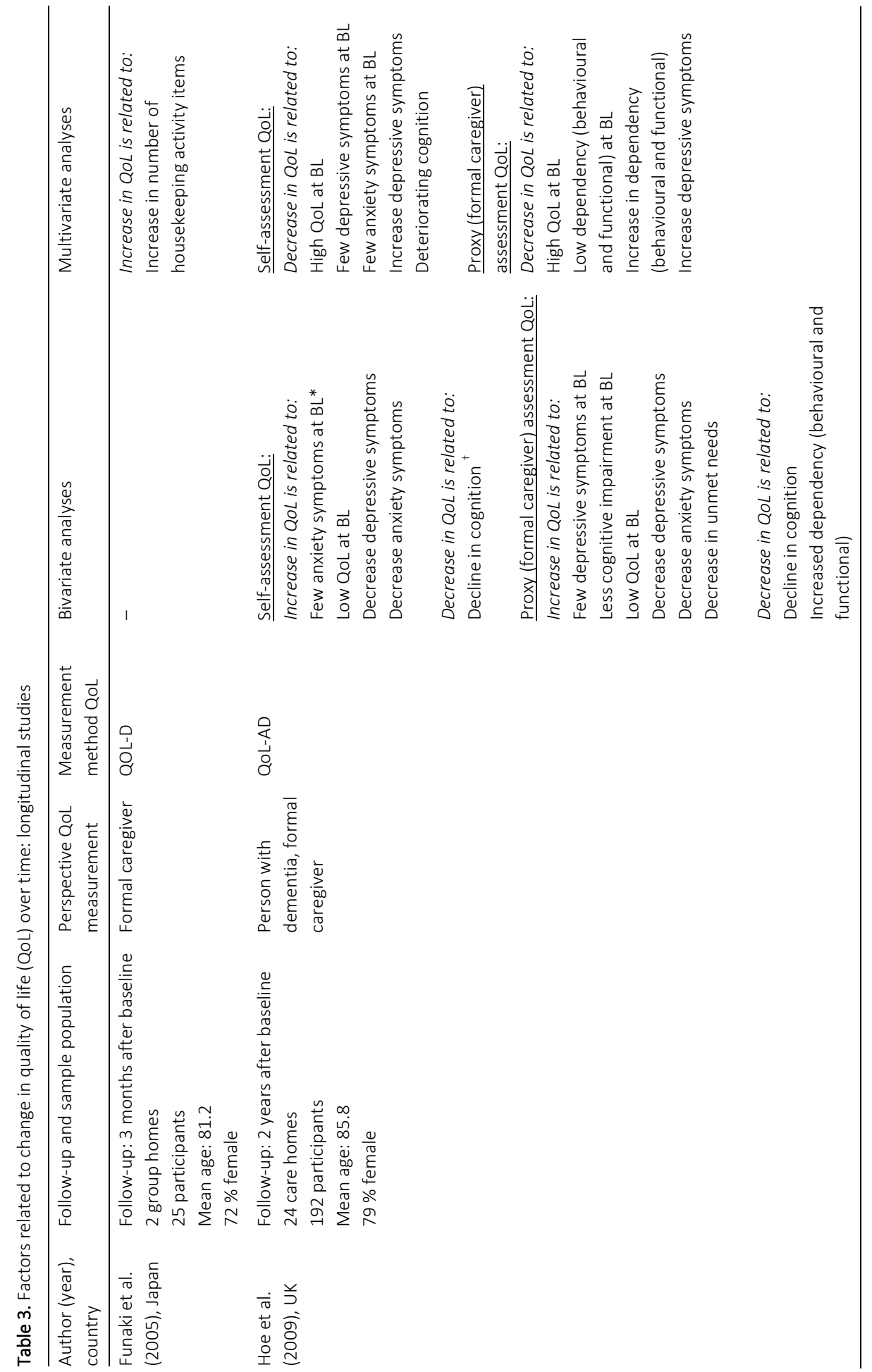


CHAPTER 2

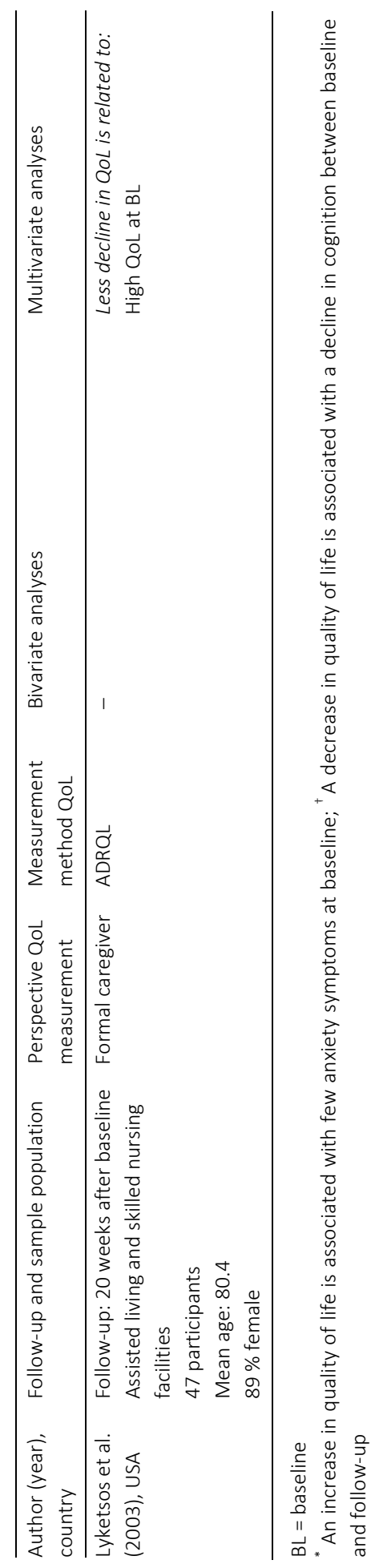




\section{DISCUSSION}

From the findings of this systematic review it can be concluded that mood, and especially depressive symptoms, is a consistent factor which is negatively related to selfrated QoL of people with dementia living in long-term care facilities, indicating that more depressive symptoms are related to lower QoL. The association between proxyrated QoL and depressive symptoms is less clear. There are also reasonable indications that behavioural disturbances, and especially agitation, are negatively related to QoL, indicating that the presence of agitation is associated with lower QoL of people with dementia. The relationship between $\mathrm{QoL}$, cognition and ADL is complex. Bivariate analyses show that cognition and $A D L$ are negatively related to QoL, although this clear relationship cannot be confirmed by multivariate analyses, controlling for confounding factors. Furthermore, the negative relationship between cognition and QoL is found only with proxy-reported measures. The relationship between QoL and psychotropic drug use remains unclear, since only a few studies took these factors into account. Finally, there does not seem to be an association between QoL and socio-demographic factors and severity of dementia. Perspective of the QoL measurement, i.e. self- or proxy rating, seems to influence the reported associations.

To our best knowledge, this is the first systematic review that explores associations with (change in) QoL in people with dementia living in long-term care facilities. This extensive review shows that high-quality studies regarding factors associated with QoL of people with dementia living in long-term care facilities are scarce, particularly high quality longitudinal studies. Only one longitudinal study was considered to be of high quality and only five cross-sectional studies adhered to all the quality criteria set in advance. Our study did not detect striking differences in QoL between people living at home and people living in institutional care. This is in line with our finding that cognition and functional status, which are discriminating factors for place of residence, ${ }^{39,40}$ have less impact on QoL ratings than was hypothesized.

Some limitations must be noted. The review was only based on published manuscripts and the information provided in those publications. We did not contact the authors of included studies in order to obtain any additional information or explanations about methods or results. In addition, since only published peer-reviewed papers were included, 'grey' literature was not taken into account. Therefore, we may have missed information. Finally, QoL is still an ambiguous concept, and the included studies used different operationalisations and measurement instruments. This is a possible explanation of the contradictory results. However, we only included studies that used reliable and valid QoL instruments and we could not detect any relationship between a specific measurement instrument and factors associated with QoL.

Our review findings show that depressive symptoms and anxiety are related to lower QoL as assessed by people with dementia living in long-term care settings themselves, but not always to QoL as assessed by proxies. This indicates that QoL assessment 
from the perspective of people with dementia is strongly influenced by their own mood. With regard to proxies, depressive symptoms or anxiety seem to play a smaller role in rating residents' QoL. This could be related to the difficulty they have in signalling and detecting depressive and anxious symptoms displayed by people with dementia. Since about $19-21 \%$ of the people with dementia suffer from depression or anxiety, ${ }^{41,42}$ this calls for the use of guidelines by caregivers, especially nurses, to improve diagnostic processes and to implement interventions if necessary. ${ }^{43,44}$

It is questionable how well proxies are able to estimate the influence of depression and anxiety on QoL from the viewpoint of people with dementia. It is difficult to decide which viewpoint is most valid, because both perspectives can include systematic biases. ${ }^{45}$ It is suggested that in people with mild to moderately severe dementia self-ratings should be performed because these people are able to give valid answers on dementiaspecific QoL instruments. In other cases proxy ratings might be preferred. ${ }^{46,47}$ In addition, results from Wetzels et al. (2010) and González-Salvador et al. (2000) suggest that depression is a stronger predictor of lower QoL in people with mild to moderately severe cognitive impairment than in people with severe cognitive impairment. ${ }^{28,}{ }^{33}$ This indicates that people with fewer cognitive abilities are perceived to suffer less from their depression, possibly because of their reduced awareness. Nurses are most frequently in contact with patients and are therefore the first caregivers to detect signals of depressive symptoms. Increased knowledge and skills regarding detection of depressive symptoms are therefore recommended.

The relationship between QoL and behaviour appears to be relatively unclear. The use of different measurement instruments to establish behaviour may play an important role in this. Behaviour is usually measured with a single instrument, although it seems more useful to take separate domains of behaviour into account. Studies that analysed separate domains of behaviour have unambiguously concluded that the presence of agitation is the most important factor in decreasing QoL ratings. Psychosocial interventions might lower the level of agitation because the need for stimulation and activities can be a cause of agitation. ${ }^{48-50}$ It is recommended that nursing staff encourage activities that stimulate people with dementia, even when there is limited time or room for social contact. ${ }^{51}$ Future research should investigate how working methods can facilitate guidance of people with dementia with behavioural disturbances. ${ }^{52}$

Our results report conflicting evidence regarding the association between $\mathrm{QoL}$ and the factors ADL-dependency and cognitive function. In a considerable number of studies, however, it was not clear whether they had checked for multicollinearity. Therefore, it is plausible that ADL and cognition are intercorrelated, making it hard to determine which one studies were measuring. This makes it hard to determine what the contribution of each measure is regarding its relation to QoL. Future studies should investigate possible multicollinearity between cognition and ADL dependency.

Recently, critiques have emerged on the extensive use of psychotropic drugs for people with dementia in long-term care settings. ${ }^{53-55}$ They argue that there is evidence 
that psychotropic drugs are related to negative health outcomes such as survival. The relationship between the use of this drugs and QoL has not yet been established. Our review indicates that psychotropic drugs might be negatively related to QoL. This also justifies recent guidelines' restrictions on the use of psychotropic drugs as treatment. The need for psychosocial interventions performed for example by nurses should gain high priority. ${ }^{56-58}$

\section{CONCLUSION}

This review provides evidence for nurses and other caregivers working in long-term care facilities who aim to improve QoL of people with dementia and shows that attention to depressive symptoms and agitated behaviour should have priority. This could for example be realized in the development and execution of psychosocial interventions, but it is recommended that associations of QoL be further explored. In particular, longitudinal studies are needed in order to determine which factors are related to change in QoL over time. This information is essential for the development of interventions that aim to improve QoL of people with dementia living in long-term care facilities. Recently, we have launched a study, RightTimePlaceCare, to provide information about QoL of people with dementia both at home and in long-term care facilities. ${ }^{59}$ Since the study is longitudinal it will also gain insight into change in QoL and its associations. 


\section{REFERENCES}

1. Ferri $\mathrm{CP}$, Prince $\mathrm{M}$, Brayne $\mathrm{C}$, et al. Global prevalence of dementia: a Delphi consensus study. Lancet 2005;366:2112-2117.

2. Rabins PV and Black BS. Measuring quality of life in dementia: purposes, goals, challenges and progress. International Psychogeriatrics 2007;19:401-407.

3. Moniz-Cook E, Vernooij-Dassen M, Woods R, et al. A European consensus on outcome measures for psychosocial intervention research in dementia care. Aging \& Mental Health 2008;12:14-29.

4. World Health Organization. The World Health Organization Quality of Life assessment (WHOQOL): position paper from the World Health Organization. Social Science and Medicine 1995;41:1403-1409.

5. Lawton MP. Quality of Life in Alzheimer Disease. Alzheimer Disease and Associated Disorders 1994;8:138150.

6. Banerjee S, Samsi K, Petrie CD, et al. What do we know about quality of life in dementia? A review of the emerging evidence on the predictive and explanatory value of disease specific measures of health related quality of life in people with dementia. International Journal of Geriatric Psychiatry 2009;24:15-24.

7. Banerjee S, Smith S, Lamping D, et al. Quality of life in dementia: more than just cognition. An analysis of associations with quality of life in dementia. Journal of Neurology, Neurosurgery and Psychiatry 2006;77:146-148.

8. Fuh JL and Wang SJ. Assessing quality of life in Taiwanese patients with Alzheimer's disease. International Journal of Geriatric Psychiatry 2006;21:103-107.

9. Hoe J, Katona C, Orrell M and Livingston G. Quality of life in dementia: care recipient and caregiver perceptions of quality of life in dementia: the LASER-AD study. International Journal of Geriatric Psychiatry 2007;22:1031-1036.

10. Logsdon RG, Gibbons LE, McCurry SM and Teri L. Assessing quality of life in older adults with cognitive impairment. Psychosomatic Medicine 2002;64:510-519.

11. Missotten P, Ylieff M, Di Notte D, et al. Quality of life in dementia: a 2-year follow-up study. International Journal of Geriatric Psychiatry 2007;22:1201-1207.

12. Shin IS, Carter M, Masterman D, et al. Neuropsychiatric symptoms and quality of life in Alzheimer disease. American Journal of Geriatric Psychiatry 2005;13:469-474.

13. Cooper C, Mukadam N, Katona C, et al. Systematic review of the effectiveness of non-pharmacological interventions to improve quality of life of people with dementia. International Psychogeriatrics 2012;24:856-870.

14. Cooper C, Mukadam N, Katona C, et al. Systematic Review of the Effectiveness of Pharmacologic Interventions to Improve Quality of Life and Well-being in People With Dementia. American Journal of Geriatric Psychiatry 2012;21:173-183.

15. Raina P, Santaguida P, Ismaila A, et al. Effectiveness of cholinesterase inhibitors and memantine for treating dementia: evidence review for a clinical practice guideline. Annals of Internal Medicine 2008;148:379-397.

16. Woods B, Aguirre E, Spector AE and Orrell M. Cognitive stimulation to improve cognitive functioning in people with dementia. Cochrane Database of Systematic Reviews 2012;2.

17. Verbeek H, Zwakhalen SMG, van Rossum E, et al. Dementia care redesigned: Effects of small-scale living facilities on residents, their family caregivers, and staff. Journal of the American Medical Directors Association 2010;11:662-670.

18. O'Shea E, Devane D, Murphy K, et al. Effectiveness of a structured education reminiscence-based programme for staff on the quality of life of residents with dementia in long-stay units: A study protocol for a cluster randomised trial. Trials 2011;12:41.

19. Phillips $L J$, Reid-Arndt SA and Pak Y. Effects of a creative expression intervention on emotions, communication, and quality of life in persons with dementia. Nursing Research 2010;59:417-425.

20. Nikmat AW, Hawthorne G and Al-Mashoor SH. Quality of life in dementia patients: nursing home versus home care. International Psychogeriatrics 2011;23:1692-1700. 
21. Funaki Y, Kaneko F and Okamura H. Study on factors associated with changes in quality of life of demented elderly persons in group homes. Scandinavian Journal of Occupational Therapy 2005;12:4-9.

22. OECD. The OECD Health Project. Long-term Care for Older People. Paris: OECD Publishing, 2005.

23. Downs SH and Black N. The feasibility of creating a checklist for the assessment of the methodological quality both of randomised and non-randomised studies of health care interventions. Journal of Epidemiology and Community Health 1998;52:377-384.

24. Zaza S, Wright-De Aguero LK, Briss PA, et al. Data collection instrument and procedure for systematic reviews in the Guide to Community Preventive Services. Task Force on Community Preventive Services. American Journal of Preventive Medicine 2000;18:44-74.

25. Sanderson S, Tatt ID and Higgins JP. Tools for assessing quality and susceptibility to bias in observational studies in epidemiology: a systematic review and annotated bibliography. International Journal of Epidemiology 2007;36:666-676.

26. Barca ML, Engedal K, Laks J and Selbaek G. Quality of life among elderly patients with dementia in institutions. Dementia and Geriatric Cognitive Disorders 2011;31:435-442.

27. Beer C, Flicker L, Horner B, et al. Factors associated with self and informant ratings of the quality of life of people with dementia living in care facilities: a cross sectional study. PloS One 2010;5:e15621.

28. González-Salvador T, Lyketsos CG, Baker A, et al. Quality of Life in Dementia Patients in Long-term Care. International Journal of Geriatric Psychiatry 2000;15:181-189.

29. Hoe J, Hancock G, Livingston G and Orrell M. Quality of life of people with dementia in residential care homes. The British Journal of Psychiatry 2006;188:460-464.

30. Missotten $P$, Squelard G, Ylieff $M$, et al. Relationship between quality of life and cognitive decline in dementia. Dementia and Geriatric Cognitive Disorders 2008;25:564-572.

31. Nakanishi K, Hanihara T, Mutai $\mathrm{H}$ and Nakaaki S. Evaluating the quality of life of people with dementia in residential care facilities. Dementia and Geriatric Cognitive Disorders 2011;32:39-44.

32. Samus QM, Rosenblatt A, Steele C, et al. The Association of Neuropsychiatric Symptoms and Environment With Quality of Life in Assisted Living Residents With Dementia. The Gerontologist 2005;45:19-26.

33. Wetzels RB, Zuidema SU, de Jonghe JF, et al. Determinants of quality of life in nursing home residents with dementia. Dementia and Geriatric Cognitive Disorders 2010;29:189-197.

34. Winzelberg GS, Williams CS, Preisser JS, et al. Factors Associated With Nursing Assistant Quality-of-Life Ratings for Residents With Dementia in Long-Term Care Facilities. The Gerontologist 2005;45:106-114.

35. Zimmerman S, Sloane PD, Williams CS, et al. Dementia Care and Quality of Life in Assisted Living and Nursing Homes. The Gerontologist 2005;45:133-146.

36. Hoe J, Hancock G, Livingston G, et al. Changes in the quality of life of people with dementia living in care homes. Alzheimer Disease and Associated Disorders 2009;23:285-290.

37. Lyketsos CG, Gonzales-Salvador T, Chin JJ, et al. A follow-up study of change in quality of life among persons with dementia residing in a long-term care facility. International Journal of Geriatric Psychiatry 2003;18:275-281.

38. Cummings JL, Mega M, Gray K, et al. The Neuropsychiatric Inventory: comprehensive assessment of psychopathology in dementia. Neurology 1994;44:2308-2308.

39. Dramé $M$, Lang PO, Jolly $D$, et al. Nursing home admission in elderly subjects with dementia: predictive factors and future challenges. Journal of the American Medical Directors Association 2012;13:83 e17-20.

40. Gaugler JE, Yu F, Krichbaum K and Wyman JF. Predictors of nursing home admission for persons with dementia. Medical Care 2009;47:191-198.

41. Steffens DC, Fisher GG, Langa KM, et al. Prevalence of depression among older Americans: the Aging, Demographics and Memory Study. International Psychogeriatrics 2009;21:879-888.

42. Zuidema SU, Derksen E, Verhey FRJ and Koopmans RTCM. Prevalence of neuropsychiatric symptoms in a large sample of Dutch nursing home patients with dementia. International Journal of Geriatric Psychiatry 2007;22:632-638.

43. Verkaik R, Francke AL, van Meijel B, et al. The effects of a nursing guideline on depression in psychogeriatric nursing home residents with dementia. International Journal of Geriatric Psychiatry 2011;26:723-732. 


\section{CHAPTER 2}

44. Smalbrugge M. Nosologische dementie diagnostiek volgens de nieuwe CBO-richtlijn dementie. Tijdschrift voor VerpleeghuisGeneeskunde 2006;31:48-53.

45. Crespo M, Bernaldo de Quiros M, Gomez MM and Hornillos C. Quality of life of nursing home residents with dementia: a comparison of perspectives of residents, family, and staff. The Gerontologist 2012;52:56-65.

46. Gräske J, Fischer T, Kuhlmey A and Wolf-Ostermann K. Quality of life in dementia care-differences in quality of life measurements performed by residents with dementia and by nursing staff. Aging \& Mental Health 2012;16:819-827.

47. Moyle W, Murfield JE, Griffiths SG and Venturato L. Assessing quality of life of older people with dementia: a comparison of quantitative self-report and proxy accounts. Journal of Advanced Nursing 2011;68:2237-2246.

48. Cohen-Mansfield J and Werner P. Management of verbally disruptive behaviors in nursing home residents. The Journals of Gerontology Series A: Biological Sciences and Medical Sciences 1997;52:M369M377.

49. Cohen-Mansfield J. Nonpharmacologic interventions for inappropriate behaviors in dementia: a review, summary, and critique. American Journal of Geriatric Psychiatry 2001;9:361-381.

50. Scherder EJA, Bogen T, Eggermont LHP, et al. The more physical inactivity, the more agitation in dementia. International Psychogeriatrics 2010;22:1203-1208.

51. Cohen-Mansfield J, Thein K, Dakheel-Ali M and Marx MS. The underlying meaning of stimuli: Impact on engagement of persons with dementia. Psychiatry Research 2010;177:216-222.

52. Zwijsen SA, Smalbrugge M, Zuidema SU, et al. Grip on challenging behaviour: a multidisciplinary care programme for managing behavioural problems in nursing home residents with dementia. Study protocol. BMC Health Services Research 2011;11:41.

53. Ballard C, Hanney ML, Theodoulou M, et al. The dementia antipsychotic withdrawal trial (DART-AD): longterm follow-up of a randomised placebo-controlled trial. The Lancet Neurology 2009;8:151-157.

54. Guthrie B, Clark SA and McCowan C. The burden of psychotropic drug prescribingin people with dementia: a populationdatabase study. Age and Ageing 2010;39:637-642.

55. Schneider LS, Dagerman KS and Insel P. Risk of death with atypical antipsychotic drug treatment for dementia. Journal of the American Medical Association 2005;294:1934-1943.

56. Buchanan D, Tourigny-Rivard M, Cappeliez P, et al. National Guidelines for Seniors' Mental Health: The Assessment and Treatment of Depression. Canadian Journal of Geriatrics 2006;9:S52-58.

57. Kverno KS, Black BS, Nolan MT and Rabins PV. Research on treating neuropsychiatric symptoms of advanced dementia with non-pharmacological strategies, 1998-2008: a systematic literature review. International Psychogeriatrics 2009;21:825-943.

58. Vasse E, Vernooij-Dassen M, Cantegreil I, et al. Guidelines for psychosocial interventions in dementia care: a European survey and comparison. International Journal of Geriatric Psychiatry 2012;27:40-48.

59. Verbeek H, Meyer G, Leino-Kilpi H, et al. A European study investigating patterns of transition from home care towards institutional dementia care: the protocol of a RightTimePlaceCare study. BMC Public Health 2012;12:68. 


\section{CHAPTER 3}

Quality of life and quality of care for people with dementia receiving long-term institutional care or professional home care: The European RightTimePlaceCare study

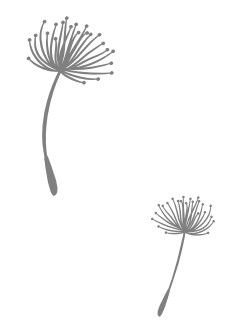

This chapter was published as:

Beerens HC, Sutcliffe C, Renom-Guiteras A, Soto ME, Suhonen R, Zabalegui A, Bökberg C, Saks K, Hamers JPH, on behalf of the RightTimePlaceCare Consortium. Quality of life and quality of care for people with dementia receiving long-term institutional care or professional home care: the European RightTimePlaceCare study. Journal of the American Medical Directors Association 2014;15:54-61.

doi:10.1016/j.jamda.2013.09.010. 


\section{ABSTRACT}

Objectives: To explore how quality of life (QoL) and quality of care $(\mathrm{QoC})$ for people with dementia (PwD) vary across eight European countries; to explore how QoL and QoC for PwD vary across living arrangements; and to assess the association between QoL and QoC.

Design: Cross-sectional survey.

Setting: Institutional long term care and home care in eight European countries (England, Estonia, Finland, France, Germany, the Netherlands, Spain, and Sweden).

Participants: PwD receiving formal home care but at risk for admission to an institutional setting, and PwD who were recently admitted.

Measurements: QoL was assessed by the PwD and by their best informed proxies using the Quality of Life-Alzheimer's Disease scale (QoL-AD) (range 13-52). QoC was measured using quality of care indicators (e.g. the presence of depressive symptoms, the presence of pressure ulcers).

Results: A total of 1123 PwD living at home (mean age 82.2, 63\% women) and 791 PwD living in institutional care (mean age 84.1, 74\% women) participated. QoL of PwD was most often rated highest in Sweden and England and lowest in Estonia and Spain. No differences in QoL were detected among the settings. For the QoC indicators no consistent patterns were visible in such a way that certain countries or settings scored 'higher' or 'lower'. The presence of depressive symptoms was most consistently associated with lower QoL ( $\mathrm{p} \leq .001)$.

Conclusion: There is great variation in QoL and QoC scores among European countries and settings. To gain insight into the underlying causes of these differences, more knowledge is needed about the effect of different national health care systems and dementia strategies on QoL and QoC indicators. Depressive symptoms were associated with QoL, and executing longitudinal studies investigating which factors are associated with change in QoL is highly recommended. 


\section{INTRODUCTION}

Approximately $6.2 \%$ of European citizens older than 60 suffers from dementia. ${ }^{1}$ The resulting health care expenditures, estimated at $€ 177$ billion per year in 2008 , have a great societal impact. ${ }^{2,3}$ During the past decades much effort has been made to develop treatments for dementia. However, until now, the progression of the syndrome can be only slightly delayed and groundbreaking research with regard to cure or prevention is still lacking. As a result, much emphasis in dementia care is placed on quality of care $(\mathrm{QoC})^{4}$ and maintaining a satisfactory level of quality of life $(\mathrm{QoL}) .^{5,6}$

Two previous studies indicate that QoL of and QoC for older people differ among European countries. ${ }^{7,8}$ However, extensive European research on QoL and QoC specifically about dementia care is still lacking. Furthermore, questions can be raised on the justification of the fact that European governments aim to enhance and expand home care resources to enable people with dementia (PWD) to live at home as long as possible. 9, 10 The association between QoL, QoC and place of residence (i.e. living at home or living in institutional long-term nursing care (ILTC)) is yet unclear since different studies report positive, negative, or no associations. ${ }^{7,11-14}$ Finally, there is little knowledge about the relationship between QoL of PWD and indicators for QoC. Sixsmith et al. (2008) studied the association between QoL and a variety of QoC indicators and reported an association between QoL and 'pain', but found no association with 'weight loss' and 'falls'. However, this study did not differentiate between living at home and living in ILTC although the difference between these settings is of crucial importance because PwD living in ILTC have more advanced dementia ${ }^{15}$ and perceptions about what is important in life might change as the syndrome progresses. ${ }^{16}$

Insight into country-differences, differences between living arrangements, and the association between $\mathrm{QoL}$ and $\mathrm{QoC}$ is needed to inform (inter)national policy makers, making it possible to prioritize the right strategies and to develop best practice strategies to improve QoL and QoC for PwD. ${ }^{17}$

\section{Aim}

The current study aims to explore QoL and QoC indicators of PwD who are between the margins of care in eight European countries; i.e. those people who are at a "breakingpoint" when home care may become insufficient and/or inadequate and admission to institutional nursing care might be necessary. The following research questions were postulated:

1. How do QoL and QoC vary for PwD across eight European countries?

2. How do QoL and QoC vary for PwD between home care and ILTC?

3. Which indicators of QoC are associated with QoL? 


\section{METHODS}

\section{Design}

This prospective survey is part of a larger study named RightTimePlaceCare (RTPC) that overall aims to improve health and social care services for European citizens with dementia. ${ }^{18}$ The survey was undertaken in eight European countries (England, Estonia, Finland, France, Germany, the Netherlands, Spain and Sweden). Data were collected on QoC and QoL of PwD receiving long-term care. Detailed information about the design of the survey is published elsewhere. ${ }^{19}$

\section{Participants}

Two groups were included:

1. PWD (and their formal caregivers) who were newly admitted to ILTC and were resident for at least one month but less than three months;

2. PwD (and their informal caregivers) who received home care but were at risk of admission to ILTC within six months, as judged by a professional caregiver responsible for their care.

PwD were included if they: 1) had an official diagnosis of dementia as diagnosed by an expert (for example: physician, psychiatrist, neurologist, geriatrician, or general practitioner, depending on countries' diagnostic procedures); 2) scored 24 or lower on the Standardized Mini Mental State Examination (S-MMSE); ${ }^{20,21}$ and 3) had an informal caregiver who visited their relative at least twice a month. PWD were excluded when they: 1) were younger than 65 years; 2) had a primary psychiatric diagnosis or Korsakoff's syndrome; and, for the first group (recently admitted PwD) 3) were only temporarily resident in the home (e.g. revalidation, respite of the informal caregiver) with the intention of moving back home.

\section{Procedures}

Each country obtained ethical approval from a country specific legal authority for research on human beings to conduct the study in accordance with the national regulations and standards of the participating countries.

Country-specific consent procedures were followed. After receiving written informed consent from the informal caregiver (and sometimes also the PwD), trained interviewers with at least a Bachelor's degree interviewed the PWD, their informal caregivers and formal caregivers via face-to-face interviews. All measures were assessed by the best informed proxies of the PwD. In the home care setting, these were usually the informal caregivers and in ILTC these were usually formal caregivers (i.e. nursing staff). 
QoL of the PwD was also assessed by the PwD themselves. Data were collected between November 2010 and April 2012.

\section{Measures}

\section{Sample characteristics}

Sample characteristics of the PWD were assessed, including age, gender, and marital status. Cognitive status was assessed with the S-MMSE. ${ }^{20,21}$ The total score of this scale ranges from 0 to 30, with higher scores indicating less cognitive impairment. Functional status was assessed with the Katz Index of Independence in Activities of Daily Living $(A D L) .{ }^{22}$ The total score of this scale ranges from 0 to 6 , with higher scores indicating less dependency in ADL. Comorbidity was assessed with the Charlson Comorbidity Index, ${ }^{23}$ which is a scale originally developed to determine the risk of mortality within one year from measurement. The total score of this scale ranges from 0 to 37, with higher scores indicating the presence of more (severe) comorbidities that might influence the risk of mortality. Finally, neuropsychiatric symptoms were assessed with the NeuroPsychiatric Inventory Questionnaire (NPI-Q). ${ }^{24}$ The total score ranges from 0 to 36, with higher scores indicating the presence of more (severe) neuropsychiatric symptoms.

\section{Quality of life}

QoL of the PWD was assessed from both PwD as well as the caregivers' perspective with the Quality of Life-Alzheimer's Disease (QoL-AD) scale. ${ }^{25}$ The QoL-AD is a 13 -item questionnaire using a four-point Likert scale ranging from poor $=1$ to excellent $=4$. Summing these items results in a total score with a possible range of 13 to 52, with higher scores indicating a better QoL. The QoL-AD was assessed by PwD only when they had an SMMSE score of 3 or higher. Other studies showed that this is an appropriate cut-off point to obtain self-reported QoL using the QoL-AD. ${ }^{26}$ A clinically meaningful difference is defined as a difference of three or more points on the total QoL-AD score. ${ }^{14,27}$

\section{Quality of care}

QoC was assessed in two ways. First, QoC was assessed by the subjective judgement of the informal caregiver using an adapted version of the Client INTerview instrument (CLINT). ${ }^{28}$ In the home care setting, the CLINT consists of nine questions with a possible total range of 9 to 45 . In ILTC, the CLINT consists of 10 questions with a possible total range from 10 to 50 . Higher scores indicate lower quality of care as judged by the informal caregiver.

Second, indicators of QoC were evaluated. These indicators were selected based on literature that includes $\mathrm{QOC}$ indicators ${ }^{29-33}$ and comprise depressive symptoms, psychotropic drug use, mortality rate, nutritional status, use of physical restraints, presence of pain, presence of pressure ulcers, and fall incidents. Depressive symptoms were assessed during an interview with the best informed proxy, using the Cornell Scale for 
Depression in Dementia (CSDD). ${ }^{34}$ The total score ranges from 0 to 38, with higher scores indicating the presence of more depressive symptoms. Scores higher than 6 indicate the presence of considerable depressive symptoms. ${ }^{35}$ Psychotropic drug use was classified by means of the Anatomical Therapeutical Chemical (ATC) classification ${ }^{36}$ containing antipsychotics (N05A), anxiolytics (N05B), hypnotics/sedatives (N05C) and antidepressants (N06A). Standardized prescriptions as well as 'as needed' psychotropic drug use were included. Furthermore we included mortality rate (deceased within three months after baseline interview); nutritional status (single question: 'did the patient experience a weight loss of $4 \%$ or more in the past year?'); ${ }^{37}$ use of physical restraints, (belt restraints, locked chair/table, deep/overturned chair, bedrails); ${ }^{38}$ presence of pain in last week; ${ }^{39}$ presence of pressure ulcers; fall incidents in the past 30 days (home care setting), or fall incidents since admission (ILTC).

\section{Statistical analyses}

Analyses were performed using SPSS version 20.0. Two-tailed tests with a significance level of 0.05 were used. For continuous scales, in general a maximum of $10 \%$ missing items were replaced by the mean score of the remaining items of the respondent. For the QoL-AD a maximum of 2 missing items were replaced using the same procedure. ${ }^{16}$ Both versions of the CLINT showed good internal consistency, tested using Cronbach's alpha (home care: 0.67, ILTC: 0.74). Statistical model assumptions were examined before conducting further analyses. For QoL, only clinically relevant differences were tested.

First, differences between the countries in general were tested. Therefore, analyses of variance, $\chi^{2}$ tests, and Fisher's exact tests were performed.

To test differences in QoL and QoC indicators between the countries and the settings, independent samples t-tests and $\chi^{2}$ tests were conducted. To test the difference between self-reported and proxy-reported QoL, paired samples t-tests were conducted. To compare an individual country's mean with the mean of the other seven countries, dummy coding was used, making it possible to exclude a country's own result from the general mean. Because the two versions of the CLINT have a different content, it was not possible to compare the CLINT between the settings.

The association between QoL and QoC indicators was tested with multilevel hierarchical regression analyses (random intercept). At level one, the dependent variable was QoL and the independent variables were the QoC indicators, corrected for age, gender, neuropsychiatric symptoms, cognition, and ADL. ${ }^{40}$ These measures were nested within 'country', which was therefore the level two variable. Missing data for the S-MMSE and the CSDD were imputed using multiple imputations. The CLINT questionnaires were not included in the hierarchical model because of the large number of missing values and the instability of these measures in our models. Besides running the whole model, we performed the analyses using a backward procedure removing QoC indicators with $p>.2$. 


\section{RESULTS}

\section{Sample characteristics}

A total number of 1223 PwD and their caregivers were included in the home care sample and 791 PwD and their caregivers were included in the ILTC sample. The PWD in the samples were on average 84.1 (ILTC) and 82.2 (home care) years old and both samples contained predominantly women (ILTC: $63.4 \%$, home care setting: $74.0 \%$ ). Compared to PWD living in ILTC, PWD living at home were more often married $(p<.001)$, had a higher cognitive status $(p<.001)$, were more independent in their ADL $(p<.001)$, had fewer comorbidities $(p<.001)$, and displayed more neuropsychiatric symptoms $(p<.001)$. Although few patterns emerge from the data, there is some variation among the countries. For example, the Estonian sample contained relatively few married PwD. Table 1 provides detailed characteristics of the sample split by country and living situation.

\section{Quality of life}

Table 2 gives an overview of QoL measurements split by country, the perspective of QoL measurement, and setting. In ILTC, between 41\% (France) and 85\% (Sweden) of the PwD were able to complete the self-reported QoL-AD questionnaire. In the home care setting, between 49\% (France) and 90\% (Sweden) of the PwD were able to complete the QoL-AD.

\section{Variation across countries}

In general, self- and proxy reported QoL of PwD scored higher in northern and western countries of Europe (like Sweden and England) compared with eastern and southern European countries (like Estonia and Spain).

Self-reported QoL of PWD living in ILTC was, compared with the mean of selfreported QoL in the other seven countries, lower in Estonia $(p<.001$, mean difference $5.2)$ and Finland ( $<<.001$, mean difference 3.1), whereas England ( $p=.002$, mean difference 3.0) and Sweden ( $p<.001$, mean difference 3.8) had higher QoL scores. With regard to self-reported QoL in the home care setting, QoL was lower in Estonia $(p<.001$, mean difference 6.4), and higher in Sweden ( $p<.001$, mean difference 3.0) and England $(p<.001$, mean difference 3.4) than in other countries.

Proxy-reported QoL of PWD living in ILTC was, compared with the mean of proxyreported QoL in the other seven countries, lower in Spain $(p<.001$, mean difference 6.7) and Estonia ( $p<.001$, mean difference 4.1), and higher in Germany $(p<.001$, mean difference 4.1) and Sweden ( $p<.001$, mean difference 4.6). With regard to proxy-reported QoL in the home care setting, proxy-reported QoL was lower in Estonia $(p<.001$, mean difference 3.5) compared to the mean of other countries. 


\begin{tabular}{|c|c|c|c|c|c|c|c|c|}
\hline$*^{\text {ən|e }} \mathrm{d}$ & & & \& đ & $\stackrel{8}{\sigma} \tilde{8}$ & 우 & & $\overline{8}$ & $\overrightarrow{8}$. \\
\hline иәрәмs & 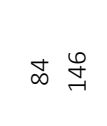 & ๆ & 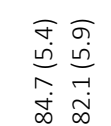 & 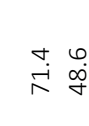 & 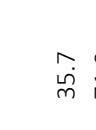 & & 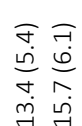 & 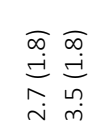 \\
\hline uleds & $\stackrel{m}{\exists} \underset{ન}{ \pm}$ & 아 & 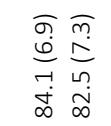 & 㤩 & $\stackrel{\sim}{\stackrel{m}{m}}$ & & 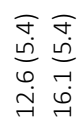 & 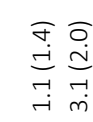 \\
\hline spue|дәчғәN ә૫ц & $\underset{\exists}{\stackrel{F}{F}}$ & 도 & 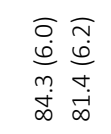 & 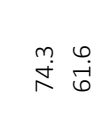 & $\vec{m}$ & & 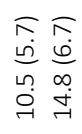 & 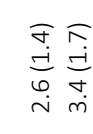 \\
\hline Киешиәу & $\underset{\exists}{\overrightarrow{7}} \stackrel{0}{7}$ & $\stackrel{\varphi}{m}$ & 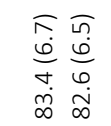 & 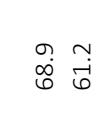 & 疋 & & 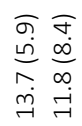 & 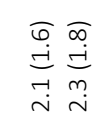 \\
\hline әэиены & g 朵 & $\stackrel{+}{m}$ & 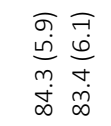 & 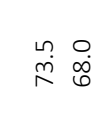 & $\hat{\phi}$ & & 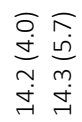 & 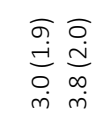 \\
\hline pueju!t & $\underset{\sim}{\sim} \underset{\sim}{\sim}$ & $\stackrel{\infty}{\sim}$ & 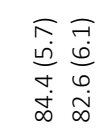 & $\stackrel{n}{\stackrel{n}{~}} \stackrel{0}{0}$ & $\stackrel{n}{\text { n. }}$ & & 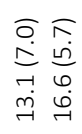 & 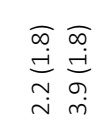 \\
\hline e!uozs & 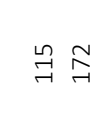 & $\stackrel{\varphi}{\sim}$ & 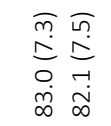 & 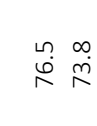 & 㝏 & & 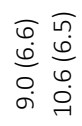 & 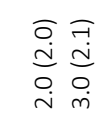 \\
\hline pue|suэ & $\stackrel{\circ}{\circ}$ & $\stackrel{\infty}{m}$ & 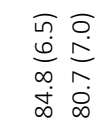 & $\begin{array}{c}0 \\
\substack{\infty \\
\infty}\end{array}$ & 亗 & & 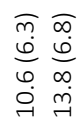 & 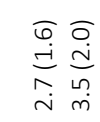 \\
\hline \|едәло & $\vec{S} \underset{\sim}{\widetilde{I}}$ & 㞻 & 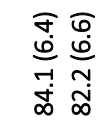 & 옷 & $\stackrel{\text { pr }}{m}$ & & 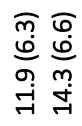 & 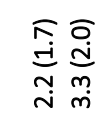 \\
\hline & 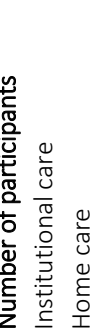 & 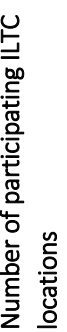 & 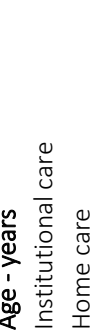 & 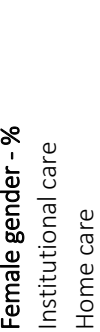 & 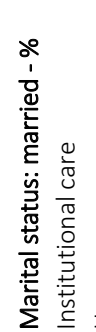 & & 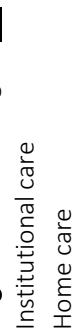 & 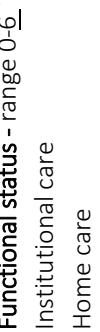 \\
\hline
\end{tabular}




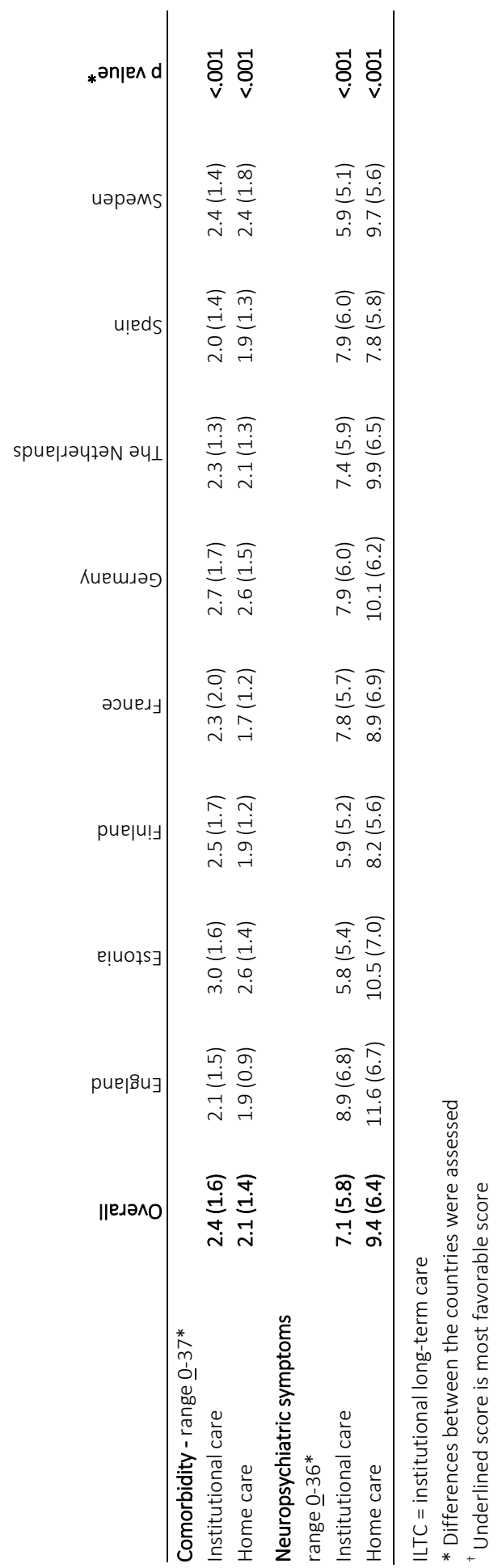




\section{Quality of life}

Table 2 gives an overview of QoL measurements split by country, the perspective of QoL measurement, and setting. In ILTC, between 41\% (France) and 85\% (Sweden) of the PwD were able to complete the self-reported QoL-AD questionnaire. In the home care setting, between 49\% (France) and 90\% (Sweden) of the PwD were able to complete the QoL-AD.

\section{Variation across countries}

In general, self- and proxy reported QoL of PwD scored higher in northern and western countries of Europe (like Sweden and England) compared with eastern and southern European countries (like Estonia and Spain).

Self-reported QoL of PWD living in ILTC was, compared with the mean of selfreported QoL in the other seven countries, lower in Estonia $(p<.001$, mean difference $5.2)$ and Finland ( $p<.001$, mean difference 3.1), whereas England ( $p=.002$, mean difference 3.0) and Sweden ( $p<.001$, mean difference 3.8) had higher QoL scores. With regard to self-reported QoL in the home care setting, QoL was lower in Estonia $(p<.001$, mean difference 6.4), and higher in Sweden ( $p<.001$, mean difference 3.0) and England $(p<.001$, mean difference 3.4$)$ than in other countries.

Proxy-reported QoL of PWD living in ILTC was, compared with the mean of proxyreported QoL in the other seven countries, lower in Spain $(p<.001$, mean difference 6.7) and Estonia ( $p<.001$, mean difference 4.1), and higher in Germany $(p<.001$, mean difference 4.1) and Sweden ( $p<.001$, mean difference 4.6). With regard to proxy-reported QoL in the home care setting, proxy-reported QoL was lower in Estonia $(p<.001$, mean difference 3.5) compared to the mean of other countries.

\section{Home care versus institutional long-term nursing care}

No clinically relevant differences in self-reported QoL of PwD between home care and ILTC could be detected. Overall, also no clinically relevant differences in proxy-reported QoL between home care and ILTC could be identified. However, country-specific analyses showed that proxy-reported QoL of PWD was higher in ILTC than in the home care setting in England ( $p<.001$, mean difference 3.0$)$, Germany $(p<.001$, mean difference 5.0), the Netherlands ( $p<.001$, mean difference 3.7), and Sweden $(p<.001$, mean difference 5.2). In contrast, proxies in Spain assessed QoL of PWD higher at home than in institutional care $(p<.001$, mean difference 3.1). 


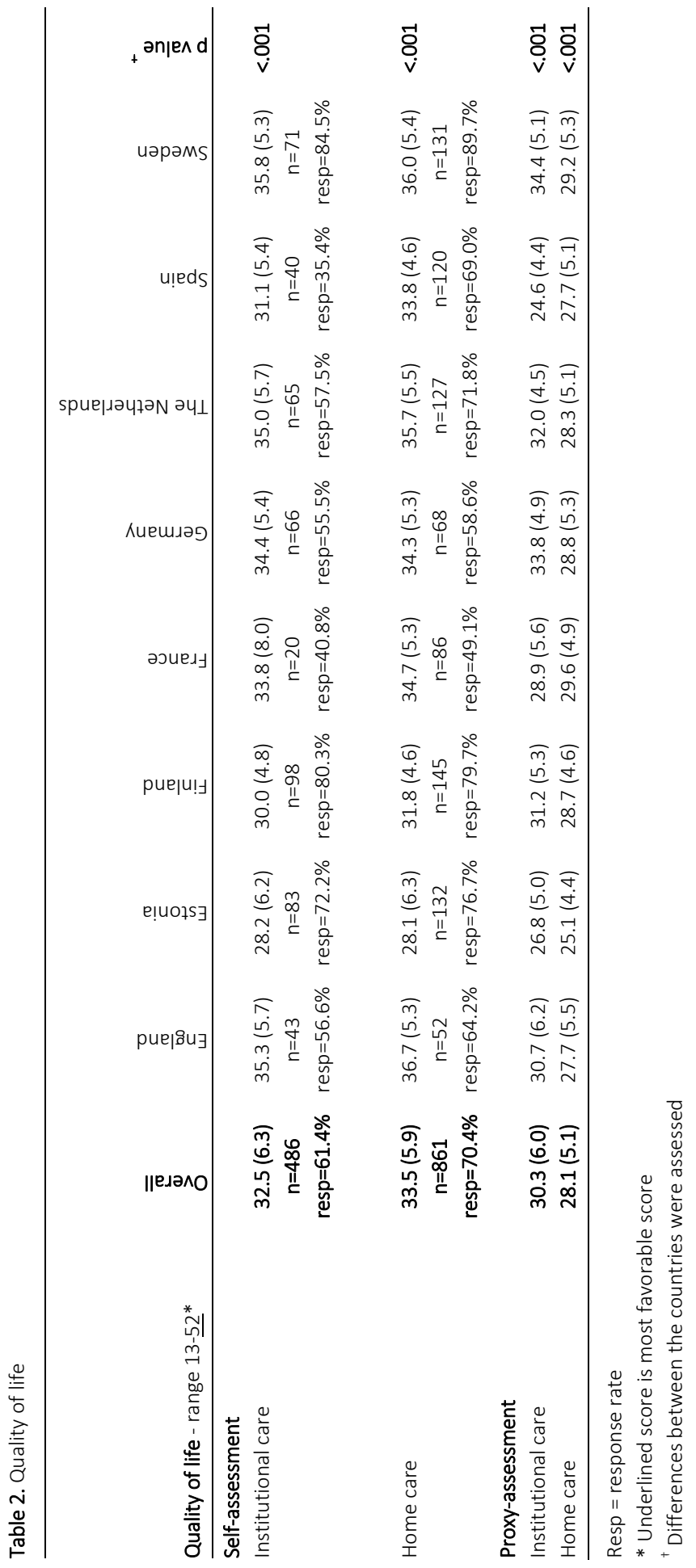




\section{Quality of care}

Table 3 gives an overview of quality of care indicators split by country and setting.

\section{Variation across countries}

As can be derived from Table 3, large differences between countries with regard to the indicators of QoC were detected. However, there were no patterns or trends visible in such a way that certain countries consistently scored 'higher' or 'lower'.

Institutional long-term care versus home care

There was no clear pattern with regard to the differences in QoC between the ILTC setting and the home care setting. For certain QoC indicators, there were more favorable outcomes in the home care setting compared with ILTC, but this was the reverse for other QoC indicators.

PWD receiving home care used less psychotropic medication $(p<.001,55.9 \%$ versus $70.0 \%)$, were less likely to have died within the three months after the interview $(p<.001,4.8 \%$ versus 9.5\%), experienced less physical restraint $(p<.001,9.9 \%$ versus $31.4 \%)$, and had fewer pressure ulcers ( $p<.001,2.6 \%$ versus $6.7 \%)$ compared to the sample living in ILTC. However, they showed more symptoms of depression $(p<.001$, mean difference 2.1 ), experienced more weight loss ( $p<.001,21.3 \%$ versus $14.5 \%$ ), and reported pain more frequently ( $p=.005,50.4 \%$ versus $44.1 \%)$. 


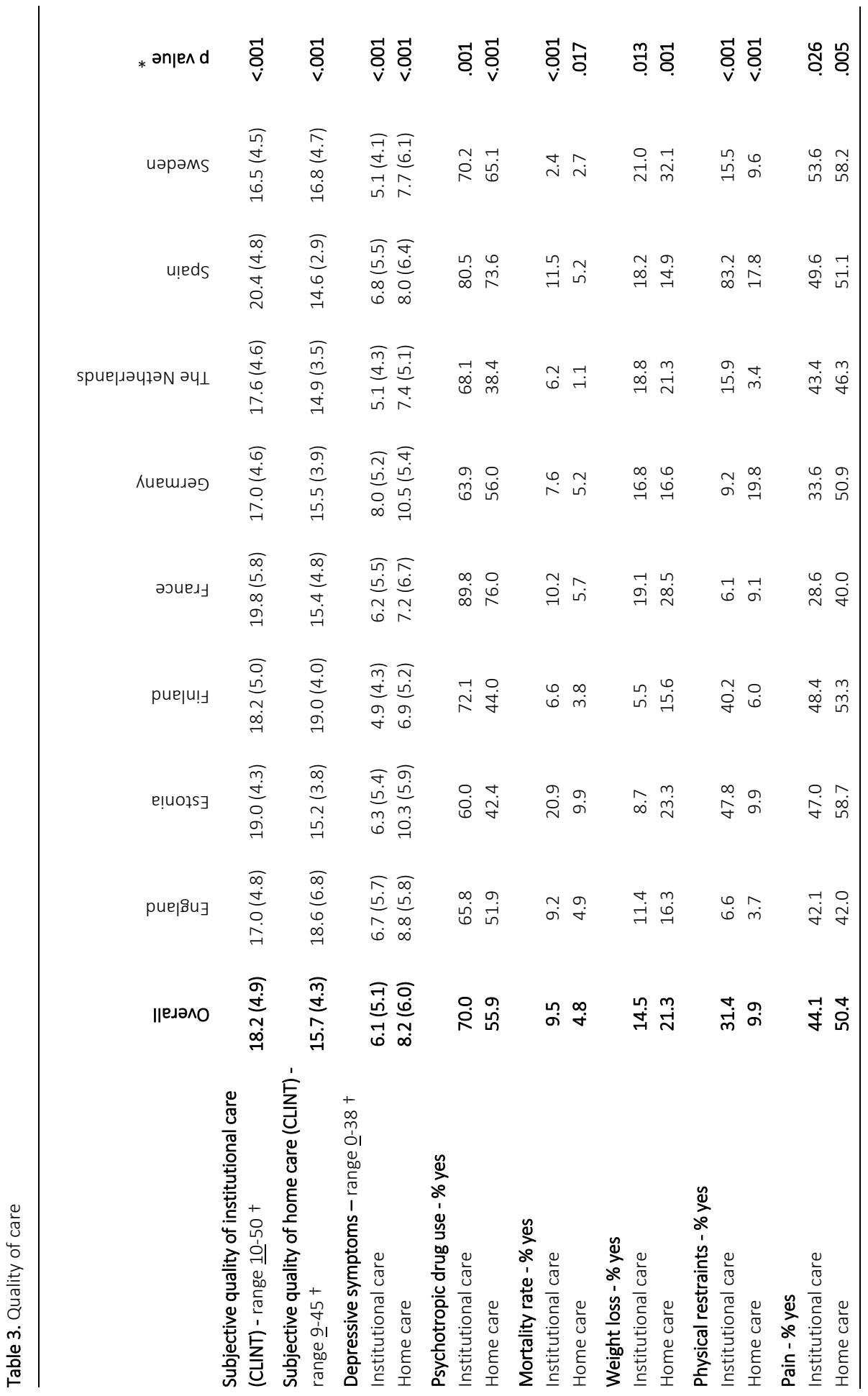




\section{CHAPTER 3}

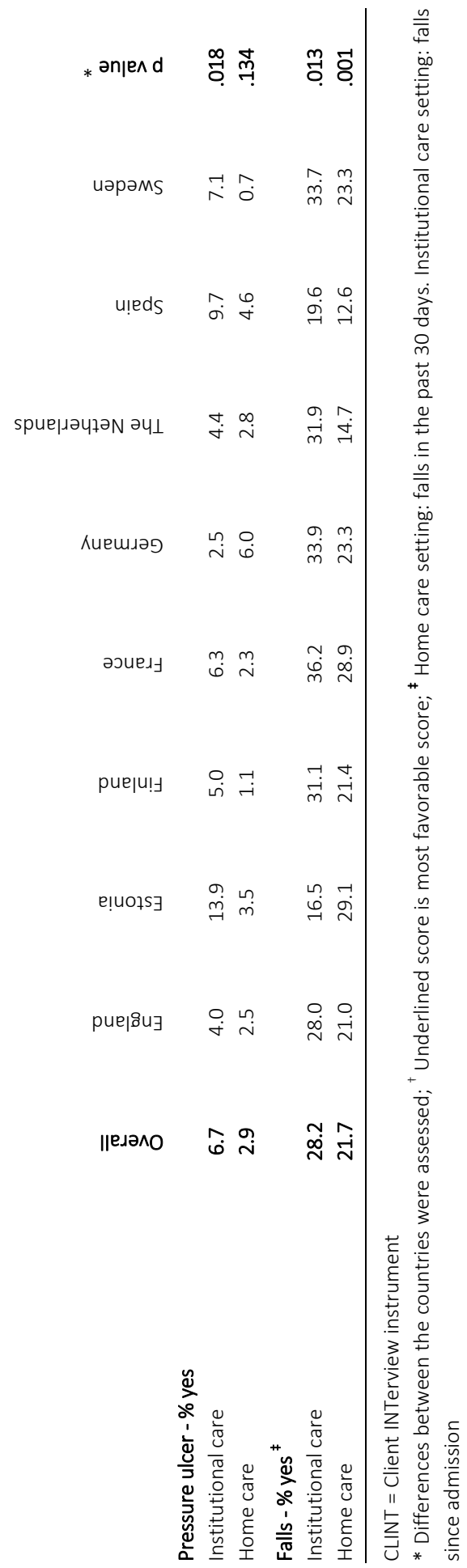




\section{Association between QoC indicators and QoL}

Tables 4 and 5 show associations between QoC indicators and QoL, split by setting and perspective of QoL measurement. The presence of depressive symptoms was most consistently associated with QoL of PwD, with more depressive symptoms significantly related to lower QoL (range: $p=.001-p<.001$ ).

Furthermore, in ILTC lower proxy-reported QoL of PwD was related to the presence of pressure ulcers $(p=.019)$.

In the home care setting lower proxy-reported QoL was related to the presence of weight loss $(p<.001)$, the presence of fall incidents in the past 30 days $(p=.007)$, the absence of pressure ulcers $(p=.037)$, and the presence of pain $(p=.047)$. Lower selfreported QoL in the home care setting was related to the occurrence of fall incidents in the past 30 days $(p=.012)$. Using the backward procedure removing QoC indicators with $p>$.2, pain also became significantly associated with self-reported QoL of PwD living at home $(p=.04)$.

Table 4. Factors influencing quality of life $(\mathrm{QOL})$ in institutional long-term nursing care

\begin{tabular}{|c|c|c|c|c|c|c|}
\hline & \multicolumn{3}{|c|}{ Self-reported QoL } & \multicolumn{3}{|c|}{ Proxy-reported QoL } \\
\hline & Estimate & Std. Error & $p$ value & Estimate & Std. Error & $p$ value \\
\hline Depressive symptoms & -.299 & .092 & $.001^{*}$ & -.347 & .060 & $<.001^{*}$ \\
\hline Psychotropic drug use & .117 & .570 & .837 & -.130 & .361 & .718 \\
\hline Mortality & -.703 & 1.049 & .503 & -.044 & .575 & .939 \\
\hline Weight loss & -.691 & .851 & .417 & -.501 & .474 & .290 \\
\hline Physical restraints & .130 & .767 & .865 & -.398 & .469 & .395 \\
\hline Pain & -.850 & .566 & .133 & .073 & .348 & .833 \\
\hline Pressure ulcer & -1.016 & 1.135 & .370 & -1.558 & .663 & $.019 *$ \\
\hline Falls & -.777 & .599 & .195 & -.485 & .366 & .185 \\
\hline
\end{tabular}

* significant quality of care indicators

Table 5. Factors influencing quality of life (QoL) at home

\begin{tabular}{|c|c|c|c|c|c|c|}
\hline & \multicolumn{3}{|c|}{ Self-reported QoL } & \multicolumn{3}{|c|}{ Proxy-reported QoL } \\
\hline & Estimate & Std. Error & $p$ value & Estimate & Std. Error & $p$ value \\
\hline Depressive symptoms & -.258 & .048 & $<.001^{*}$ & -.257 & .033 & $<.001^{*}$ \\
\hline Psychotropic drug use & -.058 & .374 & .877 & .406 & .273 & .137 \\
\hline Mortality & -.382 & .932 & .681 & -.349 & .630 & .579 \\
\hline Weight loss & -.388 & .445 & .383 & -1.136 & .327 & $.001^{*}$ \\
\hline Physical restraints & -1.360 & .834 & .103 & -.783 & .487 & .108 \\
\hline Pain & -.676 & .373 & .070 & -.534 & .269 & $.047^{*}$ \\
\hline Pressure ulcer & -.228 & 1.232 & .853 & 1.716 & .820 & $.037 *$ \\
\hline Falls & -1.130 & .449 & $.012 *$ & -.867 & .321 & $.007^{*}$ \\
\hline
\end{tabular}

* significant quality of care indicators 


\section{DISCUSSION}

Our results show four key findings: First, QoL of PwD was most often rated highest in Sweden and England and lowest in Estonia and Spain. Second, QoL ratings of neither PwD living at home nor those living in institutional care approached the minimum or the maximum score of the QoL-AD, and the ratings were comparable with other studies that include PWD living at home or in ILTC. ${ }^{41-44}$ Therefore, QoL of the study sample could be considered 'moderate'. Third, for the QoC indicators no clear, consistent, patterns were visible in such a way that certain countries or settings scored 'higher' or 'lower': there was a great variation in performance regarding the QoC indicators across the countries and the settings. Fourth, for both PwD living at home as well as PwD living in ILTC, depressive symptoms were associated with lower QoL. For PwD living at home, falls were negatively associated with QoL.

Our finding that PwD living in Sweden and England had higher QoL scores than PwD living in Estonia and Spain, is consistent with other studies that investigated QoL of European citizens older than 65 without dementia. ${ }^{45,46}$ This indicates that the dementia itself possibly does not influence the reasons for country-differences in QoL ratings. However it is difficult to designate the exact reasons for country-differences. Socioeconomic inequalities between the countries might be the reason since there are indications that in older people a higher QoL is related to a better socioeconomic position. ${ }^{47}$ Furthermore, cultural aspects, health care structures, expenditures, and legislations differ across the eight European countries, 1, 10, 48, 49 which complicates international comparisons. Finally, the response rates on the self-reported QoL-AD differed per country, ranging from $35.4 \%$ in Spain to $84.5 \%$ in Sweden. It is not known what the precise reasons for uncompleted QoL-AD questionnaires were. This also might have influenced the mean QoL-AD scores. Performances on the QoC indicators ranged widely across the countries and the settings. As a result, no general trends regarding the QoC indicators in the eight countries and the two settings are visible. Reasons for differences in specific indicators only can be speculated on. Besides differences in health care structures as previously discussed, variations between the European countries at the point at which admission to ILTC occurs ${ }^{10}$ may result in different home care and ILTC samples per country.

Although outcomes such as medication use, mortality rate, weight loss, physical restraints, pain, pressure ulcers and falls traditionally receive much attention, ${ }^{29-31}$ in ILTC few or no evidence was found for their association with QoL. This raises the question whether the attention in ILTC should be shifted toward psychosocial outcomes such as depressive symptoms.

The presence of depressive symptoms was the QoC indicator most consistently associated with QoL, for PWD living at home as well as for PWD living in ILTC, regardless of the perspective of QoL measurement. Despite depression being a widely recognized QoC indicator, ${ }^{29,}{ }^{50}$ debate about the overlap with the concept of QoL is inevitable. Alt- 
hough depression and QoL are separate constructs, both the instrument to measure depressive symptoms (CSDD) and the instrument to measure QoL (QoL-AD) contain questions about mood, physical complaints, and energy. Therefore, our finding that the presence of depressive symptoms is strongly associated with low QoL is not unexpected and in line with current literature. ${ }^{40,51}$ However, it is still unknown whether changes in depressive symptoms are associated with QoL, as longitudinal studies show conflicting results regarding this association. ${ }^{14,27,52}$ Our results indicate a general trend that PwD living at home show more depressive symptoms than PwD living in ILTC. This seems to be consistent with the study of Payne et al. (2002) who found that depressive symptoms reduce after ILTC admission. Possible reasons for this decrease are the professional approach of formal caregivers who appropriately recognize, diagnose, and treat depression. ${ }^{53}$ This is an interesting result because depressive symptoms and QoL were strongly associated and we have no indications that QoL decreases after institutionalization. However, our findings are based on cross-sectional data, and the fact that informal caregivers assessed depressive symptoms for PwD living at home and formal caregivers assessed depressive symptoms for PwD living in institutional care might have also influenced the results.

This is the first study that collected comprehensive data on QoL and QoC of PwD in a standardized way in several European countries and in diverse settings. The results of this explorative study will contribute toward improving knowledge about developments in QoL and QoC in Europe. However the results of this study should be interpreted carefully because of some limitations. First, this study reports on a specific sample of PwD; those at the margins of care (those at risk for institutionalization and those who were recently institutionalized). In respect of the ILTC setting, temporarily admitted PWD were excluded since these people were expected to face specific challenges beyond the scope of this study which could have influenced the outcomes. As a result, our findings cannot be extrapolated to all PWD receiving long-term care in Europe. Second, national samples may not be representative because these were not randomly selected from national populations. Furthermore, ILTC settings can differ within a country, which complicates the generalization of findings. However, in this study, at least 10 different institutional locations per country were included to ensure a broadly representative sample was gathered of PWD living in ILTC in the participating countries. Third, crosscountry comparisons on QoL could be impeded because the national study samples differed from each other and, in some countries, only a few PwD were able to complete the QoL-AD questionnaire. Finally, our cross-sectional study provides no information about causal relationships between QoL and the QoC indicators. 


\section{CONCLUSION AND RECOMMENDATIONS}

Our study showed clear country-differences in QoL ratings and variation between the countries regarding QoC indicators. Some countries scored 'high' on some indicators but 'low' on others. Dementia care is very complex and simplification by, for example, comparing indicators in an explorative way does not result in conclusive statements about the whole QoC. To gain insight into the underlying causes of these countrydifferences, more knowledge is needed about the effect of the different national health care systems and dementia strategies ${ }^{54}$ on QoL and QoC indicators. Furthermore, remaining at home is not per se beneficial for PwD: QoL and QoC are not convincingly better in one setting or in another. In addition, depressive symptoms were associated with QoL, but because of the cross-sectional nature of our study, causal relationships between the QoC indicators and QoL could not be established. For these reasons executing longitudinal studies investigating which factors are associated with change in QoL is highly recommended. This will make it possible to determine for which subgroups living at home or living in ILTC is preferable, and which QoC indicators should be manipulated to improve QoL. 


\section{REFERENCES}

1. Prince M, Ferri CP, Sousa R, et al. World Alzheimer Report 2009. London: Alzheimer's Disease International, 2009.

2. Wimo A, Jonsson L, Gustavsson A, et al. The economic impact of dementia in Europe in 2008-cost estimates from the Eurocode project. International Journal of Geriatric Psychiatry 2011;26:825-832.

3. Wimo A and Prince M. World Alzheimer Report 2010. London: Alzheimer's Disease International, 2010.

4. Tolson D, Rolland Y, Andrieu S, et al. International Association of Gerontology and Geriatrics: a global agenda for clinical research and quality of care in nursing homes. Journal of the American Medical Directors Association 2011;12:184-189.

5. Moniz-Cook E, Vernooij-Dassen M, Woods R, et al. A European consensus on outcome measures for psychosocial intervention research in dementia care. Aging \& Mental Health 2008;12:14-29.

6. Rabins PV and Black BS. Measuring quality of life in dementia: purposes, goals, challenges and progress. International Psychogeriatrics 2007;19:401-407.

7. Sixsmith A, Hammond M and Gibson G. Quality of Life and Dementia. In: M Vaarama, R Pieper and A Sixsmith, eds. Care-Related Quality of Life in Old Age. Concepts, Models and Empirical Findings. New York: Springer, 2008.

8. Onder G, Carpenter I, Finne-Soveri H, et al. Assessment of nursing home residents in Europe: the Services and Health for Elderly in Long TERm care (SHELTER) study. BMC Health Services Research 2012;12:5.

9. Knapp M, Comas-Herrera A, Somani A and Banerjee S. Dementia: International comparisons. Summary report for the National Audit Office. London: Personal Social Services Research Unit, London School of Economics and Political Science, 2007.

10. OECD. The OECD Health Project. Long-term Care for Older People. Paris: OECD Publishing, 2005.

11. Hoe J, Katona C, Orrell M and Livingston G. Quality of life in dementia: care recipient and caregiver perceptions of quality of life in dementia: the LASER-AD study. International Journal of Geriatric Psychiatry 2007;22:1031-1036.

12. Missotten P, Thomas P, Squelard G, et al. Impact of Place of Residence on Relationship Between Quality of Life and Cognitive Decline in Dementia. Alzheimer Disease and Associated Disorders 2009;23:395-400.

13. Fahey T, Montgomery AA, Barnes J and Protheroe J. Quality of care for elderly residents in nursing homes and elderly people living at home: controlled observational study. BMJ 2003;326:580.

14. Selwood A, Thorgrimsen $L$ and Orrell M. Quality of life in dementia. A one-year follow-up study. International Journal of Geriatric Psychiatry 2005;20:232-237.

15. Gaugler JE, Yu F, Krichbaum K and Wyman JF. Predictors of nursing home admission for persons with dementia. Medical Care 2009;47:191-198.

16. Logsdon RG, Gibbons LE, McCurry SM and Teri L. Assessing quality of life in older adults with cognitive impairment. Psychosomatic Medicine 2002;64:510-519.

17. Eur-Lex. Access to European Law. Available from: http://eur-lex.europa.eu/smartapi/cgi/sga_doc? smartapi!celexapi!prod!CELEXnumdoc\&lg=EN\&numdoc=32002D1786\&model=guichett.

18. EU-Project. RightTimePlaceCare. Available from: http://righttimeplacecare.eu/.

19. Verbeek H, Meyer $\mathrm{G}$, Leino-Kilpi $\mathrm{H}$, et al. A European study investigating patterns of transition from home care towards institutional dementia care: the protocol of a RightTimePlaceCare study. BMC Public Health 2012;12:68.

20. Molloy DW, Alemayehu E and Roberts R. Reliability of a Standardized Mini-Mental State Examination compared with the traditional Mini-Mental State Examination. American Journal of Psychiatry 1991;148:102-105.

21. Folstein MF, Folstein SE and McHugh PR. Mini-Mental State: a practical method for grading the cognitive state of patients for the clinician. Journal of Psychiatric Research 1975;12:189-198.

22. Katz S, Ford AB, Moskowitz RW, et al. Studies of Illness in the Aged. The Index of Adl: A Standardized Measure of Biological and Psychosocial Function. Journal of the American Medical Association 1963;185:914-919. 
23. Charlson ME, Pompei P, Ales KL and MacKenzie CR. A new method of classifying prognostic comorbidity in longitudinal studies: development and validation. Journal of Chronic Diseases 1987;40:373-383.

24. Kaufer DI, Cummings JL, Ketchel P, et al. Validation of the NPI-Q, a brief clinical form of the Neuropsychiatric Inventory. Journal of Neuropsychiatry and Clinical Neurosciences 2000;12:233-239.

25. Logsdon RG, Gibbons LE, McCurry SM and Teri L. Quality of life in Alzheimer's disease: patient and caregiver reports. Journal of Mental Health and Aging 1999;5:21-32.

26. Thorgrimsen L, Selwood A, Spector A, et al. Whose quality of life is it anyway? The validity and reliability of the Quality of Life-Alzheimer's Disease (QoL-AD) scale. Alzheimer Disease and Associated Disorders 2003;17:201-208.

27. Hoe J, Hancock G, Livingston G, et al. Changes in the quality of life of people with dementia living in care homes. Alzheimer Disease and Associated Disorders 2009;23:285-290.

28. Vaarama M. Care-related quality of life in old age. European Journal of Ageing 2009;6:113-125.

29. Du Moulin MF, van Haastregt JC and Hamers JP. Monitoring quality of care in nursing homes and making information available for the general public: state of the art. Patient Education and Counseling 2010;78:288-296.

30. Saliba D and Buchanan J. Development \& Validation of a Revised Nursing Home Assessment Tool: MDS 3.0. Baltimore: Quality Measurement and Health Assessment Group, Office of Clinical Standards and Quality, Centers for Medicare \& Medicaid Services, 2008.

31. Nakrem S, Vinsnes AG, Harkless GE, et al. Nursing sensitive quality indicators for nursing home care: international review of literature, policy and practice. International Journal of Nursing Studies 2009;46:848-857.

32. Guthrie B, Clark SA and McCowan C. The burden of psychotropic drug prescribingin people with dementia: a populationdatabase study. Age and Ageing 2010;39:637-642.

33. Higashi T, Shekelle PG, Adams JL, et al. Quality of care is associated with survival in vulnerable older patients. Annals of Internal Medicine 2005;143:274-281.

34. Alexopoulos GS, Abrams RC, Young RC and Shamoian CA. Cornell Scale for Depression in Dementia. Biological Psychiatry 1988;23:271-284.

35. Alexopoulos GS. The Cornell Scale for Depression in Dementia. Administration \& Scoring Guidelines. New York: Cornell Institute of Geriatric Psychiatry, Weill Medical College of Cornell University, 2002.

36. WHO Collaborating Centre for Drug Statistics Methodology. Guidelines for ATC classification and DDD assignment 2011. Oslo: Norwegian Institute of Public Health, 2010.

37. Wallace JI, Schwartz RS, LaCroix AZ, et al. Involuntary weight loss in older outpatients: incidence and clinical significance. Journal of the American Geriatrics Society 1995;43:329.

38. Hamers JP, Meyer G, Kopke S, et al. Attitudes of Dutch, German and Swiss nursing staff towards physical restraint use in nursing home residents, a cross-sectional study. International Journal of Nursing Studies 2009;46:248-255.

39. InterRAI Corporation. RAl for Nursing Home Care (RA/ 2.1). Utrecht: InterRAI Corporation, 2002.

40. Beerens HC, Zwakhalen SM, Verbeek H, et al. Factors associated with quality of life of people with dementia in long-term care facilities: a systematic review. International Journal of Nursing Studies 2013;50:1259-1270.

41. Gräske J, Fischer T, Kuhlmey A and Wolf-Ostermann K. Quality of life in dementia care-differences in quality of life measurements performed by residents with dementia and by nursing staff. Aging \& Mental Health 2012;16:819-827.

42. Zhao H, Novella JL, Dramé M, et al. Factors Associated with Caregivers' Underestimation of Quality of Life in Patients with Alzheimer's Disease. Dementia and Geriatric Cognitive Disorders 2012;33:11-17.

43. Conde-Sala JL, Garre-Olmo J, Turro-Garriga O, et al. Factors related to perceived quality of life in patients with Alzheimer's disease: the patient's perception compared with that of caregivers. International Journal of Geriatric Psychiatry 2009;24:585-594.

44. Hoe J, Hancock G, Livingston G and Orrell M. Quality of life of people with dementia in residential care homes. The British Journal of Psychiatry 2006;188:460-464. 
45. Eurofound. Third European Quality of Life Survey - Quality of life in Europe: Impacts of the crisis. Luxembourg: Publications Office of the European Union, 2012.

46. Saks K and Tiit E. Subjective Quality of Life of Care-Dependent Older People in Five European Union Countries. In: M Vaarama, R Pieper and A Sixsmith, eds. Care-Related Quality of Life in Old Age. Concepts, Models and Empirical Findings New York: Springer, 2008.

47. von dem Knesebeck O, Wahrendorf M, Hyde M and Siegrist J. Socioeconomic position and quality of life among older people in 10 European countries: results of the SHARE study. Ageing and Society 2007; 27:269-284

48. Lipszyc B, Sail E and Xavier A. European Economy. Long-term care: need, use and expenditure in the EU27. Brussels: European Commission, 2012.

49. Diener E and Suh EM. Culture and subjective well-being. Cambridge: MIT Press, 2000.

50. Zimmerman DR. Improving nursing home quality of care through outcomes data: the MDS quality indicators. International Journal of Geriatric Psychiatry 2003;18:250-257.

51. Banerjee S, Samsi K, Petrie CD, et al. What do we know about quality of life in dementia? A review of the emerging evidence on the predictive and explanatory value of disease specific measures of health related quality of life in people with dementia. International Journal of Geriatric Psychiatry 2009;24:15-24.

52. Lyketsos CG, Gonzales-Salvador T, Chin JJ, et al. A follow-up study of change in quality of life among persons with dementia residing in a long-term care facility. International Journal of Geriatric Psychiatry 2003;18:275-281.

53. Payne JL, Sheppard JM, Steinberg M, et al. Incidence, prevalence, and outcomes of depression in residents of a long-term care facility with dementia. International Journal of Geriatric Psychiatry 2002;17:247-253.

54. Alzheimer Europe. National Dementia Plans. A snapshot of the status of National Dementia Strategies around Europe. Available from: http://www.alzheimer-europe.org/EN\%E7\%B9\%A1/Policy-in-Practice2/ National-Dementia-Plans. 



\section{CHAPTER 4}

Change in quality of life of people with dementia recently admitted to long-term care facilities
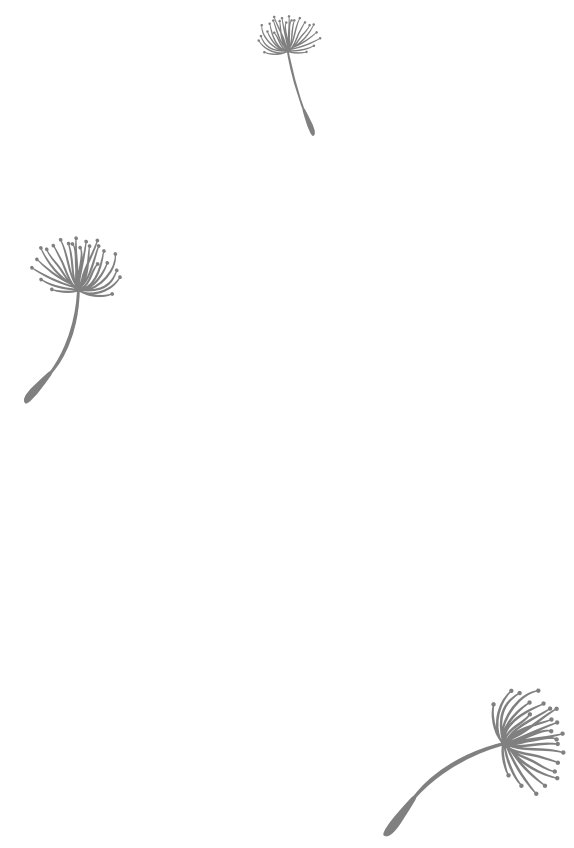

This chapter was published as:

Beerens HC, Zwakhalen SMG, Verbeek H, Ruwaard D, Ambergen AW, Leino-Kilpi H, Stephan A, Zabalegui A, Soto M, Saks K, Bökberg C, Sutcliffe CL, Hamers JPH, on behalf of the RightTimePlaceCare Consortium. Change in quality of life of people with dementia recently admitted to long-term care facilities. Journal of Advanced Nursing 2014;71:1435-1447. doi: 10.1111/jan.12570. 


\section{ABSTRACT}

Aim: To assess which factors are associated with change in quality of life of people with dementia who have recently been admitted to long-term care facilities.

Background: Many people with dementia will be admitted to long-term care facilities at some point during their disease. It is currently unknown which factors are associated with improvement and/or deterioration of quality of life immediately following admission.

Design: An observational and longitudinal survey.

Methods: Data on 343 people with dementia who have been recently admitted to longterm care facilities across eight European countries were collected between November 2010 and April 2012. Quality of life was assessed by people with dementia and their proxies using the 'Quality of Life-Alzheimer's Disease scale'. Explanatory variables included cognitive status, comorbidities, activities of daily living, depressive symptoms, and neuropsychiatric symptoms. Descriptive and multilevel regression analyses were performed.

Results: Better cognitive abilities at baseline were associated with a decrease in selfreported quality of life. Greater dependency and more depressive symptoms at baseline were associated with declined proxy-reported quality of life. Furthermore, an increased dependency and an increase of depressive symptoms between baseline and follow-up were associated with a decreased proxy-reported quality of life. On an individual level, three groups were identified, namely people whose quality of life: 1) decreased; 2) stayed the same; and 3) increased.

Conclusion: Cognitive functioning, functional rehabilitation and treatment of depressive symptoms should receive special attention. However, quality of life of people with dementia does not necessarily decrease after institutionalization. 


\section{INTRODUCTION}

Given that there is little prospect of a cure for dementia, maximizing quality of life (QoL) has gained increasing attention from European patient organizations, health authorities and policy makers. Researchers stress the importance of QoL measurement and identified QoL as a major outcome in dementia research. ${ }^{2,3}$ This is reflected by the growing body of literature paying attention to QoL in dementia. e.g. 4,5

Although common European policy principles aim to keep people with dementia (PWD) at home for as long as possible, ${ }^{6}$ many of them will be admitted to long-term care facilities as the dementia progresses. ${ }^{7}$ This admission involves challenges for PWD concerning their loss of home and changes in their own standards of living. ${ }^{8}$ Two studies found that QoL of PWD who were recently admitted was lower than QoL of PWD who lived in those facilities for longer periods of time. ${ }^{9,} 10$ These studies and others that found that QoL of PWD does not necessarily decrease as the dementia progresses, ${ }^{\text {e.g. }}$ 11, ${ }^{12,13}$ suggest that decline in QoL is not inevitable for recently admitted PwD.

The fact that QoL of PWD might fluctuate, justifies the need to investigate how PwD's QoL develops over time and what factors are associated with a change in QoL. Studies focusing on factors associated with change in QoL of PwD living in long-term care facilities are scarce, ${ }^{5}$ especially studies focusing on people who are recently admitted to a long-term care facility. Identifying which factors are associated with change in QoL in the months after the period of admission, makes it possible to determine which factors could be modified to improve PWD's QoL following admission to long-term care facilities.

\section{BACKGROUND}

Dementia, most frequently caused by Alzheimer's disease, mainly affects a person's cognition, behavioural state, and psychological state. ${ }^{14}$ Although there is no consensus about what QoL in dementia exactly constitutes, ${ }^{15}$ consensus exists that QoL is a multidimensional construct consisting of objective components (like behaviour and environment) as well as subjective components (like psychological wellbeing and perceived QoL). ${ }^{16,17}$

A variety of cross-sectional studies investigated which factors are associated with QoL of PwD. Two systematic literature reviews summarized current evidence with regard to this topic. They report the presence of depressive symptoms to be most consistently related to low self-reported and low proxy-reported QoL. In addition, they found an association between behavioural disturbances, especially agitation, and low self-reported QoL. ${ }^{4,5}$ The association with, for example, cognition and dependency in Activities of Daily Living ( $A D L)$ is less clear and remains a topic of discussion. With regard to longitudinal studies, one study that followed community-dwelling PwD over 20 months reported a positive association between QoL and a good bond between PWD and caregivers. ${ }^{18}$ An- 
other longitudinal study targeted at institutionalized PwD lasted 20 weeks and found a reduction in QoL to be associated with cognitive deterioration and a negative mood. ${ }^{12}$

\section{THE STUDY}

\section{Aim}

The aim of this study was to investigate the impact of patient-related factors on change in QoL of PwD who were recently admitted - i.e. at least one month but no longer than three months - to a long-term care facility and who still lived there three months later. The following research question was postulated: Which factors are associated with change in QoL of PwD who have recently been admitted to long-term care facilities over a period of three months?

\section{Design}

An observational, longitudinal survey was conducted in eight countries: England, Estonia, Finland, France, Germany, the Netherlands, Spain, and Sweden. The survey was part of a large European project called RightTimePlaceCare (RTPC). Follow-up measurement took place three months after baseline. Detailed information about the RTPC study is published elsewhere. ${ }^{19}$

\section{Sample}

PwD living in long-term care facilities were eligible for the RTPC study if they: 1) had a formal diagnosis of dementia as judged by an expert assessment (i.e. physician, psychiatrist, neurologist, geriatrician or general practitioner, depending on countries' specific diagnostic procedures) and documented in the medical record; 2) had an informal caregiver who visited at least twice a month; 3) had a Standardized Mini Mental State Examination (S-MMSE) score ${ }^{20}$ lower than 25; and 4) were newly admitted to a long-term care facility, defined as a place of collective living where care and accommodation is provided as a package by a public agency, non-profit or private company ${ }^{21}$ for at least one month but no longer than three months. PwD were excluded if they: 1) were younger than 65 years; 2) had a primary psychiatric diagnosis or Korsakoff's syndrome; or 3) were only temporarily resident in a long-term care facility (applicable for the recently admitted group). In total, 791 PwD could be included in the long-term care facility sample of the RTPC study.

For this particular study, only PwD who were able to complete the Quality of Life in Alzheimer's Disease scale (QoL-AD) ${ }^{22}$ at baseline and follow-up were selected. Following the original guidelines from Logsdon et al., a maximum of two missing responses on the 
QoL-AD was allowed. 448 participants did not fulfil this criterion, and as a result 343 PwD were included in this study. More specifically, in Sweden 60, in Finland 74, in the Netherlands 49, in Germany 41, in Estonia 53, in France 7, in Spain 30, and in England 29 PwD completed the QoL-AD at both time points.

\section{Data collection}

\section{Procedure}

Baseline and follow-up data were collected between November 2010 and April 2012. Researchers interviewed the PWD and their best informed proxy. This was usually the formal nursing caregiver who was at least a certified nursing assistant and who confirmed to be involved in daily care for the PwD. If there was no formal caregiver who had insufficient information about the PWD, the informal caregiver was also asked to participate.

\section{Measures}

The primary outcome measure (response variable) of this study was QoL of PwD. Selfreported QoL (judged by PWD) and proxy-reported QoL (judged by caregivers) were both evaluated using the Quality of Life in Alzheimer's Disease scale (QoL-AD). ${ }^{22}$ This instrument can be used to assess PwD's and their proxies' perspectives. The QoL-AD consists of 13 items relating to QoL, each measured on a four-point scale (ranging from $1=$ poor to $4=$ =xcellent). The possible total score on the QoL-AD ranges from 13-52. Higher scores indicate a better QoL.

Furthermore, information about explanatory variables was collected. The Standardized Mini-Mental State Examination (S-MMSE) ${ }^{20}$ was used to assess the cognitive abilities of the PWD at baseline. The possible total score of the S-MMSE ranges from 0 to 30. Higher scores on the S-MMSE indicate less cognitive impairment. Comorbidity was assessed with the Charlson Comorbidity Index. ${ }^{23}$ The possible total score of this scale ranges from 0 to 37. Higher scores on this scale indicate the presence of more (severe) comorbidities. Functional status was assessed using the Katz Index of Independence in Activities of Daily Living (ADL). ${ }^{24}$ The possible total score of this scale ranges from 0 to 6 . Higher scores on this scale indicate greater independency in ADL. The Cornell Scale for Depression in Dementia (CSDD) $)^{25}$ was used to assess the presence of depressive symptoms. The possible total score of the CSDD ranges from 0 to 38. Higher scores on the CSDD indicate the presence of more depressive symptoms. Neuropsychiatric symptoms were assessed with the Neuropsychiatric Inventory Questionnaire (NPI-Q). ${ }^{26}$ In this study, four neuropsychiatric clusters were used for the analyses: hyperactivity (range 0 15, containing the items: agitation, euphoria, disinhibition, irritability, aberrant motor behaviour), mood/apathy (range 0 - 12, containing the items: depression, apathy, nighttime behaviour disturbances, appetite and eating abnormalities), psychosis (range $0-6$, containing the items: delusions and hallucinations), and anxiety (a dichotomous item 
yes/no). ${ }^{27,} 28$ Higher scores on these clusters indicate the presence of more neuropsychiatric symptoms in a certain cluster.

Finally, socio-demographic data such as age, gender, and marital status were collected.

\section{Ethical considerations}

Each participating country obtained ethical approval from country-specific legal authorities for research on human beings, following country-specific procedures. These procedures vary highly across countries. ${ }^{29}$ For study participation, written informed consent was obtained from PwD directly or via their informal caregivers. PwD who were not able to sign informed consent, were asked to assent. ${ }^{30}$ Assent is defined as the willingness to participate even without full understanding of the complexity and the whole aims of the study. For each measurement instrument that was used in the study, written permission from the copyright holders was acquired.

\section{Data analysis}

Data were analysed using SPSS version 22.0. Two-tailed tests with a significance level of $\alpha=.05$ were used. A maximum of two missing items on the QoL-AD was permissible and were replaced by the mean score of the remaining items of the respondent. ${ }^{31}$ Following this procedure, the QoL-AD was imputed for $1.47 \%$ of the questions about self-reported QoL and $2.41 \%$ of the questions about proxy-reported QoL. For the other continuous scales, a maximum of $10 \%$ of missing items was replaced using the same procedure. For the following variables, a change score (follow-up score minus baseline score) was calculated: the Katz Index, the CSDD, and the NPI-Q clusters. For each test, relevant assumptions were checked. Procedures below were the same for self-reported and proxyreported QoL.

To test the difference between self-reported QoL and proxy-reported QoL and between baseline QoL and QoL at follow-up, paired-samples t-tests were conducted.

To assess group-characteristics of PWD whose QoL decreased, stayed the same or increased after three months, PwD were divided into three groups: 1) PWD whose QoL$A D$ score decreased three points or more; 2) PWD whose QoL-AD score changed less than three points; and 3) PwD whose QoL-AD score increased three points or more. The threshold of three points was chosen because a clinically meaningful difference on QoL instruments is estimated on half a standard deviation of the total scale ${ }^{32}$ and in the RightTimePlaceCare study, one standard deviation on the QoL-AD was around 6 points. ${ }^{33}$ This cut-off point was also established by several other studies using the QoL-AD. ${ }^{11,12,18}$ Scores per group were compared using analyses of variance and chi square tests. Tukey's HSD tests were performed to analyse which group differed from another group. 
To assess the association between the clinical variables and change in QoL, change in QoL was calculated by subtracting the baseline QoL-AD score from the follow-up score. A positive score on this variable indicates an improved $\mathrm{QoL}$ in three months. Bivariate associations with change in QoL were assessed with Pearson's correlations. A correlation >.3 was considered clinically moderately meaningful. ${ }^{34}$ Multivariate associations with change in QoL were assessed using hierarchical linear regression models with 'country' as the level two variable. Due to multicollinearity between the CSDD and the NPI-Q cluster 'mood/apathy', the latter variable was removed from multivariate analyses. For this regression analysis, missing values on the total scores of the S-MMSE and the CSDD were imputed using multiple imputations. Age, gender, comorbidity, QoL, ADL independency and neuropsychiatric symptoms functioned as indicator variables for this imputation.

\section{Validity and reliability}

A European consensus study on outcome measures in dementia care suggested that the QoL-AD is the preferable measure of choice to evaluate QoL of PwD. ${ }^{3}$ Content validity, as assessed by focus groups with PwD and caregivers, is considered good. Construct validity is also good with principal component analyses presenting all 13 items loading on component 1. Internal consistency from the QoL-AD ranges from $\alpha=.82$ to $\alpha=.90$ for both PwD and caregivers. ${ }^{22,31,35}$ The responsiveness of the QoL-AD is also well documented: no major floor or ceiling effects have been reported and the scale is sensitive to change. ${ }^{35-37}$

The validity and reliability of the Mini-Mental State Examination ${ }^{38}$ have been investigated extensively. ${ }^{39}$ In this study, a standardized version of this instrument has been used because the S-MMSE's administration time is shorter and it has proven to be more reliable in institutionalized older people (intraclass correlation coefficient $=0.90$ ). ${ }^{20,40}$ Where- $^{2}$ as the Charlson Comorbidity Index was originally developed for a variety of populations, ${ }^{23}$ whereas its predictive value has also been studied in an institutionalized older population. ${ }^{41}$ Buntinx and colleagues found the Charlson Comorbidity Index to be highly predictive of mortality in six months in this population (Hazard Ratio =2.0), and recommended to include the scale as a measure of comorbidity in observational studies. The Katz Index of Independence in $\mathrm{ADL}^{24}$ is widely used and has demonstrated evidence of construct validity and predictive validity. ${ }^{42}$ Its internal consistency varies between $\alpha=0.87$ and $\alpha$ $=0.94$. ${ }^{\text {eg. }}{ }^{43}$ The validity and reliability of the $\operatorname{CSDD}^{25}$ are investigated among institutionalized older people (with dementia). The CSDD demonstrated to be both valid and reliable. ${ }^{44}$ The internal consistency varies between $\alpha=0.81$ and $\alpha=0.91$ and comparisons with DSM-IV-TR diagnoses showed high internal validity. The NPI-Q is a brief, valid and reliable instrument to evaluate neuropsychiatric symptoms of people with dementia. In addition, it demonstrated to be sensitive to change. ${ }^{26}$ The separate neuropsychiatric clusters used for this study explain $55.1 \%$ of the total variance in the NPI-Q. ${ }^{27,28}$

Most instruments were available in all languages. When this was not the case, forward and backward translation procedures were followed. ${ }^{45}$ The international data 
collection was standardized using manuals, joint meetings, site visits by external auditors and a central data entry. In addition, interviewers were trained and had at least a Bachelor's degree. $^{19}$

\section{RESULTS}

\section{Participant characteristics}

Table 1 provides baseline characteristics of the PwD who lived in long-term care facilities in the RTPC study ( $n=791)$, the PwD who did not meet and who did meet the inclusion criteria for this study ( $n=448$ and $n=343$, respectively). From the 448 PwD who were excluded, 137 dropped out at follow-up. Reasons for this were: PwD deceased $(n=75)$, caregiver related reasons $(n=41)$, and other reasons $(n=21)$. The others were not able to complete the QoL-AD at baseline and follow-up ( $n=309)$, or moved back home between baseline and follow-up $(n=2)$.

Of the 343 PwD who were able to answer the questions of the QoL-AD at baseline and follow-up and who were thus included in this study, 332 proxy-ratings were also completed. In 11 cases, only PwD ratings were available. Participating PwD were on average 84.3 years old, the majority were female (74.9\%), and a minority were married (25.1\%).

Table 1. Participant characteristics of whole RightTimePlaceCare (RTPC) sample, and excluded and included participants for this study*

\begin{tabular}{|c|c|c|c|}
\hline Variable at baseline & $\begin{array}{l}\text { RTPC } \\
n=791\end{array}$ & $\begin{array}{l}\text { Excluded } \\
n=448\end{array}$ & $\begin{array}{l}\text { Included } \\
n=343\end{array}$ \\
\hline Age & $84.1(6.4)$ & $83.8(6.7)$ & $84.3(6.0)$ \\
\hline \multirow[t]{2}{*}{ Gender: female } & $n=585$ & $n=329$ & $n=256$ \\
\hline & $74.0 \%$ & $73.2 \%$ & $74.9 \%$ \\
\hline \multirow[t]{2}{*}{ Marital status: married } & $n=244$ & $n=157$ & $n=87$ \\
\hline & $30.9 \%$ & $35.3 \%$ & $25.1 \%$ \\
\hline Cognition - range $0-\underline{30}^{\dagger}$ & $11.9(6.3)$ & $9.3(6.4)$ & $14.1(5.2)$ \\
\hline Comorbidity - range $\underline{0}-37^{+}$ & $2.4(1.6)$ & $2.4(1.7)$ & $2.4(1.5)$ \\
\hline Independency in ADL - range $0-\underline{6}^{+}$ & $2.2(1.7)$ & $1.7(1.6)$ & $2.8(1.7)$ \\
\hline Depressive symptoms - range $\underline{0}-38^{\dagger}$ & $6.1(5.1)$ & $7.0(5.5)$ & $5.0(4.3)$ \\
\hline NPI-Q subscale: hyperactivity - range $\underline{0}-15^{+}$ & $2.8(3.0)$ & $3.1(3.2)$ & $2.4(2.8)$ \\
\hline NPI-Q subscale: mood/apathy - range $\underline{0}-12^{+}$ & $2.7(2.3)$ & $3.1(2.5)$ & $2.2(2.0)$ \\
\hline NPI-Q subscale: psychosis - range $\underline{0}-6^{+}$ & $0.8(1.4)$ & $0.9(1.5)$ & $0.7(1.2)$ \\
\hline \multirow[t]{2}{*}{ NPI-Q subscale: anxiety: presence anxiety } & $n=337$ & $n=213$ & $n=124$ \\
\hline & $42.6 \%$ & $47.3 \%$ & $36.4 \%$ \\
\hline
\end{tabular}

$\mathrm{ADL}=$ Activities in Daily Living; NPI-Q = NeuroPsychiatric Inventory Questionnaire

* For categorical variables, $\mathrm{n}$ and percentages are presented. For continuous scales the mean scores and standard deviations are shown

${ }^{+}$Underlined score is most favourable score 


\section{Mean QoL scores}

The mean score on the self-reported QoL-AD at baseline was 32.8 (standard deviation 6.1) and 32.9 (standard deviation 5.7) at follow-up. There was no significant difference between these two time points $(t[342]=-.465, p=.643)$. Proxy-reported QoL-AD scores remained unchanged at 32.1 (standard deviation 5.6 and 5.4, respectively) and thus did not differ significantly $(t[331]=-.721, p=.787)$. However, the difference between the two perspectives (i.e. self-report versus proxy report) was significant (baseline: $t[336]=$ 2.065, $p=.040$; follow-up: $t[336]=2.367, p=.019$ ), but not clinically relevant (mean difference $<3$ ).

Group-characteristics of PWD whose QoL decreased, stayed the same, or increased over a three-month period

Although the mean QoL scores did not change, on an individual level it was possible to identify groups whose QoL had changed. Relative to the baseline, 25.4\% of the PwD rated their QoL at follow-up less positively with a decrease in QoL-AD scores of three points or more, $44.0 \%$ rated their QoL the same with baseline and follow-up QoL-AD scores deviating less than three points, and 30.6\% rated their QoL more positively with an increase in QoL-AD scores of three points or more.

Using the same method of subdividing groups, $25.6 \%$ of the proxies rated PwD's QoL at follow-up lower than at baseline, $48.8 \%$ of the proxies rated PwD's QoL the same at the two time points, and $25.6 \%$ of the proxies scored PWD's QoL higher at follow-up than at baseline.

The baseline and follow-up QoL-AD scores and other characteristics of these groups are summarized in Tables 2 and 3. Post hoc analyses showed that PwD whose selfreported QoL had not changed, had a better cognition than PwD whose QoL had increased (Tukey's HSD, mean difference=1.8, $p=.021$ ). Furthermore, PwD whose selfreported QoL had increased, had more comorbidities than PwD whose QoL had decreased (Tukey's HSD, mean difference=.5, $p=.030$ ). Finally, PwD whose proxy-reported QoL had increased, scored higher on the mood/apathy subscale from the NPI than PwD whose QoL had decreased (Tukey's HSD, mean difference=1.1, $p=.002$ ). 
Table 2. Characteristics of subgroups that are based on change in self-reported quality of life (QoL)*

\begin{tabular}{|c|c|c|c|c|}
\hline & $\begin{array}{l}\text { Decreased } \\
\text { self-reported } \\
\text { QoL, } n=87 \\
(25.4 \%)\end{array}$ & $\begin{array}{l}\text { No change in } \\
\text { self-reported } \\
\text { QoL, } n=151 \\
(44.0 \%)\end{array}$ & $\begin{array}{l}\text { Increased } \\
\text { self-reported } \\
\text { QoL, } n=105 \\
(30.6 \%)\end{array}$ & p value $^{\dagger}$ \\
\hline QoL at baseline (standard deviation) & $37.0(5.5)$ & $32.3(5.5)$ & $30.0(5.4)$ & $<.001$ \\
\hline QoL at follow-up (standard deviation) & $31.0(5.6)$ & $32.3(5.3)$ & $35.4(5.3)$ & $<.001$ \\
\hline \multicolumn{5}{|l|}{ Baseline variables: } \\
\hline Age & 83.6 & 84.7 & 84.5 & .390 \\
\hline Gender: female & $79.3 \%$ & $73.5 \%$ & $73.3 \%$ & .551 \\
\hline Marital status: married & $25.3 \%$ & $22.0 \%$ & $29.5 \%$ & .395 \\
\hline Cognition - range $0-\underline{30}^{\ddagger}$ & 14.1 & 14.8 & 13.0 & $.028^{\S}$ \\
\hline Comorbidity - range $\underline{0}-37^{\ddagger}$ & 2.2 & 2.3 & 2.8 & $.024^{\S}$ \\
\hline Independency in $A D L-$ range $0-\underline{6}^{\ddagger}$ & 3.0 & 2.8 & 2.7 & .481 \\
\hline Depressive symptoms - range $\underline{0}-38^{\ddagger}$ & 4.8 & 5.0 & 5.3 & .748 \\
\hline NPI-Q subscale: hyperactivity - range $\underline{0}-15^{\ddagger}$ & 2.0 & 2.6 & 2.4 & .302 \\
\hline NPI-Q subscale: mood/apathy - range $\underline{0}-12^{\ddagger}$ & 1.8 & 2.1 & 2.5 & .080 \\
\hline NPI-Q subscale: psychosis - range $\underline{0}-6^{\ddagger}$ & 0.7 & 0.8 & 0.5 & .221 \\
\hline NPI-Q subscale: anxiety: presence anxiety & $33.3 \%$ & $37.1 \%$ & $38.1 \%$ & .773 \\
\hline
\end{tabular}

QoL = Quality of Life; ADL = Activities in Daily Living

* For categorical variables, percentages are presented. For continuous scales, mean scores are shown

${ }^{+}$Analyses of variance and chi square tests were conducted to analyse the difference between the groups

‡ Underlined score is most favourable score

${ }^{\S}$ Significant difference between the three groups

Table 3. Characteristics of subgroups that are based on change in proxy-reported quality of life (QoL)*

\begin{tabular}{|c|c|c|c|c|}
\hline & $\begin{array}{l}\text { Decreased } \\
\text { proxy-reported } \\
\text { QoL, } n=85 \\
(25.6 \%)\end{array}$ & $\begin{array}{l}\text { No change in } \\
\text { proxy-reported } \\
\text { QoL, } n=162 \\
(48.8 \%)\end{array}$ & $\begin{array}{l}\text { Increased } \\
\text { proxy-reported } \\
\text { QoL, } n=85 \\
(25.6 \%)\end{array}$ & $p$ value \\
\hline QoL at baseline (standard deviation) & $35.4(4.5)$ & $31.8(5.4)$ & $29.0(5.2)$ & $<.001$ \\
\hline QoL at follow-up (standard deviation) & $29.6(4.8)$ & $31.8(5.3)$ & $35.1(4.9)$ & $<.001$ \\
\hline \multicolumn{5}{|l|}{ Baseline variables: } \\
\hline Age & 84.5 & 84.1 & 84.9 & .545 \\
\hline Gender: female & $76.5 \%$ & $73.5 \%$ & $76.5 \%$ & .818 \\
\hline Marital status: married & $31.0 \%$ & $22.8 \%$ & $24.7 \%$ & .377 \\
\hline Cognition - range $0-\underline{30}^{\ddagger}$ & 14.6 & 14.2 & 13.2 & .241 \\
\hline Comorbidity - range $\underline{0}-37^{\ddagger}$ & 2.4 & 2.4 & 2.4 & .976 \\
\hline Independency in ADL - range $0-\underline{6}^{\ddagger}$ & 3.1 & 2.6 & 2.8 & .094 \\
\hline Depressive symptoms - range $\underline{0}-38^{\ddagger}$ & 4.6 & 4.8 & 5.9 & .083 \\
\hline NPI-Q subscale: hyperactivity - range $\underline{0}-15^{\ddagger}$ & 2.4 & 2.2 & 2.7 & .370 \\
\hline NPI-Q subscale: mood/apathy - range $\underline{0}-12^{\ddagger}$ & 1.6 & 2.2 & 2.7 & $.003^{\S}$ \\
\hline NPI-Q subscale: psychosis - range $\underline{0}-6^{\ddagger}$ & 0.7 & 0.6 & 0.8 & .588 \\
\hline NPI-Q subscale: anxiety: presence anxiety & $34.1 \%$ & $35.8 \%$ & $40.0 \%$ & .708 \\
\hline
\end{tabular}

QoL = Quality of Life; ADL = Activities in Daily Living

* For categorical variables, percentages are presented. For continuous scales, mean scores are shown

${ }^{+}$Analyses of variance and chi square tests were conducted to analyse the difference between the groups

‡ Underlined score is most favourable score

${ }^{\S}$ Significant difference between the three groups 
Factors associated with change in QoL over a three-month period

Bivariate analyses showed that a decrease in self-reported QoL at follow-up was associated with high self-reported QoL at baseline (Pearson's $r=-.488$ ). A decrease in proxyreported QoL at follow-up was associated with a high proxy-reported QoL at baseline (Pearson's $r=-.464$ ) and an increase of depressive symptoms between baseline and follow-up (Pearson's $r=-.337$ ). The remaining variables had no meaningful bivariate correlation (Pearson's $r>3$ ) with change in QoL.

Table 4 displays the results of the hierarchical multivariate linear regression models. A decrease in self-reported QoL at follow-up was associated with a high self-reported QoL score at baseline $(p=<.001)$ and better cognitive abilities at baseline $(p=.008)$. A decrease in proxy-reported QoL at follow-up was associated with a high proxy-reported QoL at baseline $(p<.001)$, greater dependency in ADL at baseline $(p=.009)$, an increased ADL dependency between baseline and follow-up ( $p<.001)$, more depressive symptoms at baseline $(p=.001)$, and an increase of depressive symptoms between baseline and follow-up $(p<.001)$. 
Table 4. Factors associated with change in quality of life (QoL) at follow-up (follow-up score - baseline score)*

\begin{tabular}{|c|c|c|c|c|c|c|c|c|c|c|}
\hline & \multicolumn{5}{|c|}{ Self-reported QoL } & \multicolumn{5}{|c|}{ Proxy-reported QoL } \\
\hline & \multirow{2}{*}{\multicolumn{2}{|c|}{$\begin{array}{r}\text { EstimateStd. } \\
\text { Error }\end{array}$}} & \multicolumn{2}{|c|}{$\begin{array}{l}95 \% \text { confidence } \\
\text { interval }\end{array}$} & \multirow[t]{2}{*}{$\mathrm{p}$ value } & \multirow{2}{*}{\multicolumn{2}{|c|}{$\begin{array}{r}\text { Estimate Std. } \\
\text { Error }\end{array}$}} & \multicolumn{2}{|c|}{$\begin{array}{l}95 \% \text { confidence } \\
\text { interval }\end{array}$} & \multirow[t]{2}{*}{$p$ value } \\
\hline & & & Lower & Upper & & & & Lower & Upper & \\
\hline Baseline QoL $^{\dagger}$ & -.480 & .044 & -.566 & -.394 & $<.001^{\ddagger}$ & -.588 & -.684 & -.491 & .049 & $<.001^{\ddagger}$ \\
\hline Age & .028 & .041 & -.051 & .108 & .482 & -.005 & -.078 & .069 & .038 & .902 \\
\hline Gender & -.122 & .562 & -1.224 & .980 & .828 & .011 & -1.006 & 1.027 & .519 & .984 \\
\hline Marital status & -.306 & .583 & -1.450 & .838 & .600 & -.104 & -1.155 & .947 & .536 & .846 \\
\hline Cognition & -.131 & .049 & -.228 & -.035 & $.008^{\ddagger}$ & -.041 & -.129 & .047 & .045 & .362 \\
\hline Comorbidity & .145 & .161 & -.170 & .460 & .367 & -.122 & -.412 & .168 & .148 & .408 \\
\hline ADL independency & -.004 & .163 & -.323 & .315 & .979 & .397 & .098 & .696 & .153 & $.009^{\ddagger}$ \\
\hline $\begin{array}{l}\text { Change in ADL } \\
\text { independency }\end{array}$ & .061 & .206 & -.343 & .465 & .767 & .701 & .320 & 1.082 & .194 & $<.001^{\ddagger}$ \\
\hline Depressive symptoms & s-.130 & .086 & -.298 & .038 & .129 & -.280 & -.442 & -.118 & .083 & $.001^{\ddagger}$ \\
\hline $\begin{array}{l}\text { Change in depressive } \\
\text { symptoms }\end{array}$ & -.022 & .076 & -.172 & .127 & .769 & -.330 & -.469 & -.190 & .071 & $<.001^{\ddagger}$ \\
\hline $\begin{array}{l}\text { NPI-Q subscale: } \\
\text { Hyperactivity }\end{array}$ & .206 & .117 & -.024 & .436 & .080 & .003 & -.209 & .215 & .108 & .976 \\
\hline $\begin{array}{l}\text { NPI-Q subscale: } \\
\text { Change in } \\
\text { hyperactivity }\end{array}$ & .018 & .115 & -.207 & .243 & .874 & -.143 & -.352 & .067 & .107 & .182 \\
\hline $\begin{array}{l}\text { NPI-Q subscale: } \\
\text { Psychosis }\end{array}$ & -.272 & .248 & -.758 & .214 & .273 & .064 & -.394 & .522 & .234 & .785 \\
\hline $\begin{array}{l}\text { NPI-Q subscale: } \\
\text { Change in psychosis }\end{array}$ & .003 & .206 & -.401 & .406 & .990 & -.030 & -.418 & .358 & .198 & .879 \\
\hline $\begin{array}{l}\text { NPI-Q subscale: } \\
\text { Anxiety }\end{array}$ & -.267 & .711 & -1.661 & 1.127 & .707 & -.446 & -1.738 & .846 & 659 & .499 \\
\hline $\begin{array}{l}\text { NPI-Q subscale: } \\
\text { Change in anxiety }\end{array}$ & -.568 & .577 & -1.700 & .563 & .325 & -.526 & -1.584 & .533 & .540 & .330 \\
\hline
\end{tabular}

$A D L=$ Activities in Daily Living; $\mathrm{QOL}=$ Quality of Life; NPI-Q = NeuroPsychiatric Inventory - Questionnaire

* Hierarchical multivariate linear regression analyses were conducted

+ For the association with self-reported QoL, self-reported baseline QoL was used. For the association with proxy-reported QoL, the proxy-reported baseline QoL was used

${ }^{\ddagger}$ Significant association with change in QoL

\section{DISCUSSION}

Main study findings on associations of QoL of PwD over a period of three months following admission to long-term care facilities showed that a decrease in self-reported QoL was associated with better cognitive abilities. A decline in proxy-reported QoL was associated with greater dependency and more depressive symptoms at baseline, and an 
increased dependency and an increase of depressive symptoms between baseline and follow-up.

Recent literature often suggests that PwD-related factors such as depressive symptoms and behavioural disturbances are related to QoL of PwD living in long-term care facilities. ${ }^{5,46}$ This study demonstrated that cognitive function also influences the course of QoL of PWD who are recently admitted to long-term care facilities: self-rated QoL of recently admitted participants was more likely to increase at follow-up when they had fewer cognitive abilities at baseline. However, other studies focusing on PwD who were institutionalized for longer periods of time reported contrasting results. Hoe et al. $(2009)^{12}$ studied PwD over 20 weeks and reported no association between self-reported QoL and cognition at baseline, but did find an association between cognitive deterioration and a reduction in self-reported QOL. Another study focusing on change in QoL of institutionalized PWD over three years, did not find an association with cognitive function at all. ${ }^{46}$ Conde-Sala et al. $(2013)^{46}$ corrected for anosognosia, which is a decreased awareness about the physical and mental consequences of dementia. They claim that, instead of cognition, anosognosia would be associated with higher self-reported QoL ratings, which means that awareness about having dementia may lead PWD to have a more negative view about their QoL.

This study showed that increased ADL dependence is associated with a decrease in proxy-reported QoL of recently institutionalized PwD. Other - longitudinal - literature about this relationship is scarce and does not focus specifically on recently institutionalized PwD. One study that included ADL independence found the same association, ${ }^{46}$ whereas two others did not observe an association with change in QoL. ${ }^{11,12}$ Our results indicate that caregivers consider ADL independence to be important for QoL of recently admitted PwD. A study focusing on maximizing functional status of nursing home residents ${ }^{47}$ also showed that nursing staff recognize the importance of optimizing functional status of nursing home residents. Daily exercises such as walking activities may reduce the decline in physical dependence, improve QoL, and are therefore crucial. ${ }^{48-50}$

Our results suggest that QoL of PWD does not necessarily decrease in the period after admission to a long-term care facility. Although it may take effort getting accustomed to a new place of residence, ${ }^{8,51}$ mean QoL did not change. However, on an individual level changes were detected in half of the sample: approximately a quarter of the PwD experienced a decrease and the same proportion experienced an increase in QoL in the three months following admission. Regression to the mean cannot be excluded, but as meaningful correlations between QoL and other variables were detected, its impact is not considered dominant. Our findings correspond with the longitudinal study of Clare et al. (2013), ${ }^{18}$ who made the same subdivision with regard to change in QoL. Besides our study, only two small studies that investigated the course of QoL in the period after institutionalization could be identified. ${ }^{9}, 10$ Both reported increased mean QoL scores after admission. The heterogeneity of study results regarding the period after institutionalization is also reflected by studies that concentrated on the course of 
depressive symptoms. Although our study could not detect a mean change in depressive symptoms, other studies with follow-up periods ranging from six months to a year found a decrease, ${ }^{52,53}$ and, on the other hand, an increase in depressive symptoms ${ }^{54}$ in the period following admission to a long-term care facility. It is unclear what the reasons are for these ambiguous results. The time point and reasons for nursing home admission differ across countries, ${ }^{55}$ and could therefore have led to different characteristics and different levels of depression of newly admitted residents.

This study again reflects different views and priorities about PwD's QoL. Therefore, QoL perspectives should be considered to be complementary. ${ }^{31,56}$ Our finding that selfreported QoL only correlates with a self-assessed instrument (S-MMSE) and proxyreported QoL only correlates with proxy-assessed instruments (CSDD and Katz Index of Independence in ADL), was not earlier observed by other studies. However, consistent with three longitudinal studies focusing on change in QoL, considerably more associations with change in proxy-reported QoL could be detected as compared with associations with self-reported QoL. ${ }^{11,12,46}$ This poses challenges for researchers, who can only to a certain extent predict (changes in) PwD's self-reported QoL.

\section{Limitations}

Some limitations of this study should be mentioned. First, the results of this study could not be generalized to all PWD living in institutional settings because this study focused on a specific group, namely on recently admitted PWD who completed the QoL-AD at baseline and follow-up. As a result, PwD with severe cognitive deficits were excluded. However, the advantage of this selection is that it enabled us to make an unbiased comparison between the perspectives of PWD with the perspectives of proxies of the same PwD. Second, a longer follow-up period could have possibly led to different results because the follow-up period of three months is relatively short. On the other hand, this period allowed us to observe the period during and after admission to a longterm care facility. Third, due to the low sample sizes in each country, it was impossible to perform country-specific analyses to assess factors associated with QoL. However, using multilevel regression techniques, it was possible to correct for the effect of living in a certain country. Information about the cultural sensitivity of instruments, which is currently lacking, would contribute to comparisons between countries. Fourth, although the participating proxy was always the best informed proxy (usually the formal caregiver), information about who was interviewed at baseline and follow-up is unavailable. However, it should be stressed that procedures were standardized, formal caregivers had to be at least a certified nursing assistant and we aimed to interview the same proxy at baseline and follow-up. 


\section{CONCLUSIONS}

QoL of PwD who are recently admitted to long-term care facilities does not necessarily decrease. However, it may take effort getting accustomed to a new place of residence. Programs to improve physical activities have been developed lately and show positive outcomes on QoL, and therefore deserve special attention from nursing staff. Besides that, treatment of depressive symptoms is of major importance, and starts with timely recognition of nursing staff and other disciplines working in long-term care facilities. To get more insight into the role of cognition over time and to investigate which countryspecific factors influence QoL after institutionalization, further studies are needed. Finally, only a limited number of factors can be identified as influential on self-reported QoL. Researchers should continue to study how the variability between QoL scores of PwD can be explained. 


\section{REFERENCES}

1. Raeymaekers $P$ and Rogers MD. Improving the quality of life of people with dementia in the EU: A challenge for the European Society. Brussels: King Baudouin Foundation, 2010.

2. Cooper C, Mukadam N, Katona C, et al. Systematic review of the effectiveness of pharmacologic interventions to improve quality of life and well-being in people with dementia. American Journal of Geriatric Psychiatry 2013;21:173-183.

3. Moniz-Cook E, Vernooij-Dassen M, Woods R, et al. A European consensus on outcome measures for psychosocial intervention research in dementia care. Aging \& Mental Health 2008;12:14-29.

4. Banerjee S, Samsi K, Petrie CD, et al. What do we know about quality of life in dementia? A review of the emerging evidence on the predictive and explanatory value of disease specific measures of health related quality of life in people with dementia. International Journal of Geriatric Psychiatry 2009;24:15-24.

5. Beerens HC, Zwakhalen SM, Verbeek H, et al. Factors associated with quality of life of people with dementia in long-term care facilities: A systematic review. International Journal of Nursing Studies 2013;50:1259-1270.

6. OECD. Health at a Glance 2013: OECD indicators: OECD Publishing, 2013.

7. Prince M, Prina M, Guerchet $M$ and Alzheimer's Disease International. World Alzheimer Report 2013: Journey of Caring. An analysis of long-term care for dementia. London: Alzheimer's Disease International, 2013.

8. Sury L, Burns $\mathrm{K}$ and Brodaty $\mathrm{H}$. Moving in: adjustment of people living with dementia going into a nursing home and their families. International Psychogeriatrics 2013;25:867-876.

9. Funaki Y, Kaneko F and Okamura H. Study on factors associated with changes in quality of life of demented elderly persons in group homes. Scandinavian Journal of Occupational Therapy 2005;12:4-9.

10. Moyle W, McAllister M, Venturato $L$ and Adams T. Quality of life and dementia: The voice of the person with dementia. Dementia 2007;6:175-191.

11. Bosboom PR, Alfonso $\mathrm{H}$ and Almeida OP. Determining the Predictors of Change in Quality of Life Selfratings and Carer-ratings for Community-dwelling People With Alzheimer Disease. Alzheimer Disease and Associated Disorders 2013;27:363-371.

12. Hoe J, Hancock G, Livingston G, et al. Changes in the quality of life of people with dementia living in care homes. Alzheimer Disease and Associated Disorders 2009;23:285-290.

13. Selwood A, Thorgrimsen $L$ and Orrell M. Quality of life in dementia. A one-year follow-up study. International Journal of Geriatric Psychiatry 2005;20:232-237.

14. Prince M, Ferri CP, Sousa R, et al. World Alzheimer Report 2009. London: Alzheimer's Disease International, 2009.

15. Walker A and Lowenstein A. European perspectives on quality of life in old age. European Journal of Ageing 2009;6:61-66.

16. Keating N and Gaudet N. Quality of life of persons with dementia. The Journal of Nutrition, Health \& Aging 2012;16:454-456.

17. Lawton MP. Quality of Life in Alzheimer Disease. Alzheimer Disease and Associated Disorders 1994;8:138150.

18. Clare L, Woods RT, Nelis SM, et al. Trajectories of quality of life in early-stage dementia: individual variations and predictors of change. International Journal of Geriatric Psychiatry 2013;29:616-623.

19. Verbeek H, Meyer G, Leino-Kilpi H, et al. A European study investigating patterns of transition from home care towards institutional dementia care: the protocol of a RightTimePlaceCare study. BMC Public Health 2012;12:68.

20. Molloy DW, Alemayehu E and Roberts R. Reliability of a Standardized Mini-Mental State Examination compared with the traditional Mini-Mental State Examination. American Journal of Psychiatry 1991;148:102-105.

21. OECD. The OECD Health Project. Long-term Care for Older People. Paris: OECD Publishing, 2005. 
22. Logsdon RG, Gibbons LE, McCurry SM and Teri L. Quality of life in Alzheimer's disease: patient and caregiver reports. Journal of Mental Health and Aging 1999;5:21-32.

23. Charlson ME, Pompei P, Ales KL and MacKenzie CR. A new method of classifying prognostic comorbidity in longitudinal studies: development and validation. Journal of Chronic Diseases 1987;40:373-383.

24. Katz S, Ford AB, Moskowitz RW, et al. Studies of Illness in the Aged. The Index of Adl: A Standardized Measure of Biological and Psychosocial Function. Journal of the American Medical Association 1963;185:914-919.

25. Alexopoulos GS, Abrams RC, Young RC and Shamoian CA. Cornell Scale for Depression in Dementia. Biological Psychiatry 1988;23:271-284.

26. Kaufer DI, Cummings JL, Ketchel P, et al. Validation of the NPI-Q, a brief clinical form of the Neuropsychiatric Inventory. Journal of Neuropsychiatry and Clinical Neurosciences 2000;12:233-239.

27. Aalten $\mathrm{P}$, de Vugt ME, Lousberg R, et al. Behavioral problems in dementia: a factor analysis of the neuropsychiatric inventory. Dementia and Geriatric Cognitive Disorders 2003;15:99-105.

28. Kat MG, De Jonghe JFM, Aalten P, et al. Neuropsychiatric symptoms of dementia: psychometric aspects of the Dutch version of the Neuropsychiatric Inventory (NPI). Tijdschrift voor Gerontologie en Geriatrie 2002;33:150-155.

29. Rikkert MG, Lauque S, Frolich L, et al. The practice of obtaining approval from medical research ethics committees: a comparison within 12 European countries for a descriptive study on acetylcholinesterase inhibitors in Alzheimer's dementia. European Journal of Neurology 2005;12:212-217.

30. Slaughter S, Cole D, Jennings E and Reimer MA. Consent and assent to participate in research from people with dementia. Nursing Ethics 2007;14:27-40.

31. Logsdon RG, Gibbons LE, McCurry SM and Teri L. Assessing quality of life in older adults with cognitive impairment. Psychosomatic Medicine 2002;64:510-519.

32. Norman GR, Sloan JA and Wyrwich KW. Interpretation of changes in health-related quality of life: the remarkable universality of half a standard deviation. Medical Care 2003;41:582-592.

33. Beerens HC, Sutcliffe C, Renom-Guiteras A, et al. Quality of Life and Quality of Care for People With Dementia Receiving Long Term Institutional Care or Professional Home Care: The European RightTimePlaceCare Study. Journal of the American Medical Directors Association 2014;15:54-61.

34. Field A. Correlation. In: Discovering Statistics Using SPSS. London: SAGE Publications Ltd, 2009.

35. Thorgrimsen L, Selwood A, Spector A, et al. Whose quality of life is it anyway? The validity and reliability of the Quality of Life-Alzheimer's Disease (QoL-AD) scale. Alzheimer Disease and Associated Disorders 2003;17:201-208.

36. Spector A, Thorgrimsen L, Woods B, et al. Efficacy of an evidence-based cognitive stimulation therapy programme for people with dementia: randomised controlled trial. The British Journal of Psychiatry 2003;183:248-254.

37. Woods B, Thorgrimsen L, Spector A, et al. Improved quality of life and cognitive stimulation therapy in dementia. Aging \& Mental Health 2006;10:219-226.

38. Folstein MF, Folstein SE and McHugh PR. Mini-Mental State: a practical method for grading the cognitive state of patients for the clinician. Journal of Psychiatric Research 1975;12:189-198.

39. Tombaugh TN and Mclntyre NJ. The mini-mental state examination: a comprehensive review. Journal of the American Geriatrics Society 1992;40:922-935.

40. Molloy DW and Standish TI. A guide to the standardized Mini-Mental State Examination. International Psychogeriatrics 1997;9:87-94.

41. Buntinx F, Niclaes L, Suetens C, et al. Evaluation of Charlson's comorbidity index in elderly living in nursing homes. Journal of Clinical Epidemiology 2002;55:1144-1147.

42. Brorsson B and Asberg KH. Katz index of independence in ADL. Reliability and validity in short-term care. Scandinavian Journal of Rehabilitation Medicine 1984;16:125-132.

43. Hamrin E and Lindmark B. Evaluation of functional capacity after stroke as a basis for active intervention. Scandinavian Journal of Caring Sciences 1988;2:113-122.

44. Barca ML, Engedal K and Selbaek G. A reliability and validity study of the cornell scale among elderly inpatients, using various clinical criteria. Dementia and Geriatric Cognitive Disorders 2010;29:438-447. 


\section{CHAPTER 4}

45. Mapi Research Institute. Linguistic validation of a Patient Reported Outcomes Measure. Lyon: Mapi Research Institute, 2002.

46. Conde-Sala JL, Turro-Garriga O, Garre-Olmo J, et al. Discrepancies Regarding the Quality of Life of Patients with Alzheimer's Disease: A Three-Year Longitudinal Study. Journal of Alzheimer's Disease 2013;39:511525.

47. Resnick B, Simpson M, Galik E, et al. Making a Difference: Nursing Assistants' Perspectives of Restorative Care Nursing. Rehabilitation Nursing 2006;31:78-86.

48. Littbrand $H$, Stenvall $M$ and Rosendahl E. Applicability and effects of physical exercise on physical and cognitive functions and activities of daily living among people with dementia: a systematic review. American Journal of Physical Medicine and Rehabilitation 2011;90:495-518.

49. Olazaran J, Reisberg B, Clare L, et al. Nonpharmacological therapies in Alzheimer's disease: a systematic review of efficacy. Dementia and Geriatric Cognitive Disorders 2010;30:161-178.

50. Potter R, Ellard D, Rees $K$ and Thorogood M. A systematic review of the effects of physical activity on physical functioning, quality of life and depression in older people with dementia. International Journal of Geriatric Psychiatry 2011;26:1000-1011.

51. Steele C, Rovner B, Chase GA and Folstein M. Psychiatric symptoms and nursing home placement of patients with Alzheimer's disease. American Journal of Psychiatry 1990;147:1049-1051.

52. Barca ML, Engedal K, Laks J and Selbaek G. A 12 months follow-up study of depression among nursinghome patients in Norway. Journal of Affective Disorders 2010;120:141-148.

53. Payne JL, Sheppard JM, Steinberg M, et al. Incidence, prevalence, and outcomes of depression in residents of a long-term care facility with dementia. International Journal of Geriatric Psychiatry 2002;17:247-253.

54. Scocco P, Rapattoni $M$ and Fantoni G. Nursing home institutionalization: a source of eustress or distress for the elderly? International Journal of Geriatric Psychiatry 2006;21:281-287.

55. Afram B, Stephan A, Verbeek H, et al. Reasons for institutionalization of people with dementia: informal caregiver reports from 8 European countries. Journal of the American Medical Directors Association 2014;15:108-116.

56. Gomez-Gallego M, Gomez-Amor J and Gomez-Garcia J. Determinants of quality of life in Alzheimer's disease: perspective of patients, informal caregivers, and professional caregivers. International Psychogeriatrics 2012;24:1805-1815. 


\section{CHAPTER 5}

Daily lives of residents with dementia in nursing homes:

Development of the Maastricht Electronic Daily Life

Observation Tool
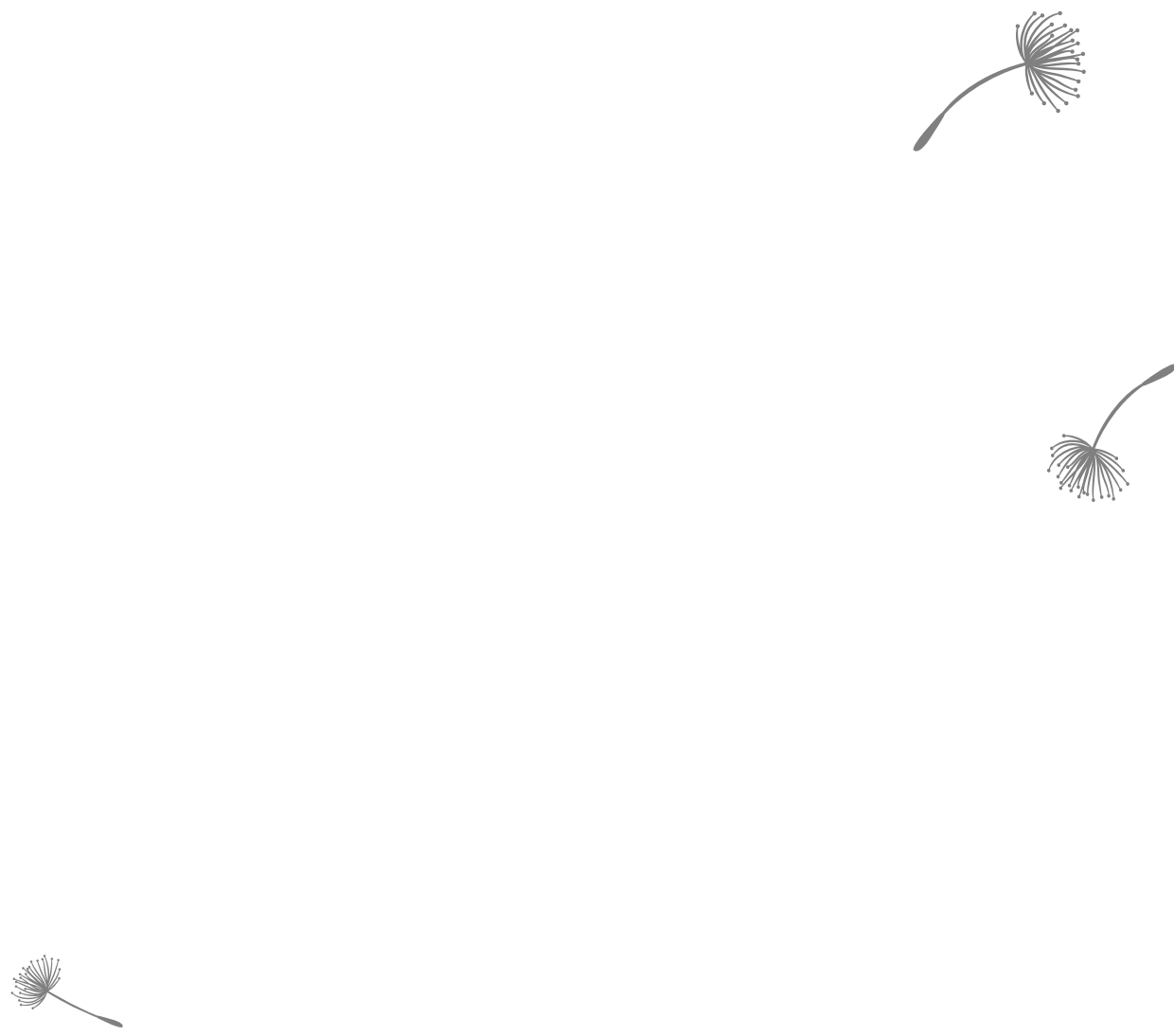

This chapter was published as:

De Boer B, Beerens HC, Zwakhalen SMG, Tan FES, Hamers JPH, Verbeek H. Daily lives of people with dementia: development of the Maastricht Electronic Daily Life Observation tool. International Psychogeriatrics 2016. doi: 10.1017/S1041610216000478. 


\section{CHAPTER 5}

\section{ABSTRACT}

Background: Daily life is a dynamic and multidimensional concept, for which appropriate assessment tools are lacking. This study describes the development of the Maastricht Electronic Daily Life Observation tool (MEDLO-tool), a freely accessible, easy to use, electronic observation tool to assess relevant daily life aspects for nursing home residents with dementia.

Methods: 1) determining relevant aspects of daily life for nursing home residents with dementia based on a literature search and expert interviews; 2) pilot testing observation procedures and operationalizations of the aspects of daily life; and 3) exploring inter-rater reliability and feasibility of the tool in a nursing home facility with 16 residents (56\% female, mean age: 77 ).

Results: Four aspects of daily life are assessed with the MEDLO-tool: 1) activity (activity performed by resident, engagement in this activity and the degree of physical effort); 2) physical environment (location of the resident and interaction with the physical environment); 3) social interaction (the level and type of social interaction, and with whom this social interaction took place) and 4) emotional well-being (mood and agitation). Each aspect of daily life is observed and scored using standardized scoring options. Agreement on the aspects is high with an average absolute agreement of $86 \%$. Users of the MEDLO- tool indicated that it was feasible in practice and contained clear operationalizations of the aspects of daily life.

Conclusion: The MEDLO- tool is a promising tool to gain real time insights into the aspects of the daily lives of nursing home residents with dementia. 


\section{INTRODUCTION}

Studies report that nursing home residents with dementia spend the majority of their daily life doing little or nothing and remain in their rooms sitting alone most of the time. ${ }^{1,2}$ Having something to do, however, is important for residents of nursing homes because it allows them to connect with other people and to experience feelings of pleasure. ${ }^{3}$ Participation in activities is an important indicator of nursing home quality and one of the basic human needs. ${ }^{4}$ Furthermore, being engaged in activities allows people to express themselves, ${ }^{3}$ and is associated with a higher quality of life of nursing home residents with dementia. ${ }^{5}$

Daily life is a dynamic and multidimensional concept, and constitutes more than activities alone. The physical and social environments of nursing homes are also important for the daily lives of their residents because they can influence agency: a person's capacity to act in the world. For example, moderate levels of sound or the presence of a small group of people can act as facilitators for engagement in activities. ${ }^{6}$ Furthermore, the provision of outdoor areas can also accommodate activities and may decrease agitation and increase physical effort of residents. ${ }^{7}$

In both clinical practice and research, the concept of person-centered care is advocated as a way to provide high quality of care. ${ }^{8}$ A 'one size fits all' approach is not suitable for interventions targeted at nursing home residents with dementia due to differences in cognitive and functional dependency among residents. ${ }^{9}$ Therefore, insight is needed into the needs, possibilities, and environmental aspects that are important for individual nursing home residents. Gaining insights into the daily lives of residents allows nursing home staff and researchers to tailor interventions for individuals by targeting the relevant aspects of daily life.

How can daily life situations of nursing home residents with dementia be measured?

Observing nursing home residents with dementia in their daily lives allows researchers to consider several aspects of daily life simultaneously. In contrast to other measurement methods such as questionnaires, observation offers the opportunity to record the activities of residents with dementia in real time in relation to contextual factors. Furthermore, observing experiences or behaviors within the context that they naturally occur, provides a more representative assessment than a single static snapshot of time. ${ }^{10}$ Such an examination of sequences of events and experiences can be referred to as ecological momentary assessment (EMA). EMA enable investigators to describe and analyze interactions between events that shape behavior over periods of minutes, hours, or days. ${ }^{10}$ In addition, electronic devices such as handheld computers or tablets allow more observations within the same time period than pen and paper and process the observation data more efficiently. ${ }^{11}$ 


\section{CHAPTER 5}

Few electronic observation tools have been reported that aim to study daily life in long-term care. A review conducted by Curyto et al. (2008) examined direct observation methods of behavior in people with dementia. They discuss over thirty-five observation tools, however, all these tools focus on one or two aspects of daily life only and do not incorporate multiple aspects to describe daily life completely. ${ }^{12}$ In addition, a freely accessible, easy to use, electronic observation tool to assess the daily lives of nursing home residents with dementia is lacking. The observation tools that have been reported show limitations in assessing aspects of daily life for nursing home residents with dementia. ${ }^{6,13,14}$ First, most existing tools do not cover the simultaneous observation of a variety of aspects of daily life (e.g. activities and social, psychological, and environmental aspects). As a result, they do not provide comprehensive insights into all the complex facets of daily life. Second, most tools are used only to observe residents within the communal living room or only during certain parts of the day and therefore miss important data. Third, existing tools require extensive training, separate licenses, and are designed to record observations using pen and paper. This makes data collection and analyses time consuming and expensive.

The aim of the current study was to develop a freely accessible, easy to use, electronic observation tool that provides a full and extensive description of the daily lives of nursing home resident with dementia. The goals were that the tool: a) allows researchers to assess multiple aspects of daily life simultaneously, b) can be used in multiple nursing home areas easily and c) provides an efficient way of data processing by using electronic devices to carry out the observations. The current paper describes the development process of the Maastricht Electronic Daily Life Observation tool (MEDLO-tool), including reliability and feasibility testing.

\section{METHODS}

To develop the MEDLO-tool, three steps were taken: 1) determining relevant aspects of daily life for nursing home residents with dementia; 2) determining observation procedure and operationalizations of the aspects of daily life; and 3) testing the final version of the MEDLO-tool. Steps were based on the development of other observation tools. ${ }^{11}$ The study protocol was reviewed by the medical ethics committee of the Maastricht University Medical Center. They declared that the study was non-invasive for nursing home residents with dementia according to the Medical Research Involving Human Subjects Act. The participating nursing homes provided informed consent for participation. All data were collected anonymously. 


\section{Determining relevant aspects of daily life for nursing home residents with dementia}

To take face- and content validity into account, the aspects of daily life which are important for nursing home residents with dementia were determined based on multiple sources. First, a literature search was conducted to determine relevant aspects of daily life. Pubmed, Web of Science, PsycINFO, and Google Scholar were searched. Search terms included 'daily life', 'meaningful activity', 'observation', 'nursing home care', 'dementia', and 'aspects of daily life'. To find additional relevant literature, snowballing techniques were used and grey literature was studied. The literature search revealed a list of important aspects of daily life. Next, experts were consulted individually and in groups to discuss relevant aspects of daily life, they were free to suggest as many aspects of daily life as they wanted. The participants included experts in the field of research ( $n=10$; background in psychology, architecture, nursing home care, nursing science, and occupational science) and professionals in dementia care ( $n=8$; nursing staff, managers of Dutch nursing home wards/ living facilities for people with dementia). All had at least a Bachelor's degree. When they had no further suggestions, they were told which aspects were found based on the literature and were then asked whether they agreed that these are indeed important and whether something was missing.

\section{Pilot testing observation procedures and operationalizations of the aspects of daily life}

To determine the observation procedure using the MEDLO-tool, the following factors were taken into account: the number of people that can be observed at the same time using the MEDLO-tool, the amount of time needed to do an observation, the areas in which the residents are going to be observed, observer fatigue, the sampling method (instantaneous or continuous), and the software and hardware needed for observations (e.g. whether observations could be carried out using standard tablets). Decisions regarding these factors were made based on the literature and by testing preliminary versions of the tool in practice. Completeness and feasibility of the tool were the main criteria guiding the decision process.

To determine the operationalizations of the relevant aspects of daily life, existing observation tools were reviewed. Several operationalization methods and procedures were tested and adapted in practice. Every adaptation was tested and re-adjusted if necessary. Following earlier observation research, ${ }^{15}$ several steps were taken to decide which operationalizations and procedures should be used. First, one researcher (BB) tested different observation procedures (e.g. ten, twenty or thirty minute observation periods, and instantaneous versus continuous sampling) and operationalizations (e.g. using a six- or a sevenpoint scale for mood) for approximately eight hours. Second, two researchers (BB and HB) 
tested preliminary versions of the tool in two different types of nursing homes (smallscale, homelike and large-scale traditional) for eight hours in total. This was done in order to check if there was agreement between observers and to see if the tool could be used in a variety of nursing home settings. If there was disagreement between the observers on how to score certain situations, discussions were held with a third researcher (HV) until agreement was reached. After five alterations, the MEDLO-tool was finalized. Parallel to the alterations a manual was written with descriptions of the full observation procedure and the operationalizations of all aspects of daily life.

\section{Testing the final version of the MEDLO-tool}

The reliability of the MEDLO-tool was tested by carrying out anonymous observations in a convenience sample at a nursing home ward providing care for 16 residents. To assess inter-rater reliability, two researchers carried out observations simultaneously of a random selection of eight residents independently for 56 observations in total (7 observations per resident). Agreement was assessed by calculating absolute agreement percentages and (weighted) kappa values. For some aspects of daily life (activity, location, social interaction with whom and interaction with the physical environment) the 'standard' kappa was calculated, as these aspects do not have a hierarchical structure but are strictly categorical (the difference between activity 1 and 3 is the same as the difference between activity 1 and 22). However, for other aspects of daily life (engagement, degree of social interaction, type of social interaction, physical effort, mood and agitation) there is a hierarchical structure in the scoring options. For example, the difference between mood scores 1 and 5 is larger (4) than the difference between mood scores 1 and 2 (1). The relative distance between 2 successive scoring options for all these aspects was always equal to 1 . This means that for example scoring options ' 1 ' and ' 3 ' had a relative distance of 2 . Therefore, weighted kappa values were calculated to take the relative distances between scoring options into account. The minimum absolute agreement was determined to be $80 \% .{ }^{16}$ The kappa values were assessed as slight $(0.01-$ $0.20)$, fair (0.21-0.40), moderate (0.41-0.60), substantial (0.61-0.80), or almost perfect (0.81-0.99) agreement. ${ }^{17}$ Resident characteristics and information on cognition and independence in activities of daily living (ADL) were collected at ward level via the nursing staff. This means that data were gathered anonymously and reported on an aggregated level instead of on an individual level. Cognition of the residents was assessed with the Cognitive Performance Scale (CPS). ${ }^{18}$ The total score of the CPS ranges from 0 to 6, with lower scores indicating better cognition. ADL independency was measured with the Activities of Daily Living - Hierarchy scale (ADL-H). ${ }^{19}$ The total score of the ADL$\mathrm{H}$ ranges from 0 to 6 , with lower scores indicating more independence in activities of daily living.

The feasibility of the MEDLO-tool was assessed by a short questionnaire, filled out by three research assistants who were trained to use the MEDLO-tool. Training observers 
to use the MEDLO-tool went as follows: First, the research assistants studied the observation manual and the app for approximately two hours. Next, they joined the main researcher for three observation periods of four hours in which they practiced the observations. After each of these 3 observation periods the observations were evaluated for 2 hours each.

The questionnaire addressed several feasibility aspects such as 1) the use of the hardware and software; 2) the practical use of the MEDLO-tool (e.g. operationalization, observer fatigue); 3) the completeness of the tool; and 4) grading the overall feasibility of the MEDLO-tool with a possible score between one and ten, with ten being the highest (completely feasible). In addition, respondents had the opportunity to add other comments.

\section{RESULTS}

Table 1 gives an overview of the aspects of daily life that are included in the MEDLOtool, their operationalization and their theoretical / empirical base.

\section{Determining relevant aspects of daily life for nursing home residents with dementia}

Based on findings from the literature and consultations with the experts $(n=18)$, the following aspects of daily life were included in the MEDLO-tool:

Activity: the activity performed by or occurring in the immediate environment of the resident (e.g. eating, household chores, playing a game), the engagement in this activity (e.g. active engagement in activity, no engagement in activity), and the degree of physical effort (e.g. lying, sitting, standing, walking, etc.).

- Physical environment: the location of the resident (e.g. communal area, own room, outside, etc.), and whether he or she has interaction with the physical environment. $^{20}$

- Social interaction: the level of social interaction (e.g. talking with one, two or more persons), the type of social interaction, ${ }^{21}$ and with whom this social interaction takes place (e.g. other residents, family, etc.).

- Emotional well-being: mood - including both positive and negative mood - and agitation were considered most relevant aspects of emotional well-being in daily life. The mood scale is based on Kitwood's model of person-centered care, ${ }^{13}$ and Dementia Care Mapping. ${ }^{16}$ The agitation scale (e.g. no, small or extreme signs of agitation) is based on the Pittsburgh Agitation Scale. ${ }^{22}$

Based on the expert's advice, the possibility to make field notes was added in case events occurred that could not be covered by the aspects of daily life in the MEDLOtool. No other aspects were suggested by the experts. 
Table 1. MEDLO-tool aspects of daily life, operationalizations, and theoretical/empirical base

\begin{tabular}{|c|c|c|c|c|c|}
\hline $\begin{array}{l}\text { Aspects of } \\
\text { daily life }\end{array}$ & $\begin{array}{l}\text { Operationali- } \\
\text { zation }\end{array}$ & \multicolumn{3}{|l|}{ Scoring options } & Based on... \\
\hline \multicolumn{6}{|l|}{ Activity } \\
\hline $\begin{array}{l}\text { Activity that is } \\
\text { being } \\
\text { performed by } \\
\text { resident or is } \\
\text { occurring in } \\
\text { vicinity }\end{array}$ & $\begin{array}{l}32 \text { category } \\
\text { options }\end{array}$ & $\begin{array}{l}\text { - Household chores } \\
\text { - Cooking } \\
\text { - Sports } \\
\text { - Dancing } \\
\text { - Spiritual activity } \\
\text { - Crafts/arts } \\
\text { - Music/singing } \\
\text { - Excursion or shopping } \\
\text { - Walking outside } \\
\text { - Playing cards/a } \\
\text { game/puzzles } \\
\text { - Reading/writing/ } \\
\text { crossword } \\
\text { - Talking groups } \\
\text { - Using the computer } \\
\text { - Sensory stimulation }\end{array}$ & $\begin{array}{l}\text { - } \text { Eating/drinking } \\
\text { - } \text { Beauty activity } \\
\text { - Speaking with } \\
\text { others/having a } \\
\text { chat } \\
\text { - } \text { Making a } \\
\text { telephone call } \\
\text { - Pets } \\
\text { - Helping others } \\
\text { - Watching } \\
\text { television/listeni } \\
\text { ng to radio } \\
\text { - Outing with } \\
\text { family or others } \\
\text { outside facility } \\
\text { - Farming activities }\end{array}$ & $\begin{array}{l}\text { - Gardening and } \\
\text { caring for plants } \\
\text { - Walking } \\
\text { - Sitting/lying } \\
\text { - Resting or } \\
\text { sleeping } \\
\text { - Visit } \\
\text { (para)medical } \\
\text { personnel } \\
\text { - (Self-)care } \\
\text { activities } \\
\text { - Purposeless } \\
\text { (repetitive) } \\
\text { behavior } \\
\text { - Not observable } \\
\text { - Other }\end{array}$ & $\begin{array}{l}\text { Literature, } \\
\text { 11, 23-29 expert } \\
\text { opinion and } \\
\text { pilot testing }\end{array}$ \\
\hline $\begin{array}{l}\text { Engagement } \\
\text { in activity }\end{array}$ & $\begin{array}{l}5 \text { category } \\
\text { options }\end{array}$ & $\begin{array}{l}\text { - Active engagement (pa } \\
\text { - Passive engagement (fo } \\
\text { - Engagement with some } \\
\text { - Not engaged (gazing wi } \\
\text { - Not engaged (sleeping) }\end{array}$ & $\begin{array}{l}\text { rticipating in activity } \\
\text { ocus on activity) } \\
\text { ething else } \\
\text { ithout focus) }\end{array}$ & & $\begin{array}{l}\text { Literature, } \\
\text { 30, }{ }^{11} \text { expert } \\
\text { opinion and } \\
\text { pilot testing }\end{array}$ \\
\hline Physical effort & $\begin{array}{l}7 \text { category } \\
\text { options }\end{array}$ & $\begin{array}{l}\text { - Lying or sitting without } \\
\text { sleeping) } \\
\text { - Sitting quietly (resident } \\
\text { - Light-to-moderate sittir } \\
\text { - Standing or light-standi } \\
\text { - Standing activity or wal } \\
\text { - Walking activity or cycli } \\
\text { - Whole-body movement }\end{array}$ & $\begin{array}{l}\text { movements (residen } \\
\text { is awake) } \\
\text { ng activity } \\
\text { ing activity } \\
\text { Iking around } \\
\text { ing } \\
\text { its }\end{array}$ & nt is gazing or & $\begin{array}{l}\text { Literature, } \\
32 \text { expert } \\
\text { opinion and } \\
\text { pilot testing }\end{array}$ \\
\hline \multicolumn{6}{|c|}{ Physical environment } \\
\hline Location & $\begin{array}{l}5 \text { category } \\
\text { options }\end{array}$ & $\begin{array}{l}\text { - Communal area on the } \\
\text { - Own room } \\
\text { - Communal area off the } \\
\text { - Bathroom/toilet } \\
\text { - Outside }\end{array}$ & ward & & $\begin{array}{l}\text { Literature, } \\
24 \\
\text { expert } \\
\text { opinion and } \\
\text { pilot testing }\end{array}$ \\
\hline $\begin{array}{l}\text { Interaction } \\
\text { with the } \\
\text { physical } \\
\text { environment }\end{array}$ & $\begin{array}{l}2 \text { category } \\
\text { options }\end{array}$ & $\begin{array}{l}\text { - No interaction with the } \\
\text { - Yes, intentional handlin } \\
\text { towards or other use of } \\
\text { environmental features }\end{array}$ & $\begin{array}{l}\text { physical environmer } \\
\text { f, holding, manipula } \\
\text { freestanding physic }\end{array}$ & $\begin{array}{l}\text { nt } \\
\text { ation, attention } \\
\text { cal objects or fixed }\end{array}$ & $\begin{array}{l}\text { Literature, }^{20,} \\
{ }^{33-36} \text { expert } \\
\text { opinion and } \\
\text { pilot testing }\end{array}$ \\
\hline
\end{tabular}




\begin{tabular}{|c|c|c|c|}
\hline $\begin{array}{l}\text { Aspects of } \\
\text { daily life }\end{array}$ & $\begin{array}{l}\text { Operationali- } \\
\text { zation }\end{array}$ & Scoring options & Based on... \\
\hline \multicolumn{4}{|c|}{ Social environment } \\
\hline $\begin{array}{l}\text { Level of social } \\
\text { interaction }\end{array}$ & $\begin{array}{l}5 \text { category } \\
\text { options }\end{array}$ & $\begin{array}{l}\text { - No social interaction } \\
\text { - Resident attempts to interact, gets no response } \\
\text { - Environment attempts to interact, but resident does not } \\
\text { respond } \\
\text { - Interaction with someone else } \\
\text { - Interaction with two or more people }\end{array}$ & $\begin{array}{l}\text { Expert } \\
\text { opinion and } \\
\text { pilot testing }\end{array}$ \\
\hline $\begin{array}{l}\text { Type of social } \\
\text { interaction of } \\
\text { environment } \\
\text { towards } \\
\text { resident }\end{array}$ & $\begin{array}{l}5 \text { category } \\
\text { options }\end{array}$ & $\begin{array}{l}\text { - Negative restrictive (interactions that oppose or resist } \\
\text { resident's freedom of action without good reason, or ignore } \\
\text { resident as a person) } \\
\text { - Negative protective (providing care, keeping safe or removing } \\
\text { from danger in a restrictive manner without explanation or } \\
\text { reassurance) } \\
\text { - Neutral (brief, indifferent interactions) } \\
\text { - Positive care (interactions during the appropriate delivery of } \\
\text { care) } \\
\text { - Positive social (interactions principally involving 'good, } \\
\text { constructive, beneficial' conversation and companionship) }\end{array}$ & $\begin{array}{l}\text { Literature, } \\
21,37 \text { expert } \\
\text { opinion and } \\
\text { pilot testing }\end{array}$ \\
\hline $\begin{array}{l}\text { Social } \\
\text { interaction } \\
\text { with whom }\end{array}$ & $\begin{array}{l}5 \text { category } \\
\text { options }\end{array}$ & $\begin{array}{l}\text { - Personnel } \\
\text { - Other residents } \\
\text { - Family and/or friends } \\
\text { - Others } \\
\text { - Combination of the above }\end{array}$ & $\begin{array}{l}\text { Expert } \\
\text { opinion and } \\
\text { pilot testing }\end{array}$ \\
\hline \multicolumn{4}{|c|}{ Emotional well-being } \\
\hline Mood & $\begin{array}{l}7 \text { point Likert } \\
\text { scale }\end{array}$ & $\begin{array}{l}\text { 1. Great signs of negative mood } \\
\text { 2. Considerable signs of negative mood } \\
\text { 3. Small signs of negative mood, discomfort or boredom } \\
\text { 4. Neutral: no positive or negative mood observable, e.g. gazing or } \\
\text { sleeping } \\
\text { 5. Contentment and small signs of well being } \\
\text { 6. Considerable positive mood } \\
\text { 7. Very high positive mood }\end{array}$ & $\begin{array}{l}\text { Literature, } \\
13,16,38 \\
\text { expert } \\
\text { opinion and } \\
\text { pilot testing }\end{array}$ \\
\hline Agitation & $\begin{array}{l}5 \text { point Likert } \\
\text { scale }\end{array}$ & $\begin{array}{l}\text { Definition of agitation: the presence of aberrant vocalization, } \\
\text { motor agitation, aggressiveness or resisting care } \\
\text { Levels: } \\
\text { 1. Not present } \\
\text { 2. Low volume, not disruptive in milieu / pacing or moving about } \\
\text { in chair at normal rate / verbal threats / procrastination or } \\
\text { avoidance } \\
\text { 3. Louder than conversational, mildly disruptive / increased rate of } \\
\text { movements / threatening gestures / verbal or gesture of refusal } \\
\text { 4. Loud and disruptive / rapid movements / physical towards } \\
\text { property / pushing away to avoid task } \\
\text { 5. Extremely loud, highly disruptive / intense movements / } \\
\text { physical towards self or others / striking out at caregiver }\end{array}$ & $\begin{array}{l}\text { Literature, }^{11,} \\
22 \text { expert } \\
\text { opinion and } \\
\text { pilot testing }\end{array}$ \\
\hline
\end{tabular}




\section{CHAPTER 5}

2. Pilot testing observation procedures and operationalizations of the aspects of daily life

\section{Observation Procedure}

The MEDLO-tool is a tablet-based observation tool. It can be run using the app e-Droidcell Pro, which is able to run Microsoft Excel (.xls) files. The Excel files consist of observation schemes and include drop down boxes for each of the observed aspects of daily life. In addition, it is possible to make field notes in case events occurred that cannot be covered by the aspects of daily life from the MEDLO-tool. Furthermore, there is room for questions and remarks that need to be discussed with fellow colleagues. Figure 1 shows the observation displayed on the tablet.

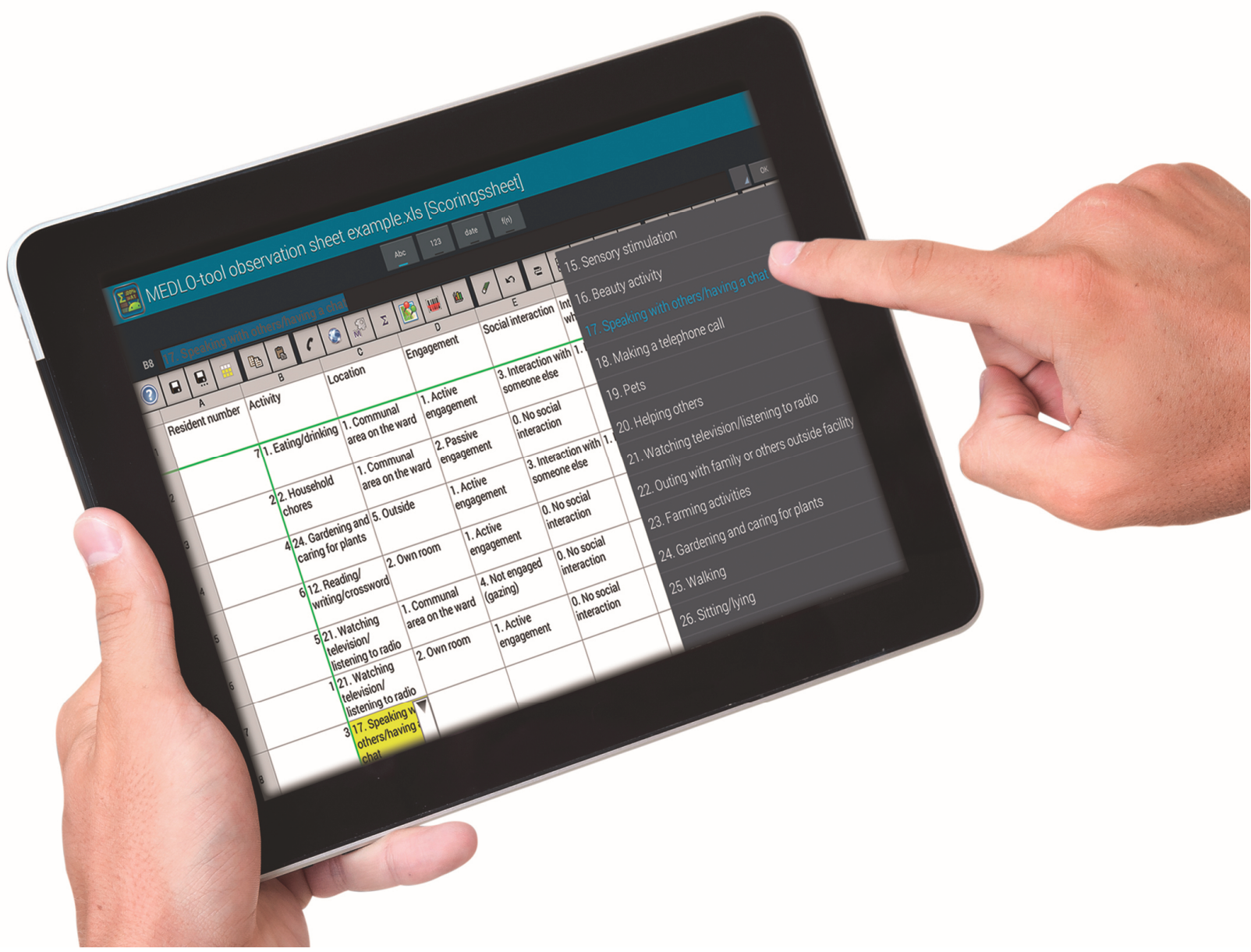


An instantaneous sampling procedure was chosen to obtain insights into the daily lives of nursing home residents. Observations are performed systematically at preselected moments, and each resident can be observed once during an observation period. Instantaneous sampling can give a good approximation of the proportion of time spent carrying out certain behaviors if an observation day consists of multiple observation periods. ${ }^{39}$

Pilot testing showed that it often was not possible to observe eight residents (the number of residents living together in a small-scale facility) within a 10 minute observation period while 30 minutes too long. Based on this it was decided 20 minutes is an appropriate amount of time for an observation period to observe eight residents. During an observation period, the researcher observes a resident for one minute during which all aspects of daily life are noted in the observation scheme. The researcher then continues to the next resident. To prevent bias due to order- effect, the order of observations of residents within an observation period needs to be randomized in advance. Entering the scores on the tablet takes approximately one minute per resident. In addition, time is reserved for the observer to find the next resident. As the MEDLO-tool highly portable and can therefore be used to observe not only in communal areas, but to observe residents outside these areas as well. As a result, activities outside the communal area are captured. Privacy of residents is taken into account: when the door of their bedroom or bathroom is closed, they are not observed.

Figure 2 provides an overview of how the MEDLO-tool can be used on an observation day. To prevent observer fatigue, researchers should not observe longer than four hours per day. Observation days should also include breaks: after two hours, a half hour break is recommended. In order to increase the reliability of measurements, the observations and interpretations of situations should be discussed weekly with other observers.

\begin{tabular}{ll}
\hline OBSERVATION DAY (observations of eight residents in randomized order) \\
\hline Hour 1 & Observation period 1 (20 minutes): 1 observation per resident \\
& Observation period 2 (20 minutes): 1 observation per resident \\
& Observation period 3 (20 minutes): 1 observation per resident \\
Hour 2 & Observation period 4 (20 minutes): 1 observation per resident \\
& Observation period 5 (20 minutes): 1 observation per resident \\
BREAK (30 minutes) & Observation period 6 (20 minutes): 1 observation per resident \\
Hour 3 & Observation period 8 (20 minutes): 1 observation per resident \\
& Observation period 9 (20 minutes): 1 observation per resident \\
Hour 4 & Observation period 10 (20 minutes): 1 observation per resident \\
& Observation period 11 (20 minutes): 1 observation per resident \\
& Observation period 12 (20 minutes): 1 observation per resident \\
\hline
\end{tabular}

Figure 2. Overview of the observation procedure on one observation day 
Operationalization of the aspects of daily life

Based on pilot testing by two researchers adjustments in operationalizations were made to increase agreement. As can be seen in Table 1, the aspects of daily life are scored as categories (activity performed by resident, engagement, location, interaction with the physical environment, level and type of social interaction, interaction with whom) or according to Likert scales (physical effort, mood, agitation). The following operationalization was determined. First, the activity that the resident is performing or that occurs in the immediate environment of the resident is scored. There are 31 options to choose from (see Table 1). The option 'other' can be chosen if the activity that is observed is not covered by the pre-defined activity options. The observer always chooses one activity based on operational rules described below. The rules should be applied one at a time, beginning with the first rule and working through rule 2, 3, and 4 until a decision can be made.

1. The most meaningful activity is chosen (e.g. 'having a chat' is more meaningful than 'sitting/lying').

2. If two meaningful activities take place, the one with the longest duration is chosen.

3. If both have the same duration, the one which had the most influence on the residents' well-being is chosen.

4. If it is still unclear which activity to choose, field notes are made to describe the situation and a decision is made based on a discussion with the research team.

Second, engagement is scored by choosing one of five categories ranging from not engaged (sleeping) to active engagement. Third, the degree of physical effort of the residents is scores. The observer chooses between seven categories ranging from 'lying or sitting without movement' to 'whole body movements'. Fourth, the observer scores where the resident is located. The options are communal area on the ward, own room, communal area off the ward, bathroom/toilet, and outside. Fifth, the interaction with the physical environment was scores as yes or no. Interaction with the physical environment is defined as whether residents perform any form of intentional handling, holding, manipulation, attention towards or other use of freestanding physical objects or fixed environmental features. ${ }^{20}$ Sixth, the level of social interaction is scored by choosing from five categories ranging from no social interaction to interaction with two or more people. Seventh, with whom the interaction takes place is scored. Eighth, the type of social interaction is scored. The type of social interaction ranges from negative restrictive to positive social (based on the quality of interactions schedul ${ }^{21}$ ). Ninth, mood is assessed using a 7-point Likert scale ranging from 1 (great signs of negative mood) to 7 (very high positive mood). Initially, in line with Dementia Care Mapping, ${ }^{16}$ only 6 scoring options were used. However, a neutral scoring option had been missed and was therefore added to the scale. ${ }^{38}$ Tenth, the presence of agitation (aberrant vocalization, motor agitation, aggressiveness, or resisting care ${ }^{22}$ ) is scored on a 5-point scale ranging from 'not present' to 'extremely present'. Finally, the observer has the option to make field notes during the observations in case events occurred that could 
not be covered by the aspects of daily life in the MEDLO-tool. These field notes can be about organizational, social, or physical environmental factors as well as any prominent deviations from the 'normal' situation. Furthermore, there is room for questions and remarks that need to be discussed with fellow colleagues.

Figure 3 shows an example of a daily life situation and demonstrates how the observer scores all aspects of daily life using the MEDLO-tool. The manual of the MEDLOtool is available upon request. 


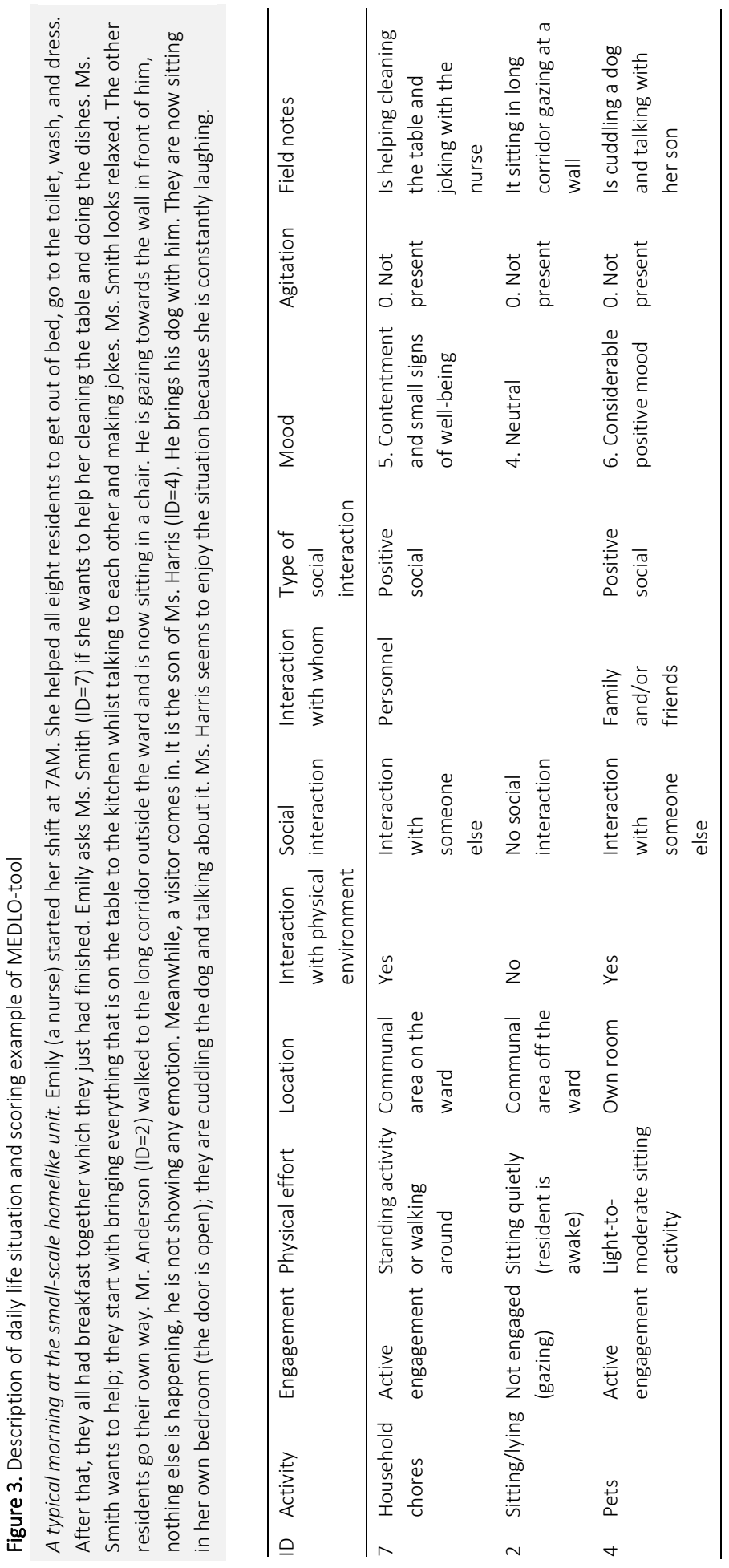




\section{Testing the final version of the MEDLO-tool}

The final version of the MEDLO-tool was tested in a nursing home ward in the Netherlands. The residents $(n=16)$ had a mean age of 77 and $56 \%$ were women. They had a mean ADL-H score of 3.8 (range 0-6) and a mean CPS score of 3.5 (range 0-6), indicating extensive functional dependence and moderate to severe cognitive impairment. Table 2 provides information regarding the inter-rater reliability of the MEDLO-tool. Agreement levels on the aspects of the MEDLO-tool are positive with an average absolute agreement of $86 \%$. Kappa values were low for 'type of social interaction' and 'mood' had low kappa values. Regarding 'type of social interaction', the low kappa values may have arisen because there were very few data for this aspect of daily life. Often no social interaction at all was scored (63\%) and consequently also no type of social interaction. For 'mood', one option (contentment and small signs of well-being) was scored in most instances (70\%). Disagreement in only a few cases caused a large decline in the kappa value. Further investigation showed that a difference of two or more points on the mood scale occurred in only $5.5 \%$ of the cases.

Table 2. Inter-rater reliability of the MEDLO-tool

\begin{tabular}{lllll}
\hline Aspect of daily life & $\begin{array}{l}\text { Absolute } \\
\text { agreement (\%) }\end{array}$ & Kappa & $\begin{array}{l}\text { Standard error } \\
\text { 95\% confidence } \\
\text { interval }\end{array}$ \\
\hline Activity & 90.7 & 0.9 & 0.05 & $0.79-0.99$ \\
Location & 100 & 1 & 0.00 & - \\
Engagement & 82.1 & 0.8 (weighted kappa) & 0.07 & $0.68-0.96$ \\
Degree of social interaction & 88.4 & 0.8 (weighted kappa) & 0.07 & $0.69-0.99$ \\
Social interaction with whom & 92.9 & 0.9 & 0.10 & $0.68-1$ \\
Type of social interaction & 55.6 & 0.5 (weighted kappa) & 0.21 & $0.10-0.90$ \\
Interaction with physical & 92.1 & 0.8 & 0.12 & $0.53-1$ \\
environment & & 0.9 (weighted kappa) & 0.04 & $0.89-1$ \\
Physical effort & 97.4 & 0.5 (weighted kappa) & 0.12 & $0.23-0.70$ \\
Mood & 69.4 & 0.8 (weighted kappa) & 0.08 & $0.62-0.94$ \\
Agitation & 93.2 & & & \\
\hline
\end{tabular}

\section{Feasibility}

The respondents completing the questionnaire $(n=3)$ all had at least a Master's degree. They were trained by the main researcher $(B d B)$ to conduct observations using the MEDLO tool. No difficulties in using the hardware and software were experienced. In addition, the practical use of the tool and its operationalization were clear. One user indicated that the observations and weekly discussions were quite time consuming. The users suggested that observer fatigue might result when the tool was intensively used for several mornings, afternoons and evenings for a long period of time. With respect to 
the completeness of the tool, the respondents indicated that the activity 'smoking' was missing as an activity option. In addition, the presence of visitors (family, friends) could be added to the MEDLO-tool. Two users graded the overall feasibility of the MEDLO-tool with an eight, one with a seven.

Overall, the observers were positive about the feasibility of the MEDLO-tool as an instrument to assess the daily lives of nursing home residents with dementia. One user answered: 'I think the observation method is a thorough method to collect detailed information about the daily lives of people with dementia. It seems very reliable because it-in contradiction to questionnaires-does not rely on retrospective assessments but on real time occurrences'. Another user considered the MEDLO-tool to be 'a good instrument which I would recommend other researchers to use'.

\section{DISCUSSION}

The current study described the development and pilot testing of the Maastricht Electronic Daily Life Observation (MEDLO) tool). The MEDLO-tool is an electronic, freely accessible tool that can be used to provide a full and extensive description of the daily life context of nursing home residents with dementia. First results indicate that the MEDLO-tool is a reliable and feasible tool to assess multiple aspects of daily life related to activity, physical environment, social interaction and emotional well-being simultaneously. By using tablets, observers are flexible to assess nursing home residents in the entire nursing home environment easily. This gives a more complete view of the daily lives than only observing them in the communal living room. Furthermore, the MEDLOtool has an efficient data processing system by using apps and tablets, which are compatible with statistical software. This prevents the time-consuming process of transferring the observation data for statistical analyses.

Some study limitations have to be acknowledged. First, this study focused on the development of the tool and first testing of reliability and validity. Therefore, some important aspects of the validity remain unknown, for example the construct validity. This requires further investigation. Second, the feasibility questionnaire was filled out by three assistants working in the same research team as the main researcher. Although they were able to freely answer in detail and clarify their responses, social desirability of their answers cannot be ruled out. Therefore, and for the further development of the tool we advise other (independent) researchers to use the tool and investigate feasibility as well.

Evidence indicates that nursing home residents with dementia perceive activities as meaningful if they experience feelings of pleasure during the activities, and if they are connected to other people., ${ }^{30,41}$ Research suggests that these aspects are also related to quality of life. ${ }^{5}$ The MEDLO-tool can be used to investigate whether activities are accompanied by active engagement, a positive mood, and social interaction, as it as- 
sesses all these aspects simultaneously in the context of everyday life. For example, the activity 'watching television' can be meaningful for nursing home residents with dementia when it matches their personal identity or when it is accompanied by feelings of pleasure and social interaction. ${ }^{40,41}$ However, it can also be accompanied by sleeping. The MEDLO addresses all these various aspects of daily life (i.e. activities, engagement, emotional well-being) simultaneously. This provides insight in possible associations between aspects of resident's daily life and their quality of life. ${ }^{42}$

A range of innovative nursing home initiatives has been developed, focusing on providing person-centered care in a small-scale and homelike environment. ${ }^{43}$ They aim to provide more meaningful activities for residents in comparison with traditional nursing homes. ${ }^{29}$ The MEDLO-tool could be a valuable tool to evaluate the nursing home environment and compare the daily lives of residents with dementia cross different settings. The MEDLO-tool considers contextual factors (both physical and social) and can therefore be used to investigate which aspects of daily life are affected by innovative nursing home care facilities. In order to gain such a detailed insight into the daily lives of nursing home residents with dementia it is important to use multiple observation periods preferably divided over weekdays/ weekends and over mornings, afternoons and evenings over a longer period of time.

\section{CONCLUSION}

This study suggests that the MEDLO-tool is a reliable and feasible method to achieve detailed, in-depth insights into the daily lives of nursing home residents with dementia. It is a tool that provides researchers with repeated, real time and simultaneous measures of multiple aspects of daily life. 


\section{REFERENCES}

1. Harper Ice G. Daily life in a nursing home: Has it changed in 25 years? Journal of Aging Studies 2002;16:345-359.

2. den Ouden M, Bleijlevens MH, Meijers JM, et al. Daily (In) Activities of Nursing Home Residents in Their Wards: An Observation Study. Journal of the American Medical Directors Association 2015;16:963-968.

3. Vernooij-Dassen M. Meaningful activities for people with dementia. Aging \& Mental Health 2007;11:359360.

4. Hancock GA, Woods B, Challis D and Orrell M. The needs of older people with dementia in residential care. International Journal of Geriatric Psychiatry 2006;21:43-49.

5. Edvardsson D, Petersson L, Sjogren K, et al. Everyday activities for people with dementia in residential aged care: associations with person-centredness and quality of life. International Journal of Older People Nursing 2014;9:269-276.

6. Cohen-Mansfield J, Thein K, Dakheel-Ali M and Marx MS. Engaging nursing home residents with dementia in activities: the effects of modeling, presentation order, time of day, and setting characteristics. Aging \& Mental Health 2010;14:471-480.

7. Whear R, Coon JT, Bethel A, et al. What is the impact of using outdoor spaces such as gardens on the physical and mental well-being of those with dementia? A systematic review of quantitative and qualitative evidence. Journal of the American Medical Directors Association 2014;15:697-705.

8. Edvardsson D, Winblad B and Sandman P.O. Person-centred care of people with severe Alzheimer's disease: current status and ways forward. The Lancet Neurology 2008;7:362-367.

9. Zarit S and Femia E. A future for family care and dementia intervention research? Challenges and strategies. Aging \& Mental Health 2008;12:5-13.

10. Shiffman S, Stone AA and Hufford MR. Ecological momentary assessment. Annual Review of Clinical Psychology 2008;4:1-32.

11. Casey AN, Low LF, Goodenough B, et al. Computer-Assisted Direct Observation of Behavioral Agitation, Engagement, and Affect in Long-Term Care Residents. Journal of the American Medical Directors Association 2014;15:514-520.

12. Curyto KJ, Van Haitsma K and Vriesman DK. Direct observation of behavior: a review of current measures for use with older adults with dementia. Research in Gerontological Nursing 2008;1:52-76.

13. Kitwood T and Bredin K. A new approach to the evaluation of dementia care. Journal of Advances in Health and Nursing Care 1992;1:41-60.

14. Brooker D. Dementia care mapping: a review of the research literature. The Gerontologist 2005;45:11-18.

15. Doherty-King B, Yoon JY, Pecanac K, et al. Frequency and duration of nursing care related to older patient mobility. Journal of Nursing Scholarship 2014;46:20-27.

16. Bradford Dementia Group. DCM 8 User's Manual. Bradford: University of Bradford, 2005.

17. Viera AJ and Garrett JM. Understanding interobserver agreement: the kappa statistic. Family Medicine 2005;37:360-363.

18. Morris JN, Fries BE, Mehr DR, et al. MDS cognitive performance scale@. Journal of Gerontology 1994;49:M174-M182.

19. Morris JN, Fries BE and Morris SA. Scaling ADLs within the MDS. The Journals of Gerontology Series A: Biological Sciences and Medical Sciences 1999;54:M546-M553.

20. Wood W. Toward Developing New Occupational Science Measures: An Example from Dementia Care Research. Journal of Occupational Science 2005;12:121-129.

21. Dean R, Proudfoot R and Lindesay J. The quality of interactions schedule (QUIS): development, reliability and use in the evaluation of two domus units. International Journal of Geriatric Psychiatry 1993;8:819826.

22. Rosen J, Burgio L, Kollar M, et al. The Pittsburgh Agitation Scale: A User-Friendly Instrument for Rating Agitation in Dementia Patients. The American Journal of Geriatric Psychiatry 1995;2:52-59. 
23. Phinney A, Chaudhury $\mathrm{H}$ and $\mathrm{O}^{\prime}$ Connor DL. Doing as much as I can do: the meaning of activity for people with dementia. Aging \& Mental Health 2007;11:384-393.

24. Bruin SRD, Oosting SJ, Kuin Y, et al. Green care farms promote activity among elderly people with dementia. Journal of Housing for the Elderly 2009;23:368-389.

25. Harmer BJ and Orrell M. What is meaningful activity for people with dementia living in care homes? A comparison of the views of older people with dementia, staff and family carers. Aging \& Mental Health 2008;12:548-558.

26. Morley JE, Philpot CD, Gill D and Berg-Weger M. Meaningful activities in the nursing home. Journal of the American Medical Directors Association 2014;15.

27. Tak SH, Kedia S, Tongumpun TM and Hong SH. Activity Engagement: Perspectives from Nursing Home Residents with Dementia. Educational Gerontology 2015;41:182-192.

28. Edvardsson D, Petersson L, Sjogren K, et al. Everyday activities for people with dementia in residential aged care: associations with person-centredness and quality of life. International Journal of Older People Nursing 2013;9:269-276.

29. Smit D, de Lange J, Willemse B and Pot AM. The relationship between small-scale care and activity involvement of residents with dementia. International Psychogeriatrics 2012;24:722-732.

30. Kovach CR and Magliocco JS. Late-stage dementia and participation in therapeutic activities. Applied Nursing Research 1998;11:167-173.

31. Kolanowski A. Factors that relate to activity engagement in nursing home residents. American Journal of Alzheimer's Disease and Other Dementias 2006;21:15-22.

32. Van Raaij J, Schonk CM, Vermaat-Miedema SH, et al. Energy cost of physical activity throughout pregnancy and the first year postpartum in Dutch women with sedentary lifestyles. The American Journal of Clinical Nutrition 1990;52:234-239.

33. Wood W. Activity situations on an Alzheimer's disease special care unit and resident environmental interaction, time use, and affect. American Journal of Alzheimer's Disease and Other Dementias 2005;20:105-118.

34. Wood W, Womack J and Hooper B. Dying of boredom: An exploratory case study of time use, apparent affect, and routine activity situations on two Alzheimer's special care units. American Journal of Occupational Therapy 2009;63:337-350.

35. Cohen-Mansfield J, Thein K, Dakheel-Ali M and Marx MS. The underlying meaning of stimuli: Impact on engagement of persons with dementia. Psychiatry Research 2010;177:216-222.

36. Day K, Carreon D and Stump C. The therapeutic design of environments for people with dementia a review of the empirical research. The Gerontologist 2000;40:397-416.

37. Knight $T$ and Mellor D. Social inclusion of older adults in care: Is it just a question of providing activities? International Journal of Qualitative Studies on Health and Well-being 2007;2:76-85.

38. Sloane PD, Brooker D, Cohen L, et al. Dementia care mapping as a research tool. International Journal of Geriatric Psychiatry 2007;22:580-589.

39. Martin P and Bateson P. Measuring behaviour: an introductory guide. Cambridge: Cambridge University Press, 2007.

40. Harmer BJ and Orrell M. What is meaningful activity for people with dementia living in care homes? A comparison of the views of older people with dementia, staff and family carers. Aging \& Mental Health 2008;12:548-558.

41. Phinney A, Chaudhury $\mathrm{H}$ and O'Connor DL. Doing as much as I can do: The meaning of activity for people with dementia. Aging \& Mental Health 2007;11:384-393.

42. Beerens HC, de Boer B, Zwakhalen SMG, et al. The association between aspects of daily life and quality of life of people with dementia living in long-term care facilities: repeated real-time observations. International Psychogeriatrics 2016.

43. Verbeek H, Zwakhalen SM, van Rossum E, et al. Small-scale, homelike facilities in dementia care: a process evaluation into the experiences of family caregivers and nursing staff. International Journal of Nursing Studies 2012;49:21-29. 



\section{CHAPTER 6}

The association between aspects of daily life and quality of life of people with dementia living in long-term care facilities:

a momentary assessment study
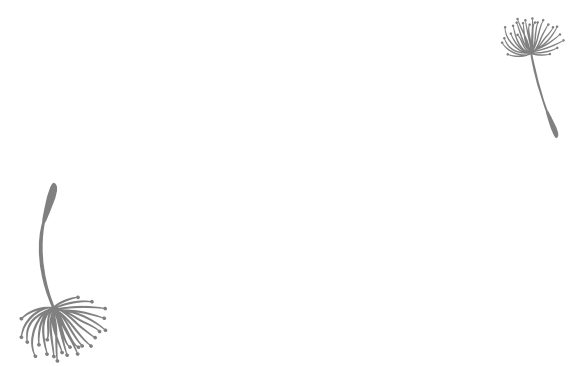

This chapter was published as:

Beerens HC, De Boer B, Zwakhalen SMG, Tan FES, Ruwaard D, Hamers JPH, Verbeek H. The association between aspects of daily life and quality of life of people with dementia living in long-term care facilities: a momentary assessment study. International Psychogeriatrics 2016. doi:10.1017/S1041610216000466. 


\section{ABSTRACT}

Background: To improve the quality of life of people with dementia living in long-term care facilities, insight into the association between quality of life and how people spend their daily lives is urgently needed. This study investigated which aspects of daily life are related to quality of life in dementia.

Methods: An observational study was conducted. Daily life was assessed with the tabletbased Maastricht Electronic Daily Life Observation-tool (MEDLO-tool). Aspects included activity, engagement in the activity, social interaction, physical effort, mood and agitation. Quality of life was assessed by formal nursing caregivers using the Quality of LifeAlzheimer's Disease scale (QoL-AD). A total of 9,660 momentary assessments were conducted.

Results: The mean age of the 115 participants was 84 and most (75\%) were women. Bivariate analyses showed that residents with a higher quality of life carried out less passive/purposeless activities (25\% vs. 38\%), were more engaged in active, expressive, and social activities, ( $40 \%$ vs. $27 \%$ ), had more social interaction (34\% vs. $22 \%$ ), and had better mood scores (scale 1-7, 5.0 vs. 4.8), compared with residents with a lower quality of life (all p-values $<0.001$ ). Multivariate analyses showed that having more social interaction and a positive mood are related to a higher quality of life.

A higher quality of life was related to having more social interaction and positive mood.

Conclusion: The results underline the importance of social interaction and a positive mood for a higher quality of life. Future research should investigate the importance of engagement in activities in more detail. 


\section{INTRODUCTION}

Quality of life (QoL) of people with dementia (PwD) living in long-term care facilities remains a priority in dementia research. ${ }^{1,2} \mathrm{QoL}$ is a complex, multidimensional construct and both objective components (e.g. behavioral competence and environment) and subjective components (perceived QoL and psychological well-being) are generally considered to be important for QoL of PwD. ${ }^{3}$ Several studies showed that clinical conditions such as depressive and behavioral symptoms have a negative impact on QoL., 5

There is less knowledge about which aspects of daily life are important for QoL and how these aspects contribute to a good QoL. As proposed by a study including expert interviews and a literature study, daily life entails: 1 ) activities performed by PwD; 2) the physical environment PwD live in; 3) social interactions of PwD with others; and 4) emotional well-being. ${ }^{6}$ Prior research suggests that PwD who engage in a variety of activities have a higher QoL than those who are inactive. ${ }^{7}$ Especially activities related to personal hobbies, ${ }^{8}$ reminiscence, leisure, expression, and vocational occupation ${ }^{9}$ have a large potential for QoL enhancement. In contrast, a low QoL is associated with passive activities such as daytime sleep and sitting/standing without doing any activities. ${ }^{7,} 10$ Qualitative literature indicates that activity engagement is important because it may give PwD pleasure and enjoyment, contributes to a sense of connection and belonging, and helps them to retain a sense of autonomy and personal identity. ${ }^{11}$ Besides activities, PwD and their caregivers also consider aspects such as social relationships, physical movement, attachment and affect, control over life and contributing to the community as important for PwD's QoL. ${ }^{12,13}$

However, to date, it is unknown how the daily lives of PwD with a higher QoL differ from those with a lower QoL. More insight is essential because it will direct QoL improvement. It will inform caregivers on how to set priorities during daily caregiving, as daily life aspects such as social interaction and activity level can be improved without complex interventions. ${ }^{14}$ Factors of daily life that contribute to a good QoL of PwD living in long-term care facilities are currently unknown. Prior research has not considered multiple aspects of daily life simultaneously. Furthermore, many studies used proxy questionnaires to investigate daily life and calculated sum scores. Such measures are prone to recall bias and do not consider the broad context in which daily life takes place. Caregivers may for example easily overestimate the time that PwD engage in activities. $^{15}$

Therefore, the current study investigates the direct context in which activity, engagement, social interaction, and other aspects of daily life naturally occur. It uses an ecological momentary assessment approach, ${ }^{16}$ taking snapshots of everyday life to picture PwD's life repeatedly. First, this study aimed to gain more insight into the daily lives of PwD of PwD living in long-term care facilities. Second, this study addressed two research questions specifically focusing on the relationship between QoL and everyday life: 1) How does the daily life of PWD living in long-term care facilities with a high QoL 
differ from those with a lower QoL?; and 2) Which aspects of daily life of PWD living in long-term care facilities are associated with QoL?

\section{METHODS}

Design

This study has an observational study design and includes ecological momentary assessments of the daily lives of PwD. ${ }^{16}$

\section{Participants and setting}

This study was part of a larger study looking at differences between long-term care facilities for PwD living in the Netherlands. ${ }^{17}$ Eighteen wards in eight locations - accommodating 158 potential participants - in the southern provinces of the Netherlands participated. PwD of all types of long-term care facilities (e.g. large- and small scaled) were eligible. All participants with a formal diagnosis of dementia were included. In total, the legal representatives of 115 of the 158 potential participants (73\%) agreed to participation in the study.

\section{Instruments}

Dependent variable: quality of life

QoL was assessed by formal caregivers using the Quality of Life-Alzheimer's Disease scale (QoL-AD). This scale allows thirteen QoL domains to be rated on a four-point Likert scale, ranging from 1 (poor) to 4 (excellent). Total scores range from 13 to 52, and higher scores indicate a better QoL. ${ }^{18}$

Independent variables: aspects of daily life

The Maastricht Electronic Daily Life Observation-tool (MEDLO-tool), ${ }^{6}$ a tablet-based observational tool, was used to conduct momentary assessments ${ }^{16}$ to gain insight in aspects of daily life. The MEDLO-tool demonstrated to be valid, reliable and feasible for research purposes with on average $86 \%$ absolute agreement between observers. ${ }^{6}$ The following daily life aspects of the MEDLO-tool were collected for this study: 1a) the activity performed by the participant or occurring in his/her vicinity; $1 \mathrm{~b}$ ) the extent to which the participant was engaged in this activity; 2) whether the participant had social interaction; 3) participant's level of physical effort; 4) the mood of the participant; and 5) participant's agitation level. Box 1 provides a full explanation of these aspects of daily life and accompanying operationalizations. A manual of the MEDLO-tool is available upon request. 
Box 1. Aspects of daily life and their operationalizations

\begin{tabular}{ll}
$\begin{array}{l}\text { 1a. Activity taking place during observation minute } \\
\text { (one of the five listed activities can be chosen as an activity that took place) } \\
0=\text { activity did not take place } \\
1=\text { activity took place }\end{array}$ & Example \\
\hline Activity & Eating/drinking, visit medical or other healthcare personnel, (self-)care \\
\hline Activity related to personal & activities \\
care & Activity related to pets, crafts/arts, music/singing, walking outside, playing \\
$\begin{array}{l}\text { Active, expressive or social } \\
\text { activity }\end{array}$ & $\begin{array}{l}\text { a game/puzzling, sensory stimulation, beauty activity, sports, speaking with } \\
\text { others, farming activities, gardening and caring for plants, household } \\
\text { chores, cooking }\end{array}$ \\
$\begin{array}{ll}\text { Passive purposeful activity } \\
\text { Passive/purposeless activity }\end{array}$ & $\begin{array}{l}\text { Witting/laying, resting or sleeping, purposeless (repetitive) behavior } \\
\text { Other activity or not }\end{array}$ \\
$\begin{array}{l}\text { When participant is not present, when door of bedroom is closed } \\
\text { observable activity }\end{array}$
\end{tabular}

\section{1b. Engagement in main activity that was chosen in step 1a}

$0=$ no, not engaged: sleeping, staring, engagement in something else

1 = yes, engaged: active participation in activity or a focus on activity

\section{Social interaction during observation minute}

$0=$ no social interaction, attempted interaction without response

$1=$ yes, social interaction with one or more persons

\section{Physical effort during observation minute}

$0=$ none/minimal physical effort: lying or sitting quietly

1 = yes, physical effort: light-to-moderate sitting activity, standing activity, walking around, cycling, wholebody movements

\section{Mood during observation minute}

Seven-point Likert scale.

1. Great signs of negative mood

2. Considerable signs of negative mood

3. Small signs of negative mood

4. Neutral

5. Contentment and small signs of well-being

6. Considerable positive mood

7. Very high positive mood

\section{Agitation during observation minute}

Defined as aberrant vocalization, motor agitation, aggressiveness, or resisting care Five-point Likert scale:

0. No agitation

1. E.g. vocalization is not disruptive, seeking comfort, verbal threats, procrastination or avoidance

2. E.g. vocalization is louder than usual, mildly intrusive movements, threatening gestures, rejection

3. E.g. loud vocalization, quick movements, physical toward material goods, pushing away

4. E.g. extremely loud vocalization, extreme movements, physical towards people, threshing

Activity and engagement were considered to be two distinct aspects of daily life. An activity occurring in the participant's vicinity does not imply that they are actually en- 
gaged in this activity. Therefore, we recorded 1a) the activity and 1b) participant's level of engagement in this activity. Engagement in active, expressive, and social activities was of particular interest and therefore, a combination variable connecting the activity cluster 'active, expressive, and social activities' (step 1a) and 'yes, engagement' (step 1b) was created.

For the dichotomous variables (activity, engagement, social interaction, physical effort), percentages of how frequently they occurred on a total of 84 observations were calculated. For the dichotomous variables (activity, engagement, social interaction, physical effort), percentages of how frequently they occurred were calculated per participant. For the continuous variables (mood and agitation), mean scores were calculated per participant.

\section{Background characteristics}

Cognitive functioning was assessed using the Standardized Mini-Mental State Examination (S-MMSE). Total scores on this scale range from 0 to 30, with higher scores indicating better cognition. ${ }^{19}$ Dependence in activities of daily living (ADL) was assessed using the Barthel Index. Total scores on this scale range from 0 to 20, with higher scores indicating more independency in ADL. ${ }^{20}$ Information on age, gender (male/female), and marital status (widowed/not widowed) was also collected.

\section{Procedure}

All data were collected by two researchers (the first and second authors) and a research assistant who spent a maximum of three weeks in every location. Within this period, all data were collected using two methods. First, standardized interviews were held with certified nursing assistants who provided hands-on care to participants (PwD's QoL and background characteristics) and PwD (cognition). Second, momentary assessments of the daily lives of PwD were carried out. PWD were not only observed in communal areas, but were followed wherever they went. If observers had the impression that they were too intrusive in the daily lives of PwD, they stepped back and recorded an observation as missing. To take privacy into account, PwD were not observed in private spaces such as the bathroom or the bedroom with a closed door.

Observations took place at one ward per observation day. The order of observations was randomized in advance. A randomized observation schedule ensured that every participant (with a maximum of eight per ward) was observed for one minute during every 20-minute period. After the end of each one-minute observation period, the observer recorded the scores of all aspects of daily life that are shown in Box 1. Observations took place on seven days: two weekday mornings (07:00-11:30), two weekday afternoons (11:30-16:00), two weekday evenings (16:00-20:30) and one Saturday afternoon (11:30-16:00). There was a half-hour break within each 4.5 hour observation 
block. In total, data of (12 one-minute observation periods per day * 7 observation days =) 84 momentary assessments were recorded per participant.

\section{Analyses}

First, the sample characteristics were described. Participants were assigned to one of two QoL groups according to whether their QoL-AD score was above or below the median of the sample (32.0). Differences in sample characteristics between PwD in the 'higher QoL' group and PwD in the 'lower QoL' group were assessed using chi-square tests in the case of marital status and gender and independent samples t-tests for other variables.

Second, differences between the aspects of the daily lives of PWD with 'higher QoL' and PwD with 'lower QoL' were evaluated. Therefore, differences between the two QoL groups regarding activities, engagement, social interaction, physical effort, mood, and agitation were assessed using chi-square tests.

Third, to assess which aspects of daily life contribute to QoL, a multiple linear regression analysis with the QoL-AD score as the dependent variable was conducted. The selection of independent variables went as follows: First, aspects of daily life that were not significantly different between the two QoL groups (see Table 2) were excluded (three activity categories, physical effort, and agitation). Second, whether or not a participant was actually engaged in activities such as musical activities, craft activities, or sports was considered most important. Therefore, we included the combination variable 'engagement in active, expressive and social activities'. As a result, two closely related variables ('active, expressive, or social activities' and 'engagement in all activities together') were removed. The final set of independent variables related to aspects of daily life included: 'passive/purposeless activity'; 'engagement in active, expressive or social activity'; 'social interaction' and 'mood'. We controlled for the potential effects of age, gender, cognitive status and location as these variables might influence the range of activities in which participants are involved, their level of engagement or social interaction. All independent variables were entered in the model simultaneously.

All analyses used a significance level of $\alpha=.05$ (two-tailed) and were conducted using SPSS version 22.0 (IBM SPSS Statistics, IBM Corporation, Chicago, IL).

\section{Ethics}

The study protocol was reviewed by the medical ethics committee of the Maastricht University Medical Center. They declared that the study was non-invasive for people with dementia according to the Medical Research Involving Human Subjects Act. Legal representatives of PWD received a letter with information about the study and an informed consent form. They were asked to return the form in which they filled out whether they provided informed consent or not. Next to this informed consent proce- 


\section{CHAPTER 6}

dure, PwD were asked to assent to participation. This was defined as a verbal agreement to participate or a non-verbal indication of willingness to cooperate with the study.

\section{RESULTS}

\section{Sample characteristics}

The legal representatives of 115 of 158 potential participants (73\%) agreed to participation in the study. The mean age of participants was 84 years and most were female (75\%) and widowed (66\%). The mean S-MMSE score was 8.5, which indicates severe cognitive impairment. The mean Barthel Index score was 9.7, which indicates a limited ability to perform ADL activities independently.

The median QoL-AD score was 32.0 and the mean QoL-AD score was 31.7 (SD=5.0). To gain insight in the difference between PwD with a higher and lower QoL, the sample was divided into two QoL groups using the median QoL-AD score as the boundary. The mean QoL-AD score was $35.9(S D=2.6)$ for the 'higher QoL' group $(n=59)$ and 27.3 $(S D=2.6)$ for the 'lower QoL' group $(n=56)$. Table 1 shows the sample characteristics for the sample as a whole and for the two QoL groups. PwD with higher QoL had significantly better cognition than those with lower QoL $(p=.006)$.

Table 1. Sample characteristics (groups defined relative to the median QoL-AD score)

\begin{tabular}{lllll}
\hline & $\begin{array}{l}\text { Total } \\
\mathrm{n}=115\end{array}$ & $\begin{array}{l}\text { Higher QoL } \\
\mathrm{n}=59\end{array}$ & $\begin{array}{l}\text { Lower QoL } \\
\mathrm{n}=56\end{array}$ & $\mathrm{p}$ value* \\
\hline Age, mean (SD) & $83.8(7.8)$ & $83.9(7.7)$ & $83.6(8.0)$ & 0.802 \\
Gender (female), \% & 75 & 78 & 71 & 0.420 \\
Marital status (widowed), \% & 66 & 70 & 63 & 0.429 \\
S-MMSE, mean (SD) & $8.5(6.9)$ & $10.1(6.6)$ & $6.5(6.7)$ & 0.006 \\
\hline
\end{tabular}

QoL-AD = Quality of Life in Alzheimer's Disease scale; QoL = quality of life; SD = standard deviation

* Independent samples t-test or chi square test of difference between the QoL groups

\section{Description of the daily lives of PWD}

In total, (115 participants * 84 observations per participant =) 9,660 observations were completed. Table 2 provides an overview of the percentage of times spent on activities, engagement, social interaction, physical effort, and the average mood and agitation scores of participating PwD during the observations. Most of the time, active, expressive, or social activities such as household activities or musical activities or passive/purposeless activities such as sleeping took place in the vicinity of the PwD during $34 \%$ and $31 \%$, respectively. Less time was spent on activities related to personal care 
(20\%), television or radio activities (8\%), and other activities (7\%). PwD were engaged in one of all these activities during $69 \%$ of the observations. However, engagement in active, expressive, or social activities occurred less frequently (31\%). PwD had any form of social interaction such as talking or eye contact during $32 \%$ of the observations. Furthermore, PwD were lying or sitting passively during 91\% of their time, and were physically active (e.g. sitting with arm movements, standing, walking) during $9 \%$ of their time. Overall, PwD were content and displayed small signs of happiness (mean mood score = 4.7) and agitation was rarely observed.

Table 2. Aspects of daily life for the sample as a whole and grouped according to QoL-AD score

\begin{tabular}{|c|c|c|c|c|c|}
\hline Aspect of daily lif & & & Higher QoL & & $p$ value* \\
\hline 1a. Activity & Personal care, \% & 20 & 20 & 19 & 0.301 \\
\hline & Active, expressive or social, \% & 34 & 40 & 27 & 0.000 \\
\hline & Television/radio, \% & 8 & 8 & 8 & 0.970 \\
\hline & Passive/purposeless, \% & 31 & 25 & 38 & 0.000 \\
\hline & Other, \% & 7 & 7 & 8 & 0.615 \\
\hline 1b. Engagement & Engagement in all activities together, \% & 69 & 75 & 63 & 0.000 \\
\hline & $\begin{array}{l}\text { Engagement in active, expressive, or social } \\
\text { activity, \% }\end{array}$ & 31 & 37 & 24 & 0.000 \\
\hline 2. Social interact & tion, \% & 32 & 38 & 26 & 0.000 \\
\hline 3. Mild to intens & e physical effort, \% & 9 & 10 & 8 & 0.195 \\
\hline 4. Mood: mean s & score $(\mathrm{SD})$, range $1-\underline{7}^{\dagger}$ & $4.7(0.2)$ & $4.8(0.1)$ & $4.7(0.2)$ & 0.000 \\
\hline 5. Agitation: mea & an score (SD), range $\underline{0}-4^{+}$ & $0.0(0.1)$ & $0.0(0.0)$ & $0.0(0.1)$ & 0.225 \\
\hline
\end{tabular}

QoL-AD = Quality of Life in Alzheimer's Disease scale; QoL = quality of life; SD = standard deviation

* Independent samples t-tests on difference between QoL groups

${ }^{+}$Underlined score is most favorable score

The daily lives of PWD with higher and lower quality of life

\section{Bivariate analyses}

Table 2 presents an overview of the aspects of daily life of PwD with higher QoL in comparison to those with lower QoL. Active, expressive, or social activities such as household activities, musical activities or conversations with others occurred most frequently in the daily lives of PwD with high QoL (40\%). In contrast, PwD with lower QoL spent more time on passive/purposeless activities such as sleeping, sitting without doing anything, or purposeless repetitive behavior (38\%). The difference between the QoL groups was statistically significant for both activity categories $(p<.001)$. Furthermore, PwD with a higher QoL were also more frequently engaged (active participation or clear focus) in active, expressive, or social activities ( $37 \%$ vs. $24 \%, p<.001$ ), had more social interaction 


\section{CHAPTER 6}

such as talking or eye contact with other people (38\% vs. $26 \%, \mathrm{p}<.001)$, and had higher mood scores (4.8 vs. 4.7, p<.001) than those with lower QoL.

\section{Multivariate analyses}

The result of the regression analysis that focused on the association between aspects of daily life and QoL is presented in Table 3. A higher QoL was associated with having frequent social interaction $(p=.007)$, and higher mood scores $(p=.017)$. In other words, PwD who had frequent social interaction or a good mood during their day were more likely to have a good QoL than PwD who had less social interaction or lower mood scores. In addition, PwD with higher QoL scores had better cognitive abilities than PwD with lower QoL ( $p=.003)$.

Table 3. Association between aspects of daily life and QoL-AD score: regression analyses

\begin{tabular}{|c|c|c|c|c|c|c|}
\hline & \multirow[t]{2}{*}{ Estimate } & \multirow[t]{2}{*}{ Std. Error } & \multirow[t]{2}{*}{$\mathrm{t}$} & \multicolumn{2}{|c|}{ 95\% confidence interval } & \multirow[t]{2}{*}{$p$ value } \\
\hline & & & & Lower & Upper & \\
\hline Age & .025 & .054 & .460 & -.082 & .131 & .647 \\
\hline Gender & .251 & 0.973 & .258 & -1.678 & 2.181 & .797 \\
\hline Cognition (S-MMSE) & .192 & .063 & 3.026 & .066 & .317 & .003 \\
\hline Passive/purposeless activity & -.035 & .041 & -.841 & -.116 & .047 & .402 \\
\hline $\begin{array}{l}\text { Engagement in active, expressive, or } \\
\text { social activity }\end{array}$ & -.047 & .048 & -.979 & -.141 & .048 & .330 \\
\hline Social interaction & .115 & .042 & 2.763 & .032 & .197 & .007 \\
\hline Mood & 6.361 & 2.612 & 2.436 & 1.183 & 11.540 & .017 \\
\hline
\end{tabular}

QoL-AD = Quality of Life in Alzheimer's Disease scale; S-MMSE = Standardized Mini-Mental State Examination

\section{DISCUSSION}

This study showed that residents with a higher quality of life carried out less passive/purposeless activities, were more engaged in active, expressive, and social activities, had more social interaction, and had better mood scores, than residents with a lower quality of life. Corrected for age and cognition, a higher quality of life was related to having more social interaction and positive mood.

The finding that frequent social interaction is associated with higher QoL is in line with studies showing that social contact is essential for PwD and improves their QoL. ${ }^{12}$ ${ }^{13}$ However, evidence suggests that the need PwD have for social contact is often not met. ${ }^{21}$ This concern is reflected by the observations of the daily lives of PWD in the current study, which shows that PwD spend most of their time without social contact. The lack of social contact may be a result of the difficulties nursing staff experience in communicating with PwD. Evidence suggests that nurses have few interactions with PwD 
with little conversational capacity, ${ }^{22}$ and find it difficult to cope with aggressive, hostile, stubborn, resistant, and unpredictable behavior. ${ }^{23}$

The current study demonstrates an association between higher QoL and a better mood as observed in daily life. This result is in line with the majority of research that focused on concepts closely related to mood, for example depressive symptoms, affect, and happiness. ${ }^{4,12} 24$ One could argue that the relationship between QoL and mood is also expected because mood is a part of the QoL construct as operationalized in the QoL-AD. The issue about whether factors such as mood should be considered correlates or a part of the QoL construct remains unresolved in the literature. ${ }^{25}$ However, it is plausible that a positive mood has a positive influence on a variety of QoL domains, e.g. social relationships and the overall judgement of QoL. Similarly, a negative mood is likely to negatively influence a variety of QoL domains such as functional abilities and social support.

It is widely recognized that it is important for PwD to be engaged in what they are doing. ${ }^{26}$ Our finding that PwD with higher QoL were more engaged in active, expressive, and social activities and did less passive/purposeless activities than PwD with lower QoL underlines the importance of activity engagement. Unexpectedly, this finding was not detected in multivariate analyses correcting for age, gender, and cognition. Other studies focusing on activity involvement suggested an association between QoL and activity engagement. 7, 9, 11 A possible reason for the discrepancy between the current study and other studies is that most were unable to perform multivariate analyses enabling correction for potential confounders such as cognitive ability. It might be true that PwD with better cognitive abilities do more daily activities than those with less cognitive capabilities and this could have influenced the relationship between QoL and activity engagement.

Behavioral symptoms, particularly agitation, are generally thought to have a negative impact on QoL of PwD. ${ }^{5}$ In the current study, agitation was rarely observed, which made it difficult to assess how agitation was related to QoL. This result is in line with another observational study which found that nursing home residents exhibited agitation sporadically. ${ }^{27}$ A Dutch prevalence study using standardized questionnaires suggested that $85 \%$ of the PwD living in nursing homes display at least one symptom of agitation within one week. ${ }^{28}$ Although this percentage appears relatively high, having one symptom within one week might be comparable to the low average agitation level in the current study.

A major strength of the current study was that the momentary assessments enabled us to build an extensive, rich picture of the daily lives of PwD. A variety of aspects of daily life that were considered potentially relevant to QoL could be observed simultaneously using one instrument. Recall bias, that can for example occur when asking nursing staff about how frequently PwD are engaged in activities, ${ }^{15}$ was avoided. This study does, however, have some limitations. QoL evaluation may be influenced by personal values which can lead to caregivers rating PwD's QoL different and often lower than 
PwD themselves. ${ }^{29}$ It should be noted, however, that caregiver reports enabled the inclusion of all PwD living in long-term care facilities, whereas self-reports of QoL can only be obtained from PwD who are able to express themselves. In addition, the QoL$A D$ has been extensively investigated and validated ${ }^{18,30}$ and has been identified as the method of choice for evaluating QoL in PwD. ${ }^{1}$ Another limitation is related to the nature of observational research as PwD's facial expressions were sometimes difficult to interpret. As a result, the observers may have influenced the recordings of subjective constructs such as mood. To overcome this observer bias as much as possible, care staff informed the observers about PWD's background and behaviors prior to the data collection. In addition, difficulties were discussed during weekly meetings with the research team. Finally, the influence of factors such as physical health on QoL was not assessed in this study. Doing this could have led to a richer insight into associations with QoL. On the other hand, a strength of the independent variables chosen for this study was that they were assessed using momentary assessments, which are less prone to proxy bias than caregiver questionnaires.

\section{Conclusion and future directions}

The results underline the importance of social activities and a positive mood for QoL of PwD living in long-term care facilities. Social interventions to achieve and maintain frequent meaningful interactions with PWD are recommended. To gain more insight into the association between social contact and QoL, future studies could incorporate information about the quality of the interaction or the identity of the interaction partner. Psychological interventions that address mood disturbances are also important. Low mood can be explained by individual factors such as unmet needs or environmental factors, so tailored guidance is preferred over a 'one size fits all' approach. It is recommended to investigate activity categories more into detail. For example, information relating the purposefulness of specific activities to specific personal characteristics (e.g. gender) would contribute to our understanding of the relationship between QoL and activities.

Fully exploiting momentary assessments by conducting hierarchical analyses would enable the assessment of the quality of the daily lives of PWD more into depth. In addition, analysis of associations between aspects of daily life and self-reported QoL is recommended. 


\section{REFERENCES}

1. Moniz-Cook E, Vernooij-Dassen M, Woods R, et al. A European consensus on outcome measures for psychosocial intervention research in dementia care. Aging \& Mental Health 2008;12:14-29.

2. Morley JE, et al. International survey of nursing home research priorities. Journal of the American Medical Directors Association 2014a;15:309-312.

3. Lawton MP. Quality of Life in Alzheimer Disease. Alzheimer Disease and Associated Disorders 1994;8:138150.

4. Banerjee S, Samsi K, Petrie CD, et al. What do we know about quality of life in dementia? A review of the emerging evidence on the predictive and explanatory value of disease specific measures of health related quality of life in people with dementia. International Journal of Geriatric Psychiatry 2009;24:15-24.

5. Beerens HC, Zwakhalen SM, Verbeek H, et al. Factors associated with quality of life of people with dementia in long-term care facilities: A systematic review. International Journal of Nursing Studies 2013;50:1259-1270.

6. de Boer B, Beerens HC, Zwakhalen SMG, et al. Daily lives of people with dementia: development of the Maastricht Electronic Daily Life Observation-tool. International Psychogeriatrics 2016.

7. Edvardsson D, Petersson L, Sjogren K, et al. Everyday activities for people with dementia in residential aged care: associations with person-centredness and quality of life. International Journal of Older People Nursing 2014;9:269-276.

8. Giebel CM, Challis DJ and Montaldi D. A revised interview for deterioration in daily living activities in dementia reveals the relationship between social activities and well-being. Dementia 2014;0:1-14.

9. Smit D, Willemse B, de Lange J and Pot AM. Wellbeing-enhancing occupation and organizational and environmental contributors in long-term dementia care facilities: an explorative study. International Psychogeriatrics 2014;26:69-80.

10. Kuhn D, Edelman P and Fulton BR. Daytime sleep and the threat to well-being of persons with dementia. Dementia 2005;4:233-247.

11. Phinney A, Chaudhury $\mathrm{H}$ and O'Connor DL. Doing as much as I can do: The meaning of activity for people with dementia. Aging \& Mental Health 2007;11:384-393.

12. Cahill S and Diaz-Ponce AM. 'I hate having nobody here. I'd like to know where they all are': Can qualitative research detect differences in quality of life among nursing home residents with different levels of cognitive impairment? Aging \& Mental Health 2011;15:562-572.

13. Moyle W, Venturto L, Griffiths S, et al. Factors influencing quality of life for people with dementia: a qualitative perspective. Aging \& Mental Health 2011;15:970-977.

14. van der Ploeg ES, Eppingstall B, Camp CJ, et al. A randomized crossover trial to study the effect of personalized, one-to-one interaction using Montessori-based activities on agitation, affect, and engagement in nursing home residents with dementia. International Psychogeriatrics 2013;25:565-575.

15. Smit D, de Lange J, Willemse B, et al. Activity involvement and quality of life of people at different stages of dementia in long term care facilities. Aging \& Mental Health 2015:1-10.

16. Shiffman S, Stone AA and Hufford MR. Ecological momentary assessment. Annual Review of Clinical Psychology 2008;4:1-32.

17. de Boer B, Hamers JPH, Beerens HC, Zwakhalen SMG, and Verbeek H. Living at the farm, innovative nursing home care for people with dementia - study protocol of an observational longitudinal study. BMC Geriatrics 2015;14:144.

18. Logsdon RG, Gibbons LE, McCurry SM and Teri L. Assessing quality of life in older adults with cognitive impairment. Psychosomatic Medicine 2002;64:510-519.

19. Molloy DW, Alemayehu E and Roberts R. Reliability of a Standardized Mini-Mental State Examination compared with the traditional Mini-Mental State Examination. American Journal of Psychiatry 1991;148:102-105.

20. de Haan R, Limburg M, Schuling J, et al. Klinimetrische evaluatie van de Barthel-Index, een maat voor beperkingen in het dagelijks leven. Nederlands Tijdschrift voor Geneeskunde 1993;137:917-921. 


\section{CHAPTER 6}

21. Ward R, Vass AA, Aggarwal N, et al. A different story: exploring patterns of communication in residential dementia care. Ageing and Society 2008;28:629-651.

22. Perkins $G$ and Nolan M. Purposeful activity as an indicator of quality in the care of elderly patients. British Journal of Nursing 1992;2:197-201.

23. Brodaty H, Draper B and Low LF. Nursing home staff attitudes towards residents with dementia: strain and satisfaction with work. Journal of Advanced Nursing 2003;44:583-590.

24. Dröes R-M, Boelens-Van Der Knoop EC, Bos J, et al. Quality of life in dementia in perspective An explorative study of variations in opinions among people with dementia and their professional caregivers, and in literature. Dementia 2006;5:533-558.

25. Ettema TP, Dröes RM, de Lange J, et al. A review of quality of life instruments used in dementia. Quality of Life Research 2005;14:675-686.

26. Morley JE, Philpot CD, Gill D and Berg-Weger M. Meaningful activities in the nursing home. Journal of the American Medical Directors Association 2014b;15:79-81.

27. Kolanowski $A$ and Litaker M. Social interaction, premorbid personality, and agitation in nursing home residents with dementia. Archives of Psychiatric Nursing 2006;20:12-20.

28. Zuidema SU, Derksen E, Verhey FRJ and Koopmans RTCM. Prevalence of neuropsychiatric symptoms in a large sample of Dutch nursing home patients with dementia. International Journal of Geriatric Psychiatry 2007;22:632-638.

29. Gräske J, Fischer T, Kuhlmey A and Wolf-Ostermann K. Quality of life in dementia care-differences in quality of life measurements performed by residents with dementia and by nursing staff. Aging \& Mental Health 2012;16:819-827.

30. Thorgrimsen L, Selwood A, Spector A, et al. Whose quality of life is it anyway? The validity and reliability of the Quality of Life-Alzheimer's Disease (QoL-AD) scale. Alzheimer Disease and Associated Disorders 2003;17:201-208 


\section{CHAPTER 7}

The relation between mood, activity and interaction in long-term dementia care
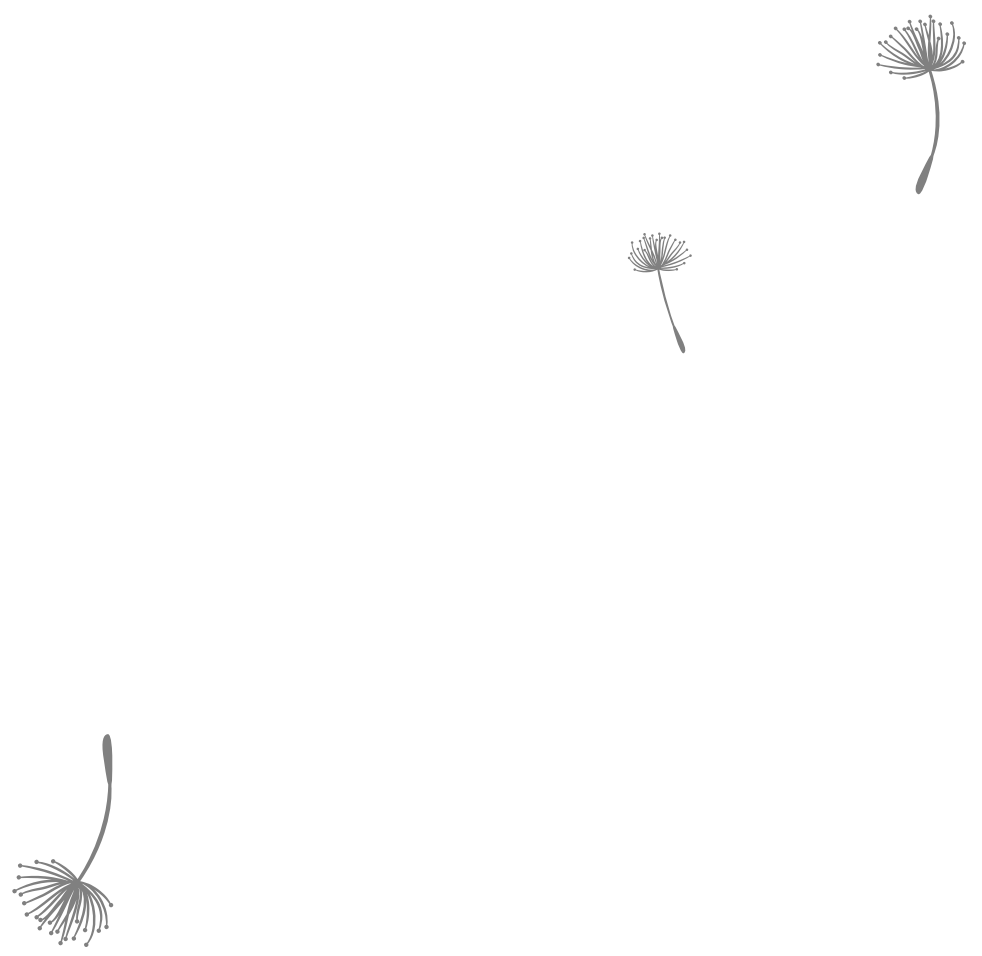

This chapter was submitted for publication as:

Beerens HC, Zwakhalen SMG, Verbeek H, Tan FES, Jolani S, Downs M, de Boer B, Ruwaard D, Hamers JPH. The relation between mood, activity and interaction in longterm dementia care. 


\section{ABSTRACT}

Objective: The aim of the study is to identify the degree of association between mood, activity engagement, activity location, and social interaction during everyday life of people with dementia (PwD) living in long-term care facilities.

Method: An observational study using momentary assessments was conducted. For all 115 participants, 84 momentary assessments of mood, engagement in activity, location during activity, and social interaction were carried out by a researcher using the tabletbased Maastricht Electronic Daily Life Observation-tool (MEDLO-tool).

Results: A total of 9,660 momentary assessments was completed. The mean age of the 115 participants was 84 and most (75\%) were women. A negative, neutral, or positive mood was recorded during $2 \%, 25 \%$, and $73 \%$ of the observations, respectively. Positive mood was associated with engagement in activities, doing activities outside and social interaction. The type of activity was less important for mood than the fact that PwD were engaged in an activity. Low mood was evident when PwD attempted to have social interaction but received no response.

Conclusion: Fulfilling PwD's need for occupation and social interaction is consistent with a person-centred dementia care focus and should have priority in dementia care. 


\section{INTRODUCTION}

Psychosocial outcomes such as mood are well established hallmarks in judging quality care for people with dementia (PwD). ${ }^{1,2}$ Numerous studies assessed constructs related to mood such as depressive symptoms, happiness, positive affect, or negative affect. Findings of these studies support the importance of a positive mood for PwD's wellbeing and quality of life $(\mathrm{QoL}) .^{3-7}$ Earlier research indicates that negative mood or major depressive symptoms are not inevitable aspects of living with advanced dementia in a long-term care facility. For example, a European survey ${ }^{8}$ found that PwD who were recently admitted to a long-term care facility had less depressive symptoms than those who lived at home at risk for admission within the next six months. Furthermore, a systematic review showed that depressive symptoms do not necessarily worsen as the dementia progresses. ${ }^{9}$ Yet there continues to be a compelling need to identify ways to ensure positive mood as studies indicate that $20 \%$ - 50\% of the PwD living in long-term care facilities experience depressive symptoms. ${ }^{10-12}$

Mood can be defined as a broad range of affective states which fluctuate over the day. ${ }^{13,14}$ As such mood may well be related to the variation in what happens during daily life. This includes activities and social interactions. ${ }^{13}$ To support residents to achieve and maintain a positive mood during the day, it is important to have an understanding of the association between mood levels and activity- and social engagement. Such an understanding can be used to provide practical guidance to long term care staff on how to improve PwD's mood.

Studies which have used questionnaires to assess associations with mood indicate that depressive symptoms of PwD living in long-term care facilities are associated with negative outcomes such as a decreased QoL, worse physical health, a decreased ability to perform activities of daily living, a lack of social support, pain, loneliness, and negative life events. ${ }^{4,15,16}$ Studies which used real-time observational assessments indicate that negative affect is associated with the presence of agitated behaviour ${ }^{17}$ and positive affect is associated with social stimulation and recreational activities. ${ }^{18,19}$

To date, in-depth knowledge about the association between mood, activities, and social interaction during everyday life is lacking. First, there is little research that directly investigates variations in mood levels in relation to variations in activities and social interaction, which would enable us to 'capture the film of PwD's daily life rather than a snapshot of daily life reality. ${ }^{20}$ Second, most studies do not specifically focus on activities and social interaction as potential correlates of mood for PwD but rather on clinical correlates such as cognition and functional dependency. This is a significant omission given that activity levels and social interaction are more amenable to change by care staff than cognitive status or functional dependency. ${ }^{\text {e.g. } 21,22}$ Third, most studies focus on correlates of negative mood such as depressive symptoms. These studies will not directly provide information to guide how a positive mood can be achieved. Again a significant omission given that positive mood is essential for PWD's well-being. ${ }^{5,7}$ Fourth, most 
studies mainly used proxy-reported questionnaires to assess mood and its associated factors. These measures may be influenced by proxies' feelings of burden or distress. ${ }^{23}$, ${ }^{24}$ In addition, questionnaires are prone to recall bias, ${ }^{25}$ which may for example affect estimates of the time spent in activities. ${ }^{26}$

The current study was designed to address these gaps in knowledge. Therefore, the aim of the current study is to identify the degree of association between mood, activity engagement, activity location, and social interaction during everyday life of PwD living in long-term care facilities.

\section{METHODS}

\section{Design}

The current study has an observational design and includes ecological momentary assessments ${ }^{27}$ during the daily lives of PwD living in long-term care facilities. These momentary assessments enable researchers to repeatedly observe and examine real processes and outcomes during daily life.

\section{Setting and Participants}

This study was part of a larger study focusing on long-term care facilities in the Netherlands. ${ }^{28}$ Eighteen wards from eight locations in the south of the Netherlands participated. In total, 158 people with an official diagnosis of dementia were potentially eligible for inclusion in the study.

\section{Measures}

Mood, activity engagement, activity location and social interaction were observed using the Maastricht Electronic Daily Life Observation-tool (MEDLO-tool). ${ }^{29}$ Using this tabletbased tool, momentary assessments ${ }^{27}$ of PwD's daily life were recorded over time. The MEDLO-tool has demonstrated feasibility, validity and reliability and interrater-reliability was sufficient for all domains (agreement ranging from 69\% - 100\%). ${ }^{29}$ A detailed manual of all scoring options is available upon request. Box 1 provides operational definitions of mood, activity engagement, activity location and social interaction. 
Box 1. Mood, activity, interaction and associated operationalisations

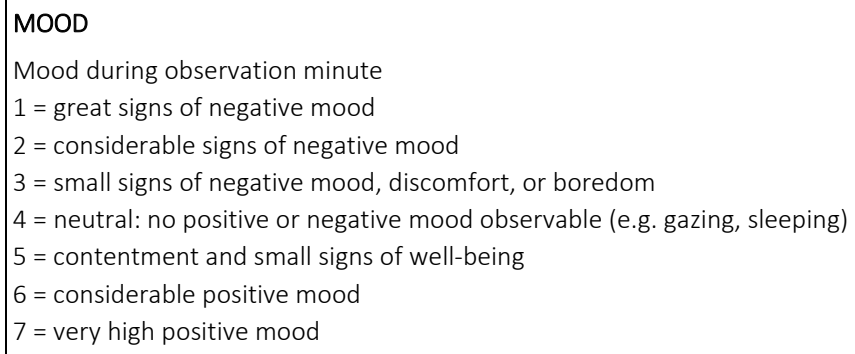

1. Engagement in activity taking place during the observation minute (one from the 14 listed activities can be chosen as an activity that took place) $0=$ was not engaged in activity (sleeping, staring, doing something else) 1 = was actively (=participating in activity) or passively (=focusing on activity) engaged in activity

\begin{tabular}{ll}
\hline Activity & Example \\
\hline Care activity & Visit (para)medical personnel, (self-) care activities \\
Communication / social activity & Talking with others, making telephone call, helping others \\
Eating / drinking & Eating or drinking \\
Household activity & Doing household chores, cooking, gardening and caring for plants \\
Intellectual activity & Playing cards or games, doing (crossword) puzzles, reading, writing \\
Musical activity & Dancing, singing \\
Nature / outdoor activity & Walking outside, farming activity, activity related to pets \\
Outing / shopping & Excursion, outing with family \\
Purposeless behaviour & Repetitive behaviour \\
Sitting / lying & Sitting or lying (not sleeping) without being occupied in an activity \\
Sleeping purposively & Sleeping \\
Television / radio activity & Watching television or listening to the radio \\
Other activity & Activity related to beauty, spirituality, arts, sensory stimulation, walking, \\
Not observable & sports, smoking, etc. \\
\hline
\end{tabular}

2. Location of activity during observation minute

$0=$ inside the facility (communal area on / off the ward, own room, bathroom / toilet)

1 = outside the facility (not present inside the facility)

3. Presence of social interaction during observation minute

$0=$ no social interaction, attempted interaction without response

$1=$ yes, social interaction with one or more persons

If 0 (no social interaction), the presence of one-way social interaction (defined as resident's attempt to have social interaction without getting a response) was recorded

$0=$ no, there was social interaction with one or more persons

1 = yes, there was one-way interaction 


\section{CHAPTER 7}

\section{Mood}

Mood was observed using a 7-point rating scale, ranging from 1 = great signs of negative mood to 7 = very high positive mood. A neutral scoring option (4) is scored in situations in which PwD's mood is not clearly positive or negative, e.g. when they are gazing.

\section{Activities and social interaction}

To determine engagement in activity, the observers recorded the type of activity (e.g. household activity, musical activity) first and the level of engagement afterwards (yes or no). Engagement recorded as 'yes' included both active engagement (real participation in the activity, for example doing household chores) and passive engagement (having a clear focus on the activity without active participation, for example watching someone else doing household chores. The location of the resident during the activity was recorded as inside or outside. Social interaction was recorded as yes or no. As a subcategory of 'no interaction', it was recorded when a resident attempted to socially interact with someone but received no response (i.e. one-way interaction) (yes versus no).

\section{Background Characteristics}

Cognitive status was assessed using the Standardized Mini-Mental State Examination (SMMSE). ${ }^{30}$ The total score of the S-MMSE ranges from 0 to 30, with higher scores indicating less cognitive impairment. Furthermore, demographic data including age, gender, and the number of months that residents lived in the facility were collected.

\section{Procedures}

All data were collected within a period of three weeks in each long-term care setting. Two researchers and one research assistant collected these data. Using the MEDLOtool, all individual PwD were observed on seven days: two weekday mornings (07:0011:30), two weekday afternoons (11:30-16:00), two weekday evenings (16:00-20:30) and one Saturday afternoon (11:30-16:00). There was a half-hour break in each 4.5 hour observation block. A randomized observation schedule ensured that every participant (with a maximum of eight per ward) was observed for one minute during every 20 minute period. After observing a resident for one minute, the observer recorded residents' individual scores on mood, activity engagement, activity location, and social interaction (see also Box 1). In total, 12 (observation minutes per day) * 7 (observation days) $=84$ momentary assessments were recorded per resident.

PwD's background characteristics were provided by certified nursing assistants (age, gender, months living in facility) and PwD themselves (S-MMSE). 


\section{Statistical Analyses}

First, descriptive analyses were conducted. Mean mood scores during activities and social interactions were calculated. Second, three groups of observations were constructed based on mood scores: observations in which PwD had 1) a negative mood (mood scores ranging from 1-3); 2) a neutral mood (mood score of 4); and 3) a positive mood (mood scores ranging from 5-7). After this, we calculated how often activity engagement, activity location, and social interaction occurred with a low, neutral, or positive mood.

Second, a random-effects regression analysis (random intercept) was conducted to assess the association between the continuous variable mood (dependent variable) and activity engagement, activity location, and social interaction (independent variables). In this hierarchical model, the repeated measurements (level one) were nested in participants (level two). Descriptive analyses indicated that engagement in any kind of activity was beneficial for PwD's mood, and therefore the variable 'engagement in activity' was included rather than variables on engagement in types of activities separately (e.g. engagement in musical activities). This increased the stability of the model. One-way social interaction (resident's attempt for social interaction without receiving a response) was excluded for this regression analyses because of its low prevalence. Furthermore, we controlled for the effects of gender, cognition, and type of long-term care facility. All independent variables were entered in the model simultaneously.

Because some participants had missing observations on both dependent and independent variables, a multiple imputation technique ${ }^{31}$ was used to complete the dataset for the regression analysis. The main reasons for missing data were unavailability of participants due to for example care activities or appointments with (para)medical personnel, which makes the missing at random assumption plausible. Missing values were imputed using the participant's mood score, scores on other observed variables, background variables such as gender and cognition and variables that were associated with the reasons for missing data (e.g. there were frequently missing observations during care activities). Missing data were imputed using the MICE package ${ }^{32}$ in $\mathrm{R}_{\text {version } 3.2 .1}$ and analysed and pooled in SPSS version 20. In this publication, the pooled result derived from five imputations is reported.

\section{Ethics}

The study protocol was reviewed by the medical ethics committee of the Maastricht University Medical Center. They declared on 24 January 2014 that the study was noninvasive for people with dementia according to the Medical Research Involving Human Subjects Act. ${ }^{33}$ Legal representatives of PwD provided written informed consent. PwD were asked to assent to participation, where 'assent' was defined as agreeing to participate without having a full understanding of the study and what it would involve. ${ }^{34}$ 


\section{CHAPTER 7}

\section{RESULTS}

\section{Sample Characteristics}

The legal representatives of 115 of 158 potential participants (73\%) agreed to participation in the study. In total, 9,660 observations were conducted (115 participants * 84 observations per participant). Table 1 provides the sample characteristics of the participants.

Table 1. Sample characteristics

\begin{tabular}{|c|c|}
\hline & $\begin{array}{l}\text { Total } \\
n=115\end{array}$ \\
\hline Age, mean (SD) & $83.8(7.8)$ \\
\hline Gender (female), \% & 75 \\
\hline Marital status (widowed), \% & 66 \\
\hline Months living in facility, mean (SD) & $29.5(22.7)$ \\
\hline S-MMSE, mean (SD) & $8.5(6.9)$ \\
\hline
\end{tabular}

$\mathrm{SD}=$ standard deviation

\section{Mood}

A negative, neutral, or positive mood was recorded during $2 \%, 25 \%$, and $73 \%$ of the observations, respectively. PWD's mean mood score was 4.8 (SD: 0.6), indicating an overall positive mood.

\section{Activities and Social Interaction}

Table 2 provides an overview of the percentage of observations PWD spent on activity engagement, where this activity took place, and social interaction.

PWD were engaged (actively and passively) in some kind of activity during $73 \%$ of the observations, whereas they were disengaged during $27 \%$ of the observations. Engagement in communication and eating or drinking occurred most frequently (20\% and 19 $\%$, respectively). Furthermore, people were engaged during sitting or lying - meaning that they were awake and actively looking around without doing a specific activity during $14 \%$ of the observations. Most activities took place inside the facility (92\%).

PwD had social interaction (verbal or non-verbal) during 33.5\% of the observations. As a subcategory of 'no interaction', PwD's attempt for social interaction without getting any response was observed during slightly more than $1 \%$ of the observations. Further analyses showed that this happened at least once to 49 (of the 115) individual PwD. 
Table 2. Activities and social interaction: frequency and associated mood score

\begin{tabular}{|c|c|c|c|}
\hline & & Frequency & Mean mood score (SD) \\
\hline Engagement in any activity (\%) & All activities together & 73.1 & $5.0(0.5)$ \\
\hline \multirow[t]{14}{*}{ Engagement in activity related to... (\%) } & Care & 7.3 & $4.8(0.7)$ \\
\hline & Communication / social & 19.7 & $5.0(0.6)$ \\
\hline & Eating / drinking & 19.1 & $5.0(0.3)$ \\
\hline & Household & 8.4 & $5.0(0.3)$ \\
\hline & Intellect & 6.5 & $5.1(0.3)$ \\
\hline & Music & 3.2 & $5.2(0.5)$ \\
\hline & Nature / outdoor & 1.2 & $5.2(0.5)$ \\
\hline & Outing / shopping & 3.6 & $5.5(0.6)$ \\
\hline & Purposeless behaviour & NA* & $N A^{*}$ \\
\hline & Sleeping & $\mathrm{NA}^{+}$ & $\mathrm{NA}^{+}$ \\
\hline & Sitting / lying & 13.6 & $4.9(0.4)$ \\
\hline & Television / radio & 7.6 & $5.0(0.3)$ \\
\hline & Other & 9.8 & $4.9(0.7)$ \\
\hline & Not observable & $\mathrm{NA}^{+}$ & $\mathrm{NA}^{+}$ \\
\hline No engagement in any activity (\%) & All activities together & 26.9 & $4.2(0.4)$ \\
\hline \multirow[t]{2}{*}{ Location of activity (\%) } & Outside & 7.6 & $5.1(0.4)$ \\
\hline & Inside & 92.4 & $4.7(0.6)$ \\
\hline \multirow[t]{3}{*}{ Social interaction (\%) } & Yes & 33.5 & $5.0(0.6)$ \\
\hline & No & 66.5 & $4.6(0.5)$ \\
\hline & One-way interaction & 1.3 & $4.4(1.0)$ \\
\hline
\end{tabular}

$\mathrm{SD}=$ standard deviation

*NA = not applicable: no engagement assessment; ${ }^{\dagger} \mathrm{NA}=$ not applicable: engagement in sleeping did not occur

Association between Mood, Activities, and Social Interaction

\section{Descriptive Analyses}

The mean mood scores during activity engagement, when PwD were inside or outside and during social interaction are shown in Table 2. In addition, Table 3 provides percentages of how activity engagement, activity location, and social interaction were accompanied by negative, neutral, or positive mood.

When PwD were engaged in an activity they had a mean mood score of 5.0. During $96 \%$ of the observations they had positive mood scores. On the other hand, PwD had mostly neutral mood scores (83\%) when they were disengaged (mean mood: 4.2). Highest mood scores were recorded when PwD were engaged in an outing or shopping activity (mean mood: 5.5), musical activity (mean mood 5.2), and (outdoor) activity related to nature (mean mood: 5.2). When activities were performed outside (mean mood: 5.1), PwD mainly had positive mood scores (95\%). When activities were per- 


\section{CHAPTER 7}

formed inside, PWD had positive mood scores during $72 \%$ of the observations (mean mood 4.7).

During social interactions - either verbal or non-verbal - PwD displayed signs of a positive mood (mean mood: 5.0) during 94\% of the observations. When PwD had no social interaction (mean mood: 4.6), their mood was positive during $63 \%$ of the observations. PwD's mood was more negative when they attempted to have social interaction but received no response (mean mood: 4.4): 26\% of the PwD showed signs of negative mood and $12 \%$ had a neutral mood during these attempts for interaction.

Table 3. Activities and social interaction divided by mood scores

\begin{tabular}{|c|c|c|c|c|}
\hline & & \multicolumn{3}{|l|}{ Mood } \\
\hline & & $\begin{array}{l}\text { Negative } \\
\text { (score 1-3) }\end{array}$ & $\begin{array}{l}\text { Neutral } \\
\text { (score 4) }\end{array}$ & $\begin{array}{l}\text { Positive } \\
\text { (score 5-7) }\end{array}$ \\
\hline Engagement in any activity (\%) & All activities together & 2.2 & 1.8 & 96.0 \\
\hline \multirow[t]{14}{*}{ Engagement in activity related to... (\%) } & Care & 5.7 & 2.6 & 91.8 \\
\hline & Communication/social & 3.5 & 1.5 & 95.0 \\
\hline & Eating / drinking & 1.3 & 1.2 & 97.5 \\
\hline & Household & 0.4 & 1.6 & 98.0 \\
\hline & Intellect & 0.2 & 0.9 & 98.8 \\
\hline & Music & 0 & 0 & 100.0 \\
\hline & Nature / outdoor & 1.6 & 0.0 & 98.4 \\
\hline & Outing / shopping & 0.0 & 0.0 & 100.0 \\
\hline & Purposeless behaviour & $N A^{*}$ & $N A^{*}$ & $N A^{*}$ \\
\hline & Sleeping & $\mathrm{NA}^{+}$ & $\mathrm{NA}^{+}$ & $\mathrm{NA}^{+}$ \\
\hline & Sitting / lying & 3.4 & 3.3 & 93.4 \\
\hline & Television / radio & 1.0 & 2.2 & 96.8 \\
\hline & Other & 6.6 & 2.7 & 90.7 \\
\hline & Not observable & $N A^{*}$ & $N A^{*}$ & $N A^{*}$ \\
\hline No engagement in any activity (\%) & All activities together & 1.0 & 82.6 & 16.3 \\
\hline \multirow[t]{2}{*}{ Location of activity (\%) } & Outside & 0.2 & 4.4 & 95.4 \\
\hline & Inside & 2.3 & 26.0 & 71.7 \\
\hline \multirow[t]{3}{*}{ Social interaction (\%) } & Yes & 3.7 & 1.9 & 94.4 \\
\hline & No & 1.5 & 35.4 & 63.0 \\
\hline & One-way interaction & 25.5 & 11.7 & 62.8 \\
\hline
\end{tabular}

*NA = not applicable: no engagement assessment; ${ }^{\dagger} \mathrm{NA}=$ not applicable: engagement in sleeping did not occur

\section{Regression Analyses}

The result of the random-effects regression analysis (adjusted for gender, cognition, and type of long-term care facility) is presented in Table 4. In line with the descriptive 
analyses, these analyses revealed that a higher (positive) mood was associated with engagement in activities, being outside during activities, and having social interaction.

Table 4. Factors associated with mood: regression analysis (adjusted for gender, cognition, and type of longterm care facility)

\begin{tabular}{llllll}
\hline & Estimate & Standard error & \multicolumn{2}{l}{ 95\% confidence interval } & p value \\
\cline { 5 - 6 } & & & Lower & Upper & \\
\hline Engagement in activity & .712 & .015 & .741 & .742 & $<.001$ \\
Location of activity & .126 & .027 & .070 & .181 & $<.001$ \\
Social interaction & .118 & .014 & .090 & .147 & $<.001$ \\
\hline
\end{tabular}

\section{DISCUSSION}

This is the first study to: 1 ) directly investigate variations in mood levels in relation to variations other variables using momentary assessments; 2 ) focus specifically on variations in activity engagement, activity location and social interaction as potential predictors of mood; 3) focus on positive mood outcomes; and 4) study the relationship between mood and PwD's attempt for interaction without getting a response. We found that PwD's mood was associated with engagement in activities, doing activities outside, and having social interaction. The type of activity was less important for mood than the fact that PWD were engaged in an activity. Furthermore, we found that PWD's mood was negative when they attempted to have social interaction but received no response.

The mood assessments in the current study indicate that PWD who live in a longterm care facility feel content and present small signs of well-being most of the time. This result is consistent with other studies that found that PWD who live in long-term care facilities express positive emotions approximately eight to thirteen times more frequently than negative emotions. ${ }^{14,35}$

Although the current study demonstrated that more activity engagement and social interaction are related to a positive mood, the best balance between activity/social engagement and disengagement is highly personal. Disengagement, which is likely to occur during for example resting, could be a self-chosen time to relax and therefore may be important for PWD as well. In addition, not every social interaction is by definition a positive experience due to misconceptions and misinterpretations that can occur. $^{36}$

Participants in the current study were engaged in an activity during $73 \%$ of the observations. This number is relatively high in comparison with other studies. ${ }^{37,} 38$ However, definitions of 'activity engagement' differ among studies. For example, in the current study 'activity engagement' was a broad construct and also included residents who were passively engaged. For example, residents were rated as engaged when they focused clearly on others who did an activity, whereas other studies regarded this as 
inactivity. ${ }^{37,38}$ Our finding that activity engagement is associated with better mood is in line with other empirical studies. ${ }^{18,26}$ Kitwood's theory on psychological needs ${ }^{39}$ also shows that occupation - defined as engagement in the process of daily life in a way that is personally relevant - is a key psychological need. Our finding that there is not one single activity that improves PwD's mood suggests that, in line with Kitwood's emphasis on individualized activities, the type of activity that has a positive influence on PwD's mood differs per person.

The current study demonstrated that a higher frequency of social interaction is associated with better mood. In line with this result, Abbott et al. (2015) reported - next to the finding that PWD showed no affect during three quarters of all social interactions - that pleasure was the type of affect that was most frequently observed during social interactions. ${ }^{40}$ Almost half of all participants were not being responded to as they attempted to interact with other people at least once during the observations. Although the percentage of these one- way interactions appears relatively low (1.3\%), it should be regarded as clinically significant as it had a detrimental effect on PwD's mood. Kitwood \& Bredin (1992b) suggest that PWD's attempt for social interaction is a positive thing and indicates the presence of agency, defined as 'the ability to control life in a meaningful way, to make some mark upon others and the world' is central to PwD's well-being. ${ }^{41}$ However, institutional living holds a great potential for the loss agency, since people are bound to the structures and routines of an institution, with few space for individual habits and preferences. ${ }^{42}$ PwD's struggle to interact and thus to maintain a sense of agency is not always recognized by nursing staff. They often have unspoken assumptions about PwD's 'problematic' behaviour and accordingly do not recognize agency. ${ }^{43}$ In addition, they label some PwD too quickly as a person who is unable to communicate. Ward et al. (2008) refer to this as 'cognitive disablism', and point out that failing to recognize PWD's communication attempts denies them the right to a relationship with the world they inhabit. Consequently, PwD's mood may decrease and their behaviour remains misunderstood. ${ }^{44}$

PwD were mostly inside the facility. However, although few activities took place outside, being outside was associated with a better mood than being inside. Outdoor areas offer PWD the opportunity to stimulate their senses and to engage in a variety of activities that may remind of their previous home life, for example gardening, walking, and relaxation. ${ }^{45,46}$ In addition, qualitative literature shows that $\mathrm{PWD}$, relatives and nursing staff value having an accessible, attractive, and safe outside space in long-term care facilities. ${ }^{47,48}$ A recent systematic literature review showed mixed results regarding the association between PwD's emotions and outdoor spaces such as gardens. ${ }^{48}$ However, they did find a clear association between decreased levels of agitation and garden use. 


\section{Limitations}

This study does have some limitations. First, no causal relationships could be established because this study focused only on associations. As a result, we cannot state that activity engagement, being outside, and social interaction cause a positive mood. It could also be that PWD with a positive mood are more likely to participate in activities, to go outside, or to have social interaction. Second, 14 of the 18 wards that participated in this study were small-scale facilities. PwD in small-scale facilities may be, compared to those in large-scale facilities, relatively often engaged in (outside) activities and may have more social interaction. This could have influenced the association between mood, activities, and social interaction.

\section{Implications for practice}

As a variety of activities have the potential to be important for a positive mood, the results of this study call for a person-centred approach by offering activities based on PwD's individual preferences ${ }^{\text {e.g. }}{ }^{49}$ PWD and their family members can therefore be involved in the development of individualized activity plans. ${ }^{49-51}$ As PwD with a lower cognition participate in fewer everyday activities, ${ }^{52}$ the inclusion of people with more advanced dementia should be promoted by activities adapted to individual possibilities. Furthermore, teaching nursing staff how to recognize PwD's sense of agency and psychological needs is a priority. Finally, nursing staff could encourage PWD to go outside, either alone or with company. A small-scale intervention study showed that recognizing resident's autonomy and independence by unlocking the exit door decreases the number of agitated behaviours. ${ }^{53}$

\section{Implications for research}

Future studies on the association between mood and social interaction should focus on the quality and type of social interactions. Quality of interaction ratings can be made with the personal enhancers and personal detractions in Dementia Care Mapping. ${ }^{54}$ Such a level of detail will provide a more sensitive picture of what happens during the daily lives of PWD and why some interactions are associated with a negative mood. For example, Ward et al. (2008) described that one of the most frequently heard carer's instruction during daily life was that PwD should 'sit down', 44 which has probably not the highest potential for a positive mood. Furthermore, more high-quality studies, preferably randomized intervention studies, are needed to assess in what way being outdoors and access to the outdoor area influence mood and which specific activities in the outside environment have the highest potential for positive mood. 


\section{REFERENCES}

1. Rabins PV and Black BS. Measuring quality of life in dementia: purposes, goals, challenges and progress. International Psychogeriatrics 2007;19:401-407.

2. Kitwood T. Dementia reconsidered: The person comes first. Buckinham: Open University Press, 1997.

3. Banerjee S, Samsi K, Petrie CD, et al. What do we know about quality of life in dementia? A review of the emerging evidence on the predictive and explanatory value of disease specific measures of health related quality of life in people with dementia. International Journal of Geriatric Psychiatry 2009;24:15-24.

4. Beerens HC, Zwakhalen SM, Verbeek H, et al. Factors associated with quality of life of people with dementia in long-term care facilities: a systematic review. International Journal of Nursing Studies 2013;50:1259-1270.

5. Byrne-Davis L, Bennett $P$ and Wilcock G. How are quality of life ratings made? Toward a model of quality of life in people with dementia. Quality of Life Research 2006;15:855-865.

6. Cahill S and Diaz-Ponce AM. 'I hate having nobody here. I'd like to know where they all are': Can qualitative research detect differences in quality of life among nursing home residents with different levels of cognitive impairment? Aging \& Mental Health 2011;15:562-572.

7. Dröes R-M, Boelens-Van Der Knoop EC, Bos J, et al. Quality of life in dementia in perspective An explorative study of variations in opinions among people with dementia and their professional caregivers, and in literature. Dementia 2006;5:533-558.

8. Beerens HC, Sutcliffe C, Renom-Guiteras A, et al. Quality of life and quality of care for people with dementia receiving long term institutional care or professional home care: the European RightTimePlaceCare study. Journal of the American Medical Directors Association 2014;15:54-61.

9. Verkaik R, Nuyen J, Schellevis F and Francke A. The relationship between severity of Alzheimer's disease and prevalence of comorbid depressive symptoms and depression: a systematic review. International Journal of Geriatric Psychiatry 2007;22:1063-1086.

10. Zuidema SU, Derksen E, Verhey FR and Koopmans RT. Prevalence of neuropsychiatric symptoms in a large sample of Dutch nursing home patients with dementia. International Journal of Geriatric Psychiatry 2007;22:632-638.

11. Garre-Olmo J, Lopez-Pousa S, Vilalta-Franch J, et al. Evolution of depressive symptoms in Alzheimer disease: one-year follow-up. Alzheimer Disease and Associated Disorders 2003;17:77-85.

12. Smalbrugge $M$, Jongenelis $L$, Pot $A M$, et al. Incidence and outcome of depressive symptoms in nursing home patients in the Netherlands. The American Journal of Geriatric Psychiatry 2006;14:1069-1076.

13. Clark LA and Watson D. Mood and the mundane: relations between daily life events and self-reported mood. Journal of Personality and Social Psychology 1988;54:296-308.

14. Lee $\mathrm{KH}$, Algase DL and McConnell ES. Daytime observed emotional expressions of people with dementia. Nursing Research 2013;62:218-225.

15. Barca ML, Engedal K, Laks J and Selbaek G. A 12 months follow-up study of depression among nursinghome patients in Norway. Journal of Affective Disorders 2010;120:141-148.

16. Jongenelis $\mathrm{K}$, Pot $\mathrm{AM}$, Eisses $\mathrm{AMH}$, et al. Prevalence and risk indicators of depression in elderly nursing home patients: the AGED study. Journal of Affective Disorders 2004;83:135-142.

17. Cohen-Mansfield J, Dakheel-Ali M, Jensen B, et al. An analysis of the relationships among engagement, agitated behavior, and affect in nursing home residents with dementia. International Psychogeriatrics 2012;24:742-752.

18. Schreiner A, Yamamoto $E$ and Shiotani H. Positive affect among nursing home residents with Alzheimer's dementia: the effect of recreational activity. Aging \& Mental Health 2005;9:129-134.

19. Cohen-Mansfield J, Marx MS, Thein K and Dakheel-Ali M. The impact of stimuli on affect in persons with dementia. The Journal of Clinical Psychiatry 2011;72:480-486.

20. Myin-Germeys I, Oorschot M, Collip D, et al. Experience sampling research in psychopathology: opening the black box of daily life. Psychological Medicine 2009;39:1533-1547. 
21. Nehen HG and Hermann D. Supporting dementia patients and their caregivers in daily life challenges: review of physical, cognitive and psychosocial intervention studies. European Journal of Neurology 2015;22:246-e220.

22. van der Ploeg ES, Eppingstall B, Camp CJ, et al. A randomized crossover trial to study the effect of personalized, one-to-one interaction using Montessori-based activities on agitation, affect, and engagement in nursing home residents with dementia. International Psychogeriatrics 2013;25:565-575.

23. Arons AM, Krabbe PF, Scholzel-Dorenbos CJ, et al. Quality of life in dementia: a study on proxy bias. BMC Medical Research Methodology 2013;13:110.

24. Sands LP, Ferreira P, Stewart AL, et al. What explains differences between dementia patients' and their caregivers' ratings of patients' quality of life? The American Journal of Geriatric Psychiatry 2004;12:272-280.

25. Bolger $N$ and Laurenceau J-P. Intensive longitudinal methods. An introduction to diary and experience sampling research. TD Little, editor. New York: The Guilford Press, 2013.

26. Smit D, de Lange J, Willemse B, et al. Activity involvement and quality of life of people at different stages of dementia in long term care facilities. Aging \& Mental health 2015.

27. Shiffman S, Stone AA and Hufford MR. Ecological momentary assessment. Annual Review of Clinical Psychology 2008;4:1-32.

28. de Boer B, Hamers JPH, Beerens HC, et al. Living at the farm, innovative nursing home care for people with dementia - design of an observational longitudinal study. BMC Geriatrics 2015;15:144.

29. de Boer B, Beerens HC, Zwakhalen SMG, et al. Daily lives of people with dementia: development of the Maastricht Electronic Daily Life Observation-tool. International Psychogeriatrics 2016.

30. Molloy DW, Alemayehu E and Roberts R. Reliability of a Standardized Mini-Mental State Examination compared with the traditional Mini-Mental State Examination. American Journal of Psychiatry 1991;148:102-105.

31. Schafer JL and Graham JW. Missing data: our view of the state of the art. Psychological Methods 2002; 7:147-177.

32. Buuren S and Groothuis-Oudshoorn K. MICE: Multivariate imputation by chained equations in R. Journal of Statistical Software 2011;45.

33. Medical Research Involving Human Subjects Act. 26 February 1998.

34. Slaughter S, Cole D, Jennings $E$ and Reimer MA. Consent and assent to participate in research from people with dementia. Nursing Ethics 2007;14:27-40.

35. Kolanowski AM, Litaker MS, Catalano PA, et al. Emotional well-being in a person with dementia. Western Journal of Nursing Research 2002;24:28-48.

36. Ericsson I, Hellström I and Kjellström S. Sliding interactions: An ethnography about how persons with dementia interact in housing with care for the elderly. Dementia 2011;10:523-538.

37. den Ouden M, Bleijlevens MH, Meijers JM, et al. Daily (In) activities of nursing home residents in their wards: an observation study. Journal of the American Medical Directors Association 2015;16:963-969.

38. Wood W, Harris S, Snider M and Patchel SA. Activity situations on an Alzheimer's disease special care unit and resident environmental interaction, time use, and affect. American Journal of Alzheimer's Disease and Other Dementias 2005;20:105-118.

39. Kitwood T. The experience of dementia. Aging \& Mental Health 1997;1:13-22.

40. Abbott KM, Sefcik JS and Van Haitsma K. Measuring social integration among residents in a dementia special care unit versus traditional nursing home: A pilot study. Dementia 2015:(Epub ahead of print).

41. Kitwood T and Bredin K. Towards a theory of dementia care: personhood and well-being. Ageing and society 1992;12:269-287.

42. Goffman E. Asylums: Essays on the social situation of mental patients and other inmates. New York: Anchor, 1968.

43. Rodriquez J. Attributions of agency and the construction of moral order: Dementia, death, and dignity in nursing-home care. Social Psychology Quarterly 2009;72:165-179.

44. Ward R, Vass AA, Aggarwal N, et al. A different story: exploring patterns of communication in residential dementia care. Ageing and Society 2008;28:629-651. 


\section{CHAPTER 7}

45. Cohen-Mansfield J and Werner P. Outdoor wandering parks for persons with dementia: a survey of characteristics and use. Alzheimer Disease \& Associated Disorders 1999;13:109-117.

46. Brawley EC. Environmental design for Alzheimer's disease: a quality of life issue. Aging \& Mental health 2010;5:79-83.

47. Innes A, Kelly F and Dincarslan O. Care home design for people with dementia: What do people with dementia and their family carers value? Aging \& Mental Health 2011;15:548-556.

48. Whear R, Coon JT, Bethel A, et al. What is the impact of using outdoor spaces such as gardens on the physical and mental well-being of those with dementia? A systematic review of quantitative and qualitative evidence. Journal of the American Medical Directors Association 2014;15:697-705.

49. Van Haitsma KS, Curyto K, Abbott KM, et al. A randomized controlled trial for an individualized positive psychosocial intervention for the affective and behavioral symptoms of dementia in nursing home residents. The Journals of Gerontology Series B: Psychological Sciences and Social Sciences 2015;70:35-45.

50. DiNapoli EA, Scogin F, Bryant AN, et al. Effect of individualized social activities on quality of life among older adults with mild to moderate cognitive impairment in a geriatric psychiatry facility. Aging \& Mental Health 2015;20:262-270.

51. Tak SH, Kedia S, Tongumpun TM and Hong SH. Activity Engagement: Perspectives from Nursing Home Residents with Dementia. Educational Gerontology 2015;41:182-192.

52. Edvardsson D, Petersson L, Sjogren K, et al. Everyday activities for people with dementia in residential aged care: associations with person-centredness and quality of life. International Journal of Older People Nursing 2014;9:269-276.

53. Namazi KH and Johnson BD. Pertinent autonomy for residents with dementias: Modification of the physical environment to enhance independence. American Journal of Alzheimer's Disease and Other Dementias 1992; 7:16-21.

54. University of Bradford. DCM 8 User's Manual. Bradford: Bradford Dementia Group, 2005. 


\section{CHAPTER 8}

General discussion

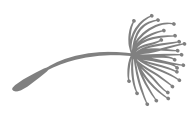


The main objectives of this dissertation were 1) to gain insight into quality of life (QoL) of people with dementia $(P W D)$ receiving long-term care at home and in long-term care facilities; and 2) to investigate which factors are associated with QoL of PwD who receive long-term care at home and in long-term care facilities. To meet the objectives, different studies employing various research methods were conducted. First, a systematic literature review was performed. Second, observational data about QoL and quality of care (QoC) for 2014 PwD from eight European countries was collected. Third, a total of 9,660 momentary observations were assessed to obtain more in-depth information about QoL and everyday life of PwD.

In this chapter, the main findings of the research presented in this dissertation are discussed and a reflection on some methodological and theoretical issues is provided. Based on the conclusions that can be drawn from this dissertation, future directions are presented.

\section{MAIN FINDINGS}

PwD who receive long-term care can have a satisfactory QoL. In this dissertation, both PwD themselves and their (in)formal caregivers evaluated a variety of QoL domains positively. We found no indications that the transition from living at home to living in a long-term care facility has a negative impact on QoL. In addition, QoL did not necessarily decrease in the months following admission. Once living in a long-term care facility, PwD had various opportunities to maintain a good QoL. PwD spent most of their day engaged in activities and had social interactions regularly. However, country- and individual differences were detected. Overall, QoL was higher in northern and western countries of Europe (like Sweden and England) than in eastern and southern European countries (like Estonia and Spain). In addition, some PwD spent their day more actively with more engagement in activities and social interactions than others.

In this dissertation, mood was consistently associated with PWD's QoL. A negative mood and more specifically depressive symptoms were associated with a lower QoL, and a positive mood was associated with higher QoL. Furthermore, a positive mood was associated with having social interaction, engagement in activities, and doing these activities outside. We did not detect specific activities that were more important for QoL or mood than other activities. Finally, there was little evidence for the association between QoL and QoC indicators. 


\section{METHODOLOGICAL CONSIDERATIONS}

This section addresses considerations regarding the methodological strengths and limitations of the studies presented in this dissertation. First, the design and the study population are discussed. Furthermore, issues related to QoL measurement are addressed.

\section{Study design}

As the main goal of this dissertation was to explore QoL of PwD, different studies employing three observational methods were used to study QoL: 1) a systematic literature review of observational studies; 2) an observational study using standardized questionnaires; and 3) an observational study using momentary assessments. Observational research is strong in realism, as it reflects real situations without artificial interventions. ${ }^{1}$ A strength of using different methodologies to investigate one aspect is that it provides an elaborated understanding and a richer insight than single observational studies. ${ }^{2}$ Using a systematic literature review and questionnaires, data about a large number of PwD could be collected. With momentary assessments, we could study more in-depth which aspects of daily life are important for QoL.

Because all the observational studies were descriptive, it was difficult to infer causal relationships. ${ }^{1}$ Therefore it is difficult to state whether QoL correlates cause a positive or negative QoL or whether they are a result of a certain QoL level. For example, it is unknown whether a positive mood or social interaction cause a good QoL, or are a result of a good QoL. On the other hand, the association between mood and QoL was established in different populations and with different study designs, which therefore lends support for a causal relationship. ${ }^{3}$ It seems plausible that depressive symptoms cause a lower QoL and a decrease in depressive symptoms will improve QoL.

\section{Study population}

Two data collections used in this dissertation included specific groups of PwD. Careful interpretation of these samples is necessary as they have implications for external validity. First, only European PwD who were at the so-called 'margins of care' were included. This means that in the home care setting, only PwD who were at risk for admission to a long-term care facility within six months were included. In the long-term care facility setting, only PWD who were recently admitted to a long-term care facility - i.e. at least one month but no longer than three months - were included. Life of PwD at 'the margins of care' is often more turbulent than the lives of other PwD. It is repeatedly associated with high caregiver burden, ${ }^{4}$ increased social isolation, ${ }^{5}$ and involves challenges concerning PwD's loss of home and changes in own standards of living. ${ }^{6}$ Considering all the changes PWD go through during this period, factors that are associated with PWD's QoL are likely to be shifting as well. 
Second, 14 of the 18 wards (78\%) in the Dutch momentary assessment-study were small-scale. In addition, five of these small-scale arrangements ( $28 \%$ of total) were located on green care farms. For Dutch standards, these percentages are high. In 2010 a quarter of the Dutch long-term care facilities for PwD was small-scale ${ }^{7}$ In addition, there are scarcely any green care farms that provide long-term institutional care. ${ }^{8}$ QoL and factors associated with QoL of PWD living in small-scale facilities - especially those in the green care farms - could be different from those living in traditional large-scale nursing homes. It could be true that PwD living in a green care farm environment have more opportunities to maintain a positive mood during the day than PWD living in other environments. For example, a study in day care farms showed that PwD participated in more activities and different activities than those in regular day care facilities. ${ }^{9}$ On the other hand, the various facility types and especially the inclusion of green care farms enabled us to investigate the association between a wide range of activities and QoL.

\section{QoL measurement}

Three methods were used to gain insight into PwD's QoL. First, using the quality of life Alzheimer's Disease questionnaire (QoL-AD), ${ }^{10,11}$ PwD were asked how they perceived their QoL. Second, proxies (formal and informal caregivers) were also asked to fill out the QoL-AD questionnaire. Third, PwD were observed during their daily life and using the Maastricht Electronic Daily Life Observation-tool (MEDLO-tool), ${ }^{12}$ information about their QoL was collected.

A European consensus study identified the QoL-AD as the measure of choice for evaluating QoL in dementia. ${ }^{13}$ However, some issues with respect to QoL measurement using a questionnaire should be acknowledged. Recall bias is an issue, especially for selfreported QoL. Reduced cognitive functioning impedes PWD's ability to comprehend their whole life and to communicate their feelings. As a result, self-ratings of QoL are more likely a reflection of PwD's well-being 'in the moment' than a comprehensive weighing of various broad QoL domains. This recall bias is less applicable for proxy reports. However, as the QoL domains are very broad, it is questionable to what extent proxy-reports reflect PWD's well-being during daily life. For instance, a bad financial situation could result in a lower QoL-AD score, despite the fact that it is questionable whether a person with dementia really experiences a lower well-being in his/her daily life due to financial constraints. Besides the discussion related to what is actually measured with QoL questionnaires (including the QoL-AD), it is important to mention that the distinction between what constitutes QoL and which factors influence QoL is blurred. ${ }^{14}$ Consequently, some factors have been identified as influential on QoL whereas they are also part of the QoL construct. For example, this dissertation assessed the association between social interactions and QoL, whereas social relationships are also part of the QoL-AD questionnaire. This increases the risk of detecting an association due to overlap between the constructs. 
Using the MEDLO-tool, detailed and frequent observations enabled the assessment of real situations and PwD's well-being 'in the moment', which therefore reduces the risk of measurement bias which has been addressed in the former paragraph. However, it should be acknowledged that the results of the QoL-AD and the MEDLO-tool are not entirely comparable as they have different theoretical backgrounds. Although the MEDLO-tool was initially developed to picture PwD's daily life and not their quality of life, it contains various domains that are important for PwD's QoL. Especially 'positive outcomes' such as activities and their social interactions are increasingly considered to be important for PwD's QoL. ${ }^{15}$

\section{THEORETICAL CONSIDERATIONS}

This section reflects on the results of this dissertation. First, a reflection on QoL of PwD is provided. Second, the association between QoL and mood will be discussed more thoroughly. Third, the association between QoL and QoC will be addressed.

\section{Quality of life and dementia}

This dissertation provided more insight into QoL of PwD receiving long-term care. The results showed that the presence or the progression of dementia does not inevitably result in a low QoL. QoL of the majority of PWD did not change over time but remained stable. Furthermore, admission to a long-term care facility itself did not by definition have a detrimental effect on QoL. On average, QoL of PwD who lived at home was comparable to QoL of those who were recently admitted to a long-term care facility. These findings confirm a concept known as the disability paradox, ${ }^{16}$ which states that people with chronic conditions may report a good QoL because they are able to adjust to their personal circumstances. What matters in life can change and priorities may become different as the dementia progresses.

Although PwD are able to adapt to various circumstances, the effect of admission to a long-term care facility on QoL differs per person. On the one hand, this dissertation found that QoL for a quarter of the PwD decreases in the period after admission. This could for example be related to the fact that admission involves various losses and changes in one's own standards of living. ${ }^{6}$ On the other hand, this dissertation showed that QoL for the majority of PwD (75\%) remained stable or even improved in the period after admission to a long-term care facility. Professional nursing staff may be better able to detect and treat depressive symptoms than informal caregivers at home, which will positively influence PwD's QoL. Furthermore, admitted PwD can perhaps seize more opportunities to engage in more social activities than before admission, which is also important for their QoL. 
Hence, a careful consideration of which physical and social environment best suits an individual is essential for QoL. To gain more insight into this, an increased understanding of the optimal 'person-environment fit ${ }^{17,18}$ should be achieved. This entails identifying the environment in which the PWD's needs, abilities and preferences best match with the environmental opportunities. In addition, besides the fact that PwD have to adapt to changing demands of their environment (which is possible to a large extent), the environment should also be modifiable to accommodate PwD's needs, abilities and preferences. ${ }^{18}$ For example, whereas the environment should provide a high level of care for largely dependent people, the environment should appeal more to the retained capacities of others. Because personal characteristics determine the environment in which people have an optimal person-environment fit, the weighing of needs, abilities, preferences and living environment should be done on an individual level.

\section{Mood}

Mood was found to be the most consistent factor associated with QoL. This is plausible because PwD are likely to evaluate various QoL domains positively if they have a positive mood. For example, PwD with an overall positive mood probably have a more extensive network and may assess their overall QoL more positively than those with depressive symptoms. Similarly, if PwD have depressive symptoms, they may be more inclined to negatively evaluate several QoL domains related to physical health or social support. $^{19}$

In this dissertation, mood was considered as both a factor that constitutes QoL (because it was part of the QoL-AD) and a factor associated with QoL (because the association between mood and the QoL-AD was assessed). Although the fact that mood was part of the QoL-AD might imply that the association between mood and QoL is obvious, two findings show that QoL is a broader construct than just mood. First, we re-analyzed all the regression analyses from this dissertation in which the association between QoL and a variable on mood/depressive symptoms was significant (Chapters 3, 4 and 5). In these additional analyses, the domain 'mood' was removed from the QoL-AD scale. This enabled the assessment of the association between the QoL-AD without mood and a variable on mood/depressive symptoms. The results reveal that the association between the QoL-AD and mood/depressive symptoms was not dependent on the mood item in the QoL-AD scale, as the significance levels of the new analyses were similar to those in the original analyses. Second, PwD who lived at home at risk for admission had more depressive symptoms than those who were recently admitted. However, we found no differences in QoL between these two groups, indicating that more depressive symptoms were not inevitably associated with a lower QoL and that other factors also play a role in QoL assessment. 
This dissertation expanded further on aspects that have the potential to affect PwD's mood. We did not detect that engagement in some specific activities was more important than engagement in activities in general. The fact that PwD are engaged in activities appears more important for mood than the specific activity or cluster of activities that is carried out. Indeed, especially a lack of occupation had a negative influence on PwD's mood. An important explanation for this finding is that PWD can literally have the feeling that they 'die of boredom'. ${ }^{20}$ Therefore, 'having something to do' may be even more important than a specific type of activity. In addition, an important explanation for not finding specific activities that are important for all PwD, is that activity preferences are highly personal. Therefore, activities should be individualized according to PwD's preferences.

\section{Quality of life and quality of care}

This dissertation did not detect a clear association between PwD's QoL (as measured with the QoL-AD) and traditional QoC indicators (e.g. psychotropic drug use, weight loss, physical restraint use). This result questions whether caregiving does not influence QoL at all or whether only the QoC indicators used for this dissertation were not important for QoL.

Although the QoC indicators that were used in this dissertation are well-established and provide important information about physical aspects of caregiving, QoC comprises more than these aspects of physical care. Interpersonal aspects of caregiving are identified as essential aspects of QoC. ${ }^{21,22}$ Indeed, PwD regard person-centeredness, sociable relationships and kindness of care personnel as even more important than practical care tasks that 'have to be done'. ${ }^{22}$ Considering the importance PwD attach to interpersonal aspects of caregiving, their QoL may be more dependent on good interpersonal care than on good physical care. Besides studying QoL in relation to the traditional QoC indicators, this dissertation also investigated the association between QoL (and mood, which is an important indicator for $\mathrm{QoL}$ ) and interpersonal aspects of care. Using momentary assessments, interpersonal caregiving such as social interactions and activities (which are often initiated by care staff) were associated with a good QoL / positive mood. These results confirm that QoL is associated with interpersonal aspects of care, which were not measured by the traditional QoC indicators such as psychotropic drug use and weight loss.

In conclusion, it could be argued that the interpersonal aspects of caregiving are more important for PwD's QoL than the traditional QoC indicators. Increasing the quality of interpersonal care will likely enhance PwD's QoL. Doing this is essential, as QoL should be considered the ultimate goal of good dementia care. 


\section{FUTURE DIRECTIONS}

\section{Practice}

The results of this dissertation have several implications for future practice.

First, future dementia care should increasingly focus on contributing to a positive mood of PwD, as this is associated with a good QoL. Currently, most attention is paid to the reduction of depressive symptoms. This is reflected by the high percentages of antidepressant drug use in long-term care facilities. ${ }^{23}$ Nursing staff should be able to investigate what the individual reasons for depressive symptoms are, and should act upon these reasons. Introducing a depression guideline and training nursing staff in applying this guideline ${ }^{24}$ may contribute to a better QoL. Besides focusing on reducing depressive symptoms, contributing to a positive mood should receive more attention. To contribute to a positive mood, care workers should identify PwD's individual (activity) preferences and - especially for PwD in a more advanced stage of dementia - sense of agency. Therefore, training for nursing staff should pay increasing attention to person-centered caregiving.

Second, employing higher educated nursing staff may also contribute to PwD's QoL. The advanced expertise of higher educated nursing staff should be used to identify what type of care is needed beyond the daily care routines. For example, they should be able to continuously critically consider the best ways to make connections with PwD and to organize their daily life in an optimal way. This is especially important in more complex situations, for example for PWD who do not easily communicate their needs and preferences anymore. Long-term care organizations should be critical about how to allocate their higher educated nursing staff, as their presence in an organization does not automatically lead to a better QoC. ${ }^{25}$ PwD might best benefit from their expertise if they spend their time (at least partially) on 'hands-on' day-to-day care.

Third, to determine the living environment in which a person with dementia has the best QoL, needs, abilities, preferences and the features of potential living environments should be critically weighed against each other. An optimal balance between personal considerations and environmental features is also referred to as an optimal personenvironment fit. Since January 1, 2015, PwD and their next of kin have the right to receive support from an independent client supporter (in Dutch: cliëntondersteuner). ${ }^{26}$ The client supporter, PwD and their next of kin should discuss together which living environment would best contribute to an individual's QoL. Traditional considerations such as a facility nearby or a place available soon remain important. In addition, information about other characteristics related to QoC and the care environment (e.g. the number of hours of care per person with dementia, tasteful meals, and the outside environment $)^{27,28}$ is available. To achieve an optimal person-environment fit, such information should be increasingly considered as well. 


\section{Research}

The results from this study point to several recommendations for future research.

First, future studies that include QoL as a primary outcome measure should not only use QoL questionnaires, but should increasingly focus on what happens with PwD's well-being in the short term. Real life observations can be used to acquire more insight into this 'here-and-now world'. The MEDLO-tool ${ }^{12}$ is a suitable instrument to perform such observations, and could be adapted and tailored to answer specific research questions. This might prevent studies from not finding an effect on QoL (as measured with a questionnaire), although qualitative process evaluations have suggested otherwise.

Second, further research with respect to the definition and more specifically the measurement of QoC is required. An optimal QoL of PwD should be the starting point for the operationalization of good QoC. Wide consensus between PwD (and their next of kin), care staff, and policy makers is essential. This would decrease the current friction between the more traditional QoC indicators that have to be measured according to fixed rules and regulations, and the interpersonal aspects of caregiving that are often considered important according to PWD and caregivers. Based on an extended operationalization of QoC, the MEDLO-tool could be developed further to capture all relevant aspects. In this way, the MEDLO-tool could be used as a QoC instrument. 


\section{REFERENCES}

1. Polit DF and Beck CT. Nursing research: Generating and assessing evidence for nursing practice. Ninth edition ed. Philadelphia: Lippincott Williams \& Wilkins, 2012.

2. Johnson RB, Onwuegbuzie AJ and Turner LA. Toward a definition of mixed methods research. Journal of Mixed Methods Research 2007;1:112-133.

3. Grimes DA and Schulz KF. Bias and causal associations in observational research. The Lancet 2002;359:248-252.

4. Afram B, Stephan A, Verbeek H, et al. Reasons for institutionalization of people with dementia: informal caregiver reports from 8 European countries. Journal of the American Medical Directors Association 2014;15:108-116.

5. Bramble M, Moyle W and McAllister M. Seeking connection: family care experiences following long-term dementia care placement. Journal of Clinical Nursing 2009;18:3118-3125.

6. Sury L, Burns K and Brodaty H. Moving in: adjustment of people living with dementia going into a nursing home and their families. International Psychogeriatrics 2013;25:867-876.

7. Willemse B, Wessel C and Pot AM. Monitor Woonvormen Dementie. Trends en succesfactoren in de verpleeghuiszorg voor mensen met dementie. 2008-2014. Utrecht: Netherlands Institute of Mental Health and Addiction, 2015

8. de Boer B, Hamers JPH, Beerens HC, et al. Living at the farm, innovative nursing home care for people with dementia - design of an observational longitudinal study. BMC Geriatrics 2015;15:144.

9. Bruin SRD, Oosting SJ, Kuin Y, et al. Green care farms promote activity among elderly people with dementia. Journal of Housing For the Elderly 2009;23:368-389.

10. Logsdon RG, Gibbons LE, McCurry SM and Teri L. Assessing quality of life in older adults with cognitive impairment. Psychosomatic Medicine 2002;64:510-519.

11. Logsdon RG, Gibbons LE, McCurry SM and Teri L. Quality of life in Alzheimer's disease: Patient and caregiver reports. Journal of Mental Health and Aging 1999;5:21-32.

12. de Boer B, Beerens HC, Zwakhalen SMG, Tan FES, Hamers JPH, Verbeek H. Daily Lives of Residents with Dementia in Nursing Homes: Development of the Maastricht Electronic Daily Life Observation Tool. International Psychogeriatrics 2016.

13. Moniz-Cook E, Vernooij-Dassen M, Woods R, et al. A European consensus on outcome measures for psychosocial intervention research in dementia care. Aging \& Mental Health 2008;12:14-29.

14. Ready RE and Ott BR. Quality of Life measures for dementia. Health and Quality of Life Outcomes 2003;1:11.

15. Moyle W, Fetherstonhaugh D, Greben M and Beattie E. Influencers on quality of life as reported by people living with dementia in long-term care: a descriptive exploratory approach. BMC Geriatrics 2015;15:50.

16. Albrecht GL and Devlieger PJ. The disability paradox: high quality of life against all odds. Social Science and Medicine 1999;48:977-988.

17. Lawton MP. A multidimensional view of quality of life in frail elders. In: JE Birren, JE Lubben, JC Rowe and DE Deutchmann, eds. The concept and measurement of quality of life in the frail elderly. San Diego: Academic press inc, 1991.

18. Lawton MP. Residential environment and self-directedness among older people. American Psychologist 1990;45:638-640.

19. Jongenelis $K$, Pot $A$, Eisses $A$, et al. Prevalence and risk indicators of depression in elderly nursing home patients: the AGED study. Journal of Affective Disorders 2004;83:135-142.

20. Wood W, Womack J and Hooper B. Dying of boredom: An exploratory case study of time use, apparent affect, and routine activity situations on two Alzheimer's special care units. American Journal of Occupational Therapy 2009;63:337-350.

21. Larrabee JH and Bolden LV. Defining patient-perceived quality of nursing care. Journal of Nursing Care Quality 2001;16:34-60. 
22. Attree M. Patients' and relatives' experiences and perspectives of 'good'and 'not so good'quality care. Journal of Advanced Nursing 2001;33:456-466.

23. Wetzels R, Zuidema S, De Jonghe J, et al. Prescribing pattern of psychotropic drugs in nursing home residents with dementia. International Psychogeriatrics 2011;23:1249-1259.

24. Verkaik R, Francke AL, van Meijel B, et al. The effects of a nursing guideline on depression in psychogeriatric nursing home residents with dementia. International Journal of Geriatric Psychiatry 2011;26:723-732.

25. Backhaus $R$, Verbeek $H$, van Rossum $E$, et al. Nurse staffing impact on quality of care in nursing homes: a systematic review of longitudinal studies. Journal of the American Medical Directors Association 2014;15:383-393.

26. Taskforce 'Waardigheid en trots'. Waardigheid en trots. Liefdevolle zorg. Voor onze ouderen. Plan van aanpak kwaliteit verpleeghuizen. The Hague: Dutch Ministry of Health, Welfare and Sport, 2015.

27. Maarse $\mathrm{H}$. The experience of searching long-term care for the elderly: client choice in long-term care in the Netherlands. Maastricht: Maastricht University, 2013.

28. Machiels M. Care farms: the experiences of informal caregivers. Maastricht: Maastricht University (unpublished Master's thesis). 2014. 



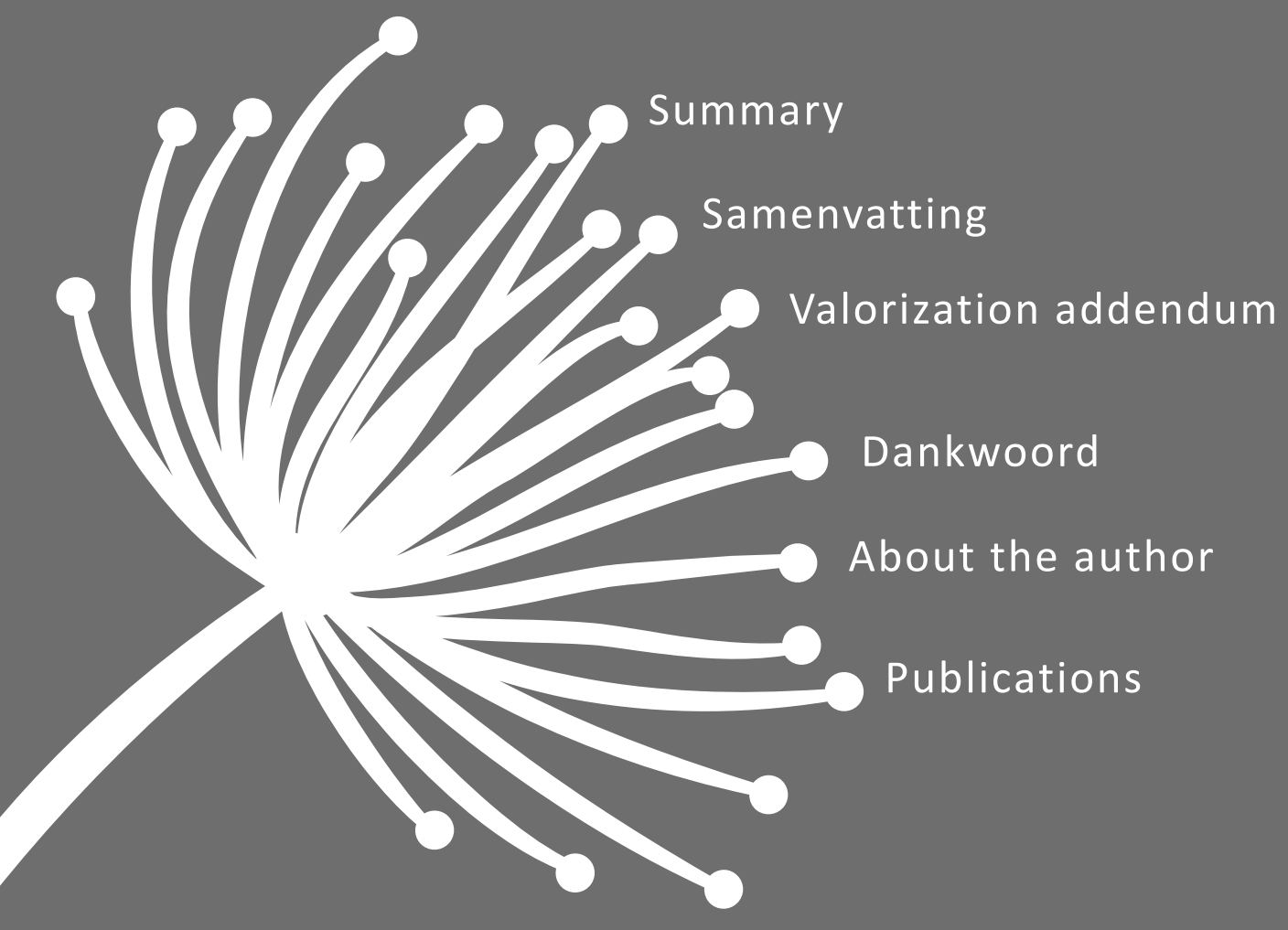





\section{SUMMARY}

This dissertation provides insight into the quality of life (QoL) of people with dementia (PWD) who receive long-term care at home and in long-term care facilities. In addition, this dissertation shows which factors are associated with QoL of PwD receiving longterm care at home and in long-term care facilities. Investigating associations with QoL is essential as it provides information about how to improve QoL. Several studies employing various research methods were conducted. First, a systematic literature review was performed (Chapter 2). Second, observational data about QoL and quality of care (QoC) of 2014 PwD from eight European countries were collected (Chapter 3 and 4). Third, a total of 9,660 ecological momentary assessments were performed in the Netherlands to obtain more in-depth information about QoL and everyday life of PwD (Chapter 5, 6 and 7). The present chapter summarizes all the studies described in this dissertation.

Chapter 1 contains a general introduction to this dissertation, addressing long-term care, dementia, and QoL. Furthermore, the aims and outline of this dissertation are specified and the data collection methods are described.

A systematic literature review (Chapter 2) identified only a few high quality studies investigating the association with (change in) QoL of PwD living in long-term care facilities. The results of this review suggested that depressive symptoms are associated with a low self-reported QoL. A low proxy-reported QoL appears to be associated with behavioral disturbances, especially agitation. As PwD rated their QoL differently than proxies such as caregivers, the perspective of QoL measurement influenced QoL associations.

An international cross-sectional survey (Chapter 3) was conducted to obtain information about QoL and QoC indicators. The survey was conducted in eight European countries (England, Estonia, Finland, France, Germany, the Netherlands, Spain, and Sweden) with PwD in one of two types of living arrangements (home or long-term care facility). Results showed that QoL of PWD is often rated highest in Sweden and England and lowest in Estonia and Spain. No differences in QoL were detected between the living arrangements. For the QoC indicators, no consistent patterns of certain countries or living arrangements scoring better or worse were detected. Furthermore, associations between QoL and QoC indicators were assessed and the presence of depressive symptoms was most consistently associated with lower QoL.

An international longitudinal survey with a follow-up period of three months (Chapter 4 ) investigated the factors associated with changes in QoL of PwD recently admitted to a long-term care facility. Again, PwD living in one of the eight participating European countries were included. On an individual level, three groups were identified in which PwD's QoL: 1) decreased (quarter of the sample); 2) stayed the same (half of the sample); and 3) increased (quarter of the sample). A decrease in self-reported QoL was associated with better cognitive ability. A decrease in proxy-reported QoL was associat- 
ed with greater dependency in activities of daily living (ADL) at baseline, more depressive symptoms at baseline, an increased ADL dependency between baseline and followup, and an increase in depressive symptoms between baseline and follow-up.

Chapter 5 reports on the development, reliability and feasibility of the Maastricht Electronic Daily Life Observational-tool (MEDLO-tool). This observational instrument assists in obtaining in-depth information about the daily lives of PwD through ecological momentary assessments. Using the MEDLO-tool, the following domains can be assessed: 1) activities; 2) physical environment; 3) social environment; and 4) emotional well-being. Initial results showed that the MEDLO-tool is reliable, feasible, and can effectively provide detailed insight into the daily lives of PwD who live in long-term care facilities.

An observational study using momentary assessments (Chapter 6) investigated relationships between aspects of daily life and proxy-reported QoL of PwD living in longterm care facilities for longer periods of time. People with dementia living in the Netherlands were included in this study. Results revealed that a high QoL is associated with frequent social interaction and a positive mood. The association between QoL and active, expressive, and social activities remained unclear.

Mood, an important indicator of QoL, was used as the primary outcome measure of the final observational study using momentary assessments (Chapter 7). This study identified the degree of association between mood, activities, and social interactions during everyday life of PwD living in long-term care facilities for longer periods of time. Results showed that a positive mood is associated with engagement in activities, doing activities outside and social interaction. The type of activity seemed less important than a specific activity itself.

Chapter 8 presents the main findings and implications of the studies presented in this dissertation. In addition, methodological considerations of the study design, study population, and QoL and theoretical considerations of quality of life and dementia, the influence of mood on quality of life, and the association between QoL and QoC are addressed. Finally, future directions for care practice and research are provided. 


\section{SAMENVATTING}

Dit proefschrift geeft inzicht in de kwaliteit van leven van mensen met dementie die thuis of in een zorginstelling langdurige zorg ontvangen. Daarnaast laat dit proefschrift zien welke factoren geassocieerd zijn met kwaliteit van leven van mensen met dementie die langdurige zorg ontvangen. Het onderzoeken van deze associaties is van belang omdat dit inzicht geeft in mogelijkheden voor het verbeteren van kwaliteit van leven. Verschillende studies met diverse onderzoeksmethodieken zijn opgezet om dit te kunnen onderzoeken. Ten eerste is er een systematisch literatuuronderzoek uitgevoerd (Hoofdstuk 2). Ten tweede is er observationele data met betrekking tot kwaliteit van leven en kwaliteit van zorg-indicatoren verzameld over 2014 Europeanen met dementie uit acht verschillende Europese landen (Hoofdstuk 3 en 4). Ten derde zijn er in Nederland 9.660 korte, herhaalde observaties in de dagelijkse leefomgeving uitgevoerd om meer inzicht te krijgen in kwaliteit van leven en het dagelijks leven van mensen met dementie (Hoofdstuk 5, 6 en 7). Dit hoofdstuk vat alle studies die beschreven staan in dit proefschrift samen.

Hoofdstuk 1 bevat een algemene introductie. Langdurige zorg, dementie en kwaliteit van leven worden hierin toegelicht. Tevens beschrijft dit hoofdstuk zowel de doelstellingen en opzet van dit proefschrift als de studies die hieraan ten grondslag liggen.

Een systematisch literatuuronderzoek (Hoofdstuk 2) identificeerde slechts enkele studies van hoge kwaliteit die associaties met (veranderingen in) kwaliteit van leven van mensen met dementie onderzocht hebben. De resultaten van dit literatuuronderzoek toonden een relatie tussen depressieve symptomen geassocieerd en een lage zelfgerapporteerde kwaliteit van leven aan. Een lage proxy-gerapporteerde kwaliteit van leven hing samen met gedragsproblemen, en agitatie in het bijzonder. Omdat mensen met dementie hun kwaliteit van leven anders beoordeelden dan proxies zoals zorgverleners, beïnvloedde het perspectief van de meting ook de associaties met kwaliteit van leven.

Een internationale cross-sectionele studie (Hoofdstuk 3) bood meer informatie over kwaliteit van leven en kwaliteit van zorg-indicatoren. Deze studie vond plaats in acht Europese landen (Duitsland, Engeland, Estland, Finland, Frankrijk, Nederland, Spanje en Zweden) en in twee typen woonomgevingen (thuis of verpleeghuis). Kwaliteit van leven werd het hoogst beoordeeld in Zweden en Engeland en het laagst in Estland en Spanje. Er werden geen verschillen in kwaliteit van leven geconstateerd tussen de twee typen woonomgevingen. Met betrekking tot de kwaliteit van zorg-indicatoren werd geen consistent patroon gevonden in die zin dat bepaalde landen of woonomgevingen beter scoorden dan andere. Ten slotte werd de kwaliteit van zorg-indicator 'depressieve symptomen' het meest consistent geassocieerd met een lage kwaliteit van leven.

Een internationale longitudinale studie met een vervolgmeting drie maanden later (Hoofdstuk 4) is gebruikt om te beoordelen welke factoren er geassocieerd zijn met 
kwaliteit van leven van mensen met dementie binnen drie maanden nadat zij zijn opgenomen in een zorginstelling. Opnieuw werden mensen met dementie uit de acht deelnemende landen geïncludeerd. Op individueel niveau werden drie groepen geïdentificeerd, namelijk mensen wier kwaliteit van leven 1) omlaag ging (kwart van de deelnemers); 2) gelijk bleef (helft van de deelnemers); en 3) omhoog ging (kwart van de deelnemers). In deze studie was achteruitgang in zelf-gerapporteerde kwaliteit van leven geassocieerd met betere cognitieve capaciteiten. Een achteruitgang in proxygerapporteerde kwaliteit van leven was geassocieerd met een grote afhankelijkheid in algemene dagelijkse levensverrichtingen (ADL) bij de nulmeting, veel depressieve symptomen bij de nulmeting, een vergrote afhankelijkheid in ADL tussen de nulmeting en de vervolgmeting, en een verergering van depressieve symptomen tussen de nulmeting en de vervolgmeting.

Hoofdstuk 5 beschrijft de ontwikkeling, betrouwbaarheid en praktische toepasbaarheid van de Maastricht Electronic Daily Life Observation-tool (MEDLO-tool). Dit observatieinstrument maakt het mogelijk om met behulp van korte, herhaalde observaties in de dagelijkse leefomgeving diepgaande informatie te verkrijgen. Met behulp van de MEDLO-tool worden de volgende domeinen in kaart gebracht: 1) activiteiten; 2) fysieke omgeving; 3) sociale omgeving; en 4) psychologisch welbevinden. De eerste bevindingen gaven aan dat de MEDLO-tool een betrouwbaar en praktisch toepasbaar instrument is om gedetailleerd inzicht te krijgen in het dagelijks leven van mensen met dementie die langdurige zorg in een zorginstelling krijgen.

Een observationele studie die gebruik maakte van korte, herhaalde observaties in de dagelijkse leefomgeving (Hoofdstuk 6) onderzocht welke aspecten van het dagelijks leven zijn geassocieerd met proxy-gerapporteerde kwaliteit van leven van mensen met dementie die al voor langere periode in het verpleeghuis wonen. De deelnemers van deze studie woonden in Nederlandse verpleeghuizen. De resultaten van deze studie toonden een relatie tussen een hoge kwaliteit van leven en frequente sociale interactie en een positieve stemming aan. De associatie tussen kwaliteit van leven en betrokkenheid bij actieve, expressieve, en sociale activiteiten bleef onduidelijk.

Stemming, een belangrijke indicator voor kwaliteit van leven, was gebruikt als primaire uitkomstmaat voor de laatste observationele studie die gebruik maakte van korte, herhaalde observaties in de dagelijkse leefomgeving (Hoofdstuk 7). Deze studie identificeerde de mate van relatie tussen stemming, activiteiten, en sociale interacties gedurende het dagelijks leven van mensen met dementie die al voor langere periode in het verpleeghuis woonden. Een positieve stemming bleek geassocieerd met betrokkenheid bij activiteiten, het buitenshuis doen van deze activiteiten, en sociale interactie. Betrokkenheid bij een activiteit leek belangrijker dan het type activiteit zelf.

Hoofdstuk 8 bevat de belangrijkste bevindingen en implicaties van studies die gepresenteerd zijn in dit proefschrift. Tevens worden methodologische overwegingen met betrekking tot het design van de studie, de studiepopulatie, en het meten van kwaliteit van leven toegelicht. Ook komen theoretische overwegingen met betrekking tot kwali- 
teit van leven bij dementie, de invloed van stemming op kwaliteit van leven, en de relatie tussen kwaliteit van leven en kwaliteit van zorg aan bod. Ten slotte worden aanbevelingen gedaan voor zowel de praktijk als voor toekomstig onderzoek. 



\section{VALORIZATION ADDENDUM}

In this chapter, important findings of this dissertation and their societal value are addressed. Furthermore, future directions for quality of life- and quality of care assessment are elaborated on. This chapter concludes with a description of activities for the dissemination of this dissertation's findings.

\section{Quality of life and long-term care in the Netherlands}

This dissertation provides an enhanced understanding of the quality of life of people with dementia receiving long-term care. Quality of life and quality of care are irrevocably linked to each other, as a good quality of life is the ultimate goal of good care. Quality of life and quality of care in Dutch nursing homes received major attention recently. In 2014, Martin van Rijn, the Dutch State Secretary for Health, Welfare, and Sport launched the program 'Dignity and Pride' ['Waardigheid en Trots']. This program was written in response to concerns about the quality of nursing home care and aimed to improve the lives of and care provided to Dutch nursing home residents. This dissertation actively responds to the often negative view society holds about the quality of life of people with dementia in long-term care. Although dementia and living in a care facility are characterized by loss and the capacity of people with dementia and their relatives to adapt to their situation is challenged, there remain possibilities to have a good life. This dissertation found that many people with dementia spend a large part of their day engaging in activities or social interactions. When compared with other European countries, Dutch people with dementia and their caregivers value the quality of life of the person with dementia comparably - and sometimes even better.

In addition to quality of life of nursing home residents, this dissertation focused on people with dementia who are living at home but at risk for imminent admission. It was found that these people's quality of life is comparable to the quality of life of those living in a long-term care facility. However, as the Dutch government increasingly encourages people to 'age in place' or, in other words, to live at home for as long as possible, people with dementia who live at home will become increasingly dependent. Consequently, it will become more challenging for them to live a good life at home. Therefore, the quality of life of people with dementia who live at home should receive major attention and supporting social networks plays a key role in this. Informal caregivers are the ones who people with dementia primarily rely on, especially in the later stages of their dementia. These informal caregivers should not only have easy access to support from care professionals, but should also receive support from their own social networks and fellow informal caregivers. 


\section{Quality of life and quality of care: future directions}

Policy makers, caregivers, and researchers should remain focusing on quality of life and quality of care as there remains room for improvement. As a first step for improved quality of life and quality of care, this dissertation advocates for these concepts to be defined and assessed differently.

First, detailed insight into well-being in 'the here and now' is more valuable than quality of life assessments which use broad questionnaires alone. This is especially the case when evaluating well-being interventions that aim to improve situations in the here and now rather than on the long term. This is especially important because people with dementia often have a limited capacity to recall past events. In this dissertation, mood was used as an indicator for well-being, however further research is necessary to investigate whether this is enough or whether other aspects should also be taken into account. For example, it has repeatedly been suggested that engagement should be part of the well-being construct.

Second, when evaluating quality of care, interpersonal aspects of caregiving such as communication and respect should be taken into account. The social interactions that were assessed in this dissertation could be regarded as indicators for quality of care. However, it has not yet been investigated which interpersonal aspects of caregiving constitute 'good' quality of care and more research into this is necessary. The Maastricht Electronic Daily Life Observation-tool (MEDLO-tool) used in this dissertation contains a scale for assessing the quality of social interactions. However, this scale does not appear sensitive enough as there is little variation in the scores regarding the quality of social interactions. Consequently, it is very difficult to assess whether there is room for improvement in the communication between caregivers and people with dementia. It is important to investigate how these interpersonal aspects of caregiving could be assessed more sensitively.

Once well-being and quality of (interpersonal) care are more clearly defined, the MEDLO-tool could function as a vehicle for nursing staff to assess which aspects of interpersonal caregiving have a positive influence on the well-being of people with dementia. This information will provide valuable information for quality of care improvements. Nursing staff could use the MEDLO-tool to observe people with dementia and their interactions with other nursing staff. However, several steps should be taken before the MEDLO-tool can be used in this way. Primarily, it should be adapted to make it easier for nursing staff to use. In particular, the analyses of associations between levels of well-being and interpersonal caregiving may be challenging for nursing staff without an academic background. A tablet application which automatically provides insight into these relationships could be developed for this purpose. After the tool becomes easier to use, nursing staff members who perform observations should be able to communicate the aspects of interpersonal caregiving which contribute to or harm the well-being 
of nursing home residents with dementia. To do so, they should be trained to appropriately communicate their findings to the nursing staff they observed.

\section{Dissemination}

To disseminate the results of this dissertation to nursing staff, policy makers, researchers, and other interested people, several steps will be taken. First, an accessible summary of the results will be distributed among all long-term care organizations who are member of the 'Living Lab in Aging \& Long-Term Care' in the province of Limburg. The summary will be in the newsletter of this organization, and will also be available on their website (https://www.academischewerkplaatsouderenzorg.nl). Second, a summary of this dissertation will be available on other websites, such as the website of the Internationale Stichting Alzheimer Onderzoek (https://www.alzheimer.nl/) and the website of Alzheimer Nederland (http://www.alzheimer-nederland.nl). Third, the two large datasets that underlie this dissertation will be available to colleagues and students. The existing datasets contain much information in underexplored areas. For example, there is unused data available about the quality of life of people with dementia who made the transition from home to nursing home and the use of physical restraints on people with dementia who live at home. In addition, the detailed descriptions of communication between people with dementia and formal caregivers could be used for further research. 



\section{DANKWOORD}

Eindelijk is het zo ver; mijn proefschrift is af! Dit proefschrift had ik niet kunnen schrijven zonder de medewerking en hulp van velen. Daarom wil ik een aantal van hen in het bijzonder danken.

Allereerst wil ik alle directe deelnemers aan het onderzoek bedanken: mensen met dementie, hun naasten, professionele zorgverleners en alle andere betrokkenen van deelnemende organisaties en woonvormen. Zonder jullie medewerking was dit proefschrift er nooit gekomen.

Daarnaast wil ik mijn promotieteam bedanken. Zij hebben ervoor gezorgd dat ik met heel veel plezier aan mijn proefschrift heb kunnen werken. Onze discussies waren erg leerzaam en ik bewaar alleen maar goede herinneringen aan de congressen en bijeenkomsten die we samen hebben bezocht. Sandra, niets is je teveel. Zelfs 's nachts kreeg ik af en toe nog feedback toegestuurd. Jouw rust en adviezen hebben me enorm geholpen om mijn proefschrift naar een hoger plan te tillen. Hilde, ook al ben je officieel geen lid van mijn begeleidingsteam; zo voelde het wel. En ook al wekt je bureau niet echt de indruk; jouw orde en structuur hebben mijn artikelen een stuk overzichtelijker gemaakt. Dirk, je gedetailleerde feedback heeft me geholpen om kritisch te blijven over alle details. Ook zorgde je ervoor dat ik oog bleef houden voor de vertaalslag van theorie naar beleid. Jan, jouw overstijgende vragen en opmerkingen hebben me echt geholpen een rode draad te vinden in mijn werk. Ik vond het ook heel inspirerend om te zien hoe je een nauw contact tussen wetenschap en praktijk bewerkstelligt. Bedankt!

Graag wil ik de leden van de beoordelingscommissie, Prof. Frans Verhey, Prof. Sandra Beurskens, Prof. Rose-Marie Droës, Prof. Jos Schols en Prof. Marieke Schuurmans, hartelijk danken voor het lezen en beoordelen van dit proefschrift.

Basema en Bram: bedankt voor onze goede, intensieve, samenwerking én bedankt dat jullie mijn paranimfen willen zijn. Basema, wat hebben we het soms (te) gezellig gehad op kantoor. Gelukkig heb ik nog veel mooie foto's waardoor ik dat niet zal vergeten. Ook heb ook veel van je geleerd. Ik ben blij dat je je op je plek voelt in Nijmegen. De altijd nuchtere Bram: ook met jou heb ik met veel plezier samengewerkt. Jouw rust en relativeringsvermogen zijn soms echt een verademing. Ik wens je heel veel succes met de laatste loodjes van je proefschrift en heb er alle vertrouwen in dat dat goed gaat komen.

Mijn promotietraject was nooit zo soepel verlopen zonder de ondersteuning van aantal collega's die nauw betrokken zijn geweest bij mijn onderzoek. Michel, de eerste twee jaar van mijn promotie hebben we intensief samengewerkt; bedankt hiervoor. Jouw hang naar structuur gaf mij ook houvast, en je persoonlijke interesse in anderen maakt 
je een fijn persoon om mee samen te werken. Elles, bedankt voor al je inspanningen om de dataverzamelingen tot een goed einde te brengen. Je hebt heel wat kilometers afgelegd en je was altijd behulpzaam. Frans en Ton, hartelijk dank voor jullie ondersteuning bij de statistische analyses. Ik heb jullie behulpzaamheid, kennis en kunde zeer gewaardeerd.

My research drew upon knowledge and experience of many researchers in the field of dementia care. I want to particularly thank professor Murna Downs and all other colleagues from the School of Dementia Studies for providing me the opportunity to conduct research at the University of Bradford. You were all very supportive and I learned a lot from your expertise and our discussions. Furthermore, I would also like to express my gratitude towards the RightTimePlaceCare consortium. It was a pleasure to collaborate with you in such an interesting project.

Mijn naaste collega's, te veel om op te noemen, wil ik graag bedanken voor de jaren dat we samen hebben opgetrokken. Zowel voor de inhoud (lunchseminars, refereerbijeenkomsten) als ter ontspanning (pauzes in de koffiecorners en het park, dagjes uit, diners) was het heel fijn om zulke goede collega's te hebben.

Lieve vrienden, vriendinnen en hockeymaatjes, bedankt voor jullie interesse en vooral voor de nodige afleiding van mijn onderzoek! Ik kan altijd bij jullie terecht en daar ben ik heel erg blij mee.

Mam, pap, Hans, en Lieke: jullie hebben me altijd gesteund in de keuzes die ik heb gemaakt. Bedankt voor jullie vertrouwen in mij. Dankzij jullie heb ik voldoende bagage om keuzes te maken en te gaan voor dingen die ik graag wil. Ook heb ik van jullie meegekregen dat ik naast hard werken af en toe moet ontspannen, bijvoorbeeld door te sporten (mama) of sport te kijken (papa). Maarten, Vera, Jasper, Sandra, Marcella, Cor, Dirk, Noud, Gerdi, Dinny, Fons, Paul en Linda: bedankt voor jullie interesse in mijn werk. Ik vond het altijd leuk om jullie weer even te vertellen hoe het met mijn proefschrift stond. Marcella, jij speciaal bedankt voor het ontwerpen van de kaft van dit proefschrift. Opa en oma: ik ben heel blij en trots dat ik jullie dit proefschrift kan laten zien. Ik ben eindelijk 'afgestudeerd' in Maastricht!

Lieve Niek, bedankt voor al het geluk, de lol, en de liefde die we samen hebben. Jij hebt me afgelopen jaren aangemoedigd om (soms letterlijk) over mijn grenzen heen te stappen en mijn ambities waar te maken. Je hebt mij altijd gesteund, vertrouwen gegeven, en voor me gezorgd. Ik kijk er erg naar uit samen met jou op reis te gaan. Ik hou van jou! 


\section{ABOUT THE AUTHOR}

Hanneke Beerens was born in Eindhoven, the Netherlands, on the 2nd of September 1986. After completing a vocational training in nursing, she obtained a Bachelor's degree in nursing at the Fontys University of Applied Sciences in 2008. In 2010, she obtained her Master's degree in public health at Maastricht University. The topics of all her theses were related to nursing. During her studies (2007-2011), Hanneke worked as a nurse in several nursing homes and home care organizations.

In 2011, Hanneke worked on a project related to older people with insufficiently explained somatic symptoms at the Psychiatry Department of the Radboud University Medical Center in Nijmegen. At the end of 2011, Hanneke started as a PhD candidate at the department of Health Services Research at Maastricht University. Her PhD study focused on quality of life of people with dementia who receive long-term care. Her research involved two major projects. The first project included a large-scale data collection about European people with dementia who receive professional home care or care in a long-term care facility. The second project comprised in-depth observations in various types of Dutch nursing homes. In addition to these core projects, Hanneke worked on projects focusing on the added value of green care farms for people with dementia, and staffing and quality of care in nursing homes. Educational activities included the supervision of Bachelor's and Master's students, teaching in courses related to chronic care and quality of care, and organizing symposia and conferences such as the European Doctoral Conference in Nursing Science.

Hanneke is member of the RightTimePlaceCare consortium and the INTERDEM Academy, both European networks of experts in the area of (psychosocial) dementia research. In 2015, Hanneke was awarded an INTERDEM Academy fellowship to conduct research at the University of Bradford. 



\section{PUBLICATIONS}

- Beerens HC, Zwakhalen SMG, Verbeek H, Tan FES, Jolani S, Downs M, de Boer B, Ruwaard D, Hamers JPH. The relation between mood, activity, and interaction in long-term dementia care. Submitted.

- Beerens HC, de Boer B, Zwakhalen SMG, Tan FES, Ruwaard D, Hamers JPH, Verbeek $\mathrm{H}$. The association between aspects of daily life and quality of life of people with dementia living in long-term care facilities: a momentary assessment study. International Psychogeriatrics 2016. doi:10.1017/S1041610216000466.

- de Boer B, Beerens HC, Zwakhalen SMG, Tan FES, Hamers JPH, Verbeek H. Daily Lives of Residents with Dementia in Nursing Homes: Development of the Maastricht Electronic Daily Life Observation Tool. International Psychogeriatrics 2016. doi: 10.1017/S1041610216000478.

- de Boer B, Hamers JPH, Beerens HC, Zwakhalen SMG, and Verbeek H. Living at the farm, innovative nursing home care for people with dementia - study protocol of an observational longitudinal study. BMC Geriatrics 2015;14:144.

- Beerens HC, Zwakhalen SMG, Verbeek H, Ruwaard D, Ambergen AW, Leino-Kilpi H, Stephan A, Zabalegui A, Soto M, Saks K, Bökberg C, Sutcliffe CL, Hamers JPH, on behalf of the RightTimePlaceCare Consortium. Change in quality of life of people with dementia recently admitted to long-term care facilities. Journal of Advanced Nursing 2014;71:1435-1447.

- Beerens HC, Sutcliffe C, Renom-Guiteras A, et al. Quality of Life and Quality of Care for People With Dementia Receiving Long Term Institutional Care or Professional Home Care: The European RightTimePlaceCare Study. Journal of the American Medical Directors Association 2014;15:54-61.

- Hamers J, Zwakhalen S, Afram B, Beerens H, Bleijlevens M, Ambergen T, Ruwaard D, Verbeek H. Dementiezorg in Europa. TVZ Tijdschrift voor Verpleegkundigen 2014;124:28-31.

- Beerens HC, Zwakhalen SM, Verbeek H, et al. Factors associated with quality of life of people with dementia in long-term care facilities: a systematic review. International Journal of Nursing Studies 2013;50:1259-1270. 
N

$\psi$
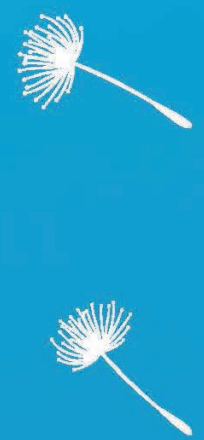